\title{
Dietary strategies to modulate the metabolic profile and substrate partitioning
}

Citation for published version (APA):

Marjet Munsters, M. J. M. (2014). Dietary strategies to modulate the metabolic profile and substrate partitioning. [Doctoral Thesis, Maastricht University]. Maastricht University. https://doi.org/10.26481/dis.20140417mm

Document status and date:

Published: 01/01/2014

DOI:

10.26481/dis.20140417mm

Document Version:

Publisher's PDF, also known as Version of record

\section{Please check the document version of this publication:}

- A submitted manuscript is the version of the article upon submission and before peer-review. There can be important differences between the submitted version and the official published version of record. People interested in the research are advised to contact the author for the final version of the publication, or visit the DOI to the publisher's website.

- The final author version and the galley proof are versions of the publication after peer review.

- The final published version features the final layout of the paper including the volume, issue and page numbers.

Link to publication

\footnotetext{
General rights rights.

- You may freely distribute the URL identifying the publication in the public portal. please follow below link for the End User Agreement:

www.umlib.nl/taverne-license

Take down policy

If you believe that this document breaches copyright please contact us at:

repository@maastrichtuniversity.nl

providing details and we will investigate your claim.
}

Copyright and moral rights for the publications made accessible in the public portal are retained by the authors and/or other copyright owners and it is a condition of accessing publications that users recognise and abide by the legal requirements associated with these

- Users may download and print one copy of any publication from the public portal for the purpose of private study or research.

- You may not further distribute the material or use it for any profit-making activity or commercial gain

If the publication is distributed under the terms of Article $25 \mathrm{fa}$ of the Dutch Copyright Act, indicated by the "Taverne" license above, 
Dietary strategies to modulate the metabolic profile and substrate partitioning 


\section{nivtrim 和}

The study presented in this thesis was performed within NUTRIM, School for Nutrition, Toxicology and Metabolism, which participates in the Graduate School VLAG (Food, Technology, Agrobiotechnology, Nutrition and Health Sciences), accredited by the Royal Netherlands Academy of Arts and Sciences.

Cover design: Guus Munsters

Lay-out: Marjet Munsters

Printed by: Druko drukkerij B.V., Veghel

(C) copyright MJM Munsters, Maastricht 2014

ISBN/EAN: 978-90-819226-3-0 


\title{
Dietary strategies to modulate the metabolic
}

\section{profile and substrate partitioning}

\author{
PROEFSCHRIFT \\ ter verkrijging van de graad doctor aan de Universiteit Maastricht, \\ op gezag van de Rector Magnificus, Prof. dr. L.L.G. Soete, \\ volgens het besluit van het College van Decanen, \\ in het openbaar te verdedigen \\ op donderdag 17 april 2014 om 16.00 uur
}

door

Marjet Jeannette Maria Munsters

geboren te Veghel op 8 Juni 1985 


\section{PROMOTOR}

Prof. dr. ir. W.H.M. Saris

\section{BEOORDELINGSCOMMISSIE}

Prof. dr. E.E Blaak (voorzitter)

Dr. G.H. Goossens

Prof. dr. ir. R.P. Mensink

Prof. dr. H. Pijl (Leiden University Medical Center)

Prof. dr. H.C. Schaper

The research described in this thesis was funded by an unrestricted grant by the Dutch Dairy Association.

Financial support by the Dutch Dairy Association for publication of this thesis is gratefully acknowledged. 


\section{TABLE OF CONTENTS}

$\begin{array}{lll}\text { Chapter } 1 \quad \text { General Introduction } & 1\end{array}$

Chapter 2 Review; Body weight regulation and obesity: dietary strategies 9 to improve the metabolic profile

Chapter 3 The effect of sugar-sweetened beverages intake on energy intake in an ad libitum 6 months low-fat high carbohydrate diet

Chapter 4 Effects of different protein and glycemic index diets on metabolic profiles and substrate partitioning in lean healthy males

Chapter 5 Effects of meal frequency on metabolic profiles and substrate partitioning in lean healthy males

Chapter 6 A low meal frequency improved the $24 \mathrm{~h}$ metabolic and gene expression profiles in subjects with impaired glucose tolerance

Summary

Samenvatting

Dankwoord

Curriculum vitae 



\section{CHAPTER 1}

General Introduction 


\section{INTRODUCTION}

The fast growing prevalence of obesity and diabetes is becoming a major health problem worldwide. There is no indication that this trend is turning into the healthy direction. Obesity develops when energy intake exceeds energy expenditure resulting in a positive energy balance, the excess energy being stored in the adipose tissue. However, the various dietary aspects that are associated with overeating and obesity are not well understood (1). As insulin resistance accompanies the incidence of obesity more attention is focused on improving glycemic control, specifically insulin responsiveness, through altering dietary macronutrient ratios, type of macronutrients and meal frequency (2-4). To develop strategies to prevent or treat obesity it is necessary to understand the mechanism of body weight regulation, i.e. energy intake regulation, such as food intake regulation and appetite control, and the metabolic mechanisms linked to energy expenditure, i.e. substrate partitioning. Before the use of molecular technologies, body weight regulation was a black box with hardly any information about the mechanisms involved. With the application of new techniques, such as nutrigenomics, underlying mechanisms and metabolic pathways can be studied in more detail leading to a better insight in the health effects of specific diets of dietary components.

\section{HYPERINSULINEMIA AND HYPERGLYCEMIA IN RELATION TO BODY WEIGHT}

\section{REGULATION}

Insulin regulates blood glucose concentrations; it stimulates glucose uptake in the muscle, glycogen synthesis, protein synthesis, fat storage, resulting in higher carbohydrate oxidation and lower fat oxidation $(5 ; 6)$. Frequent daily insulinemia will suppress fat oxidation, which could lead to weight gain on the long term $(7 ; 8)$. Furthermore, accumulating data suggests that diets intended to reduce the insulin response after carbohydrate intake might improve access to stored metabolic substrates, and stimulate weight loss (9). A higher insulinemic response to food ingestion is related to weight gain, still the scientific debate is continuing $(10 ; 11)$. In contrast, regardless of hyperinsulinemia, variable changes in insulin action might be present in obesity $(12 ; 13)$. This variability may well predict additional weight gain or that weight will stabilize. Despite insulin resistance is associated with a higher risk to develop cardiovascular diseases, a decline in insulin action might be essential to prevent further weight gain in subjects as partitioning of lipid fuels is directed from storage in adipose tissue to immediate or delayed oxidation in skeletal muscle $(12 ; 13)$. Consumption of sugar-sweetened beverages (SSBs) is associated with dental caries and an increased risk for cardiovascular diseases (14), however there is no consensus about the association between SSB consumption (hyperglycemia) and obesity and type 2 
diabetes (15-18). Nevertheless, energy restricted, high protein diets have shown to increase insulin sensitivity, improve lipid profiles and body weight loss (19; 20), and maintenance of weight loss in the RCT Diogenesis trial (21). These beneficial effects may be associated with lower glucose removal, reduced endogenous glucose output (22), and the fact that proteins increase insulin levels (23; 24). Especially dairy proteins are rich in branch chain amino acids (25) and consequently have strong insulinotropic effects (26). Furthermore, dairy products indicated to have an anti-obesity effect (27), causing changes in body weight, body fat and insulin resistance (28), although the increased postprandial insulin levels that are linked to weight gain and insulin resistance (9). Therefore, the contradiction between the concept that (dairy) proteins increase body weight control and the notion that the high postprandial insulin levels (insulinotropic effects of protein) are linked to insulin resistance and consequently weight gain warrants additional investigation (9).

\section{APPETITE CONTROL}

Changes in dietary intake can also affect appetite control. Appetite is the summation of the perceived appetite (hunger, desire to eat) and satiety sensations (feeling of being satisfactorily full and unable to eat any more food) that ultimately lead to whether food is or not consumed (29). Appetite profiles can be assessed by anchored $100-\mathrm{mm}$ visual analogue scales (VAS) with words at each end that expressed the most extreme rating to assess feelings of hunger, fullness, satiety, thirst, and desire to eat (30). Satiety refers to postprandial events that affect the interval to the following meal, in this manner regulating meal frequency (31). Post-gastric factors seem to play a key role in satiety through secretion of various peptides by the intestine in response to ingested food (32). The hormones that have the most robust effects on appetite are ghrelin, cholecystokinin (CCK), glucagon-like peptide (GLP-1) and peptide YY (PYY) (3335).

\section{ENERGY EXPENDITURE}

Carbohydrates, proteins, fats and alcohol from food supplies the fuel for the human body. All energy contained by the substrates is converted into ATP and heat via several sub-processes (36). ATP is used throughout the human body to fuel all processes needing energy. The amount of $\mathrm{O}_{2}$ consumed and $\mathrm{CO}_{2}$ produced is fixed when substrates are metabolized. Hence, energy expenditure can be calculated from the measurements of $\mathrm{O}_{2}$ consumption, $\mathrm{CO}_{2}$ production, and urine nitrogen excretion according to Brouwer (37).

Total daily energy expenditure can be separated into different compartments (38); basal metabolic rate (BMR) represents the minimal energy expenditure for a subject lying awake and relaxed in a bed. Sleeping metabolic rate (SMR) stands for the amount 


\section{Chapter 1}

of energy used during sleep. In addition, the energy expenditure related to the intake and processing of nutrients is called diet induced thermogenesis (DIT).

\section{NUTRIGENOMICS}

Nutrigenomics research will increase knowledge of the underlying mechanisms behind the health effects of specific diets of dietary components. This can be investigated on several levels, including the genome, the transcriptome, the proteome and the metabolome of cells, tissue or organisms $(39 ; 40)$. The transcriptome reflects the genes that are being expressed and transcriptomics exams the expression of messenger RNA in a cell population or tissue. Transcriptomics utilizes high-throughput genomic tools, such as DNA microarrays, to examine changes in the expression of all genes, under various conditions (dietary interventions) at a given time. This technique provides insights in genome-wide effects of dietary interventions or dietary components and will increase understanding of how nutrition influences metabolic pathways and homeostatic control (40).

\section{Tissue availability for transcriptomics}

As the application of transcriptomics in nutrition research is very promising, the major disadvantage in transcriptomics studies in healthy subjects is the availability of tissue due to practical and ethical reasons. In healthy subjects the main options for tissue sampling are muscle and adipose tissue biopsies because they are relatively easy to collect. Biopsies of other tissues such as liver or intestine could be used for these analyses, however these invasive procedures for obtaining these tissues are not generally performed in healthy subjects in dietary interventions.

Peripheral blood mononuclear cells (PBMC), a mixture of B-cells, T-cells and monocytes, are an easily accessed tissue type that show differential gene expression following nutritional stimulus in vivo (41). PBMCs demonstrated to be metabolically active and it is expected that PBMCs may reflect physiological and pathological processes in different body tissues as they circulate throughout the whole body (42). 


\section{AIMS AND OUTLINE THESIS}

The incidence of obesity and associated metabolic disorders such as hyperglycemia and hyperinsulinemia are still growing worldwide. For that reason, in this thesis potentially dietary strategies to reduce hyperglycemia, hyperinsulinemia and to achieve and maintain a healthy body weight will be investigated.

First, an overview of current literature is given about the role of hyperglycemia and hyperinsulinemia on body weight regulation (Chapter 2). Next, the effect of sugarsweetened beverage intake on energy intake in an ad libitum 6-month low-fat highcarbohydrate diet was investigated (Chapter 3). Subsequently, the effects of different protein and glycemic index diets were investigated on $24 \mathrm{~h}$ profiles of metabolic markers and substrate partitioning in lean healthy males (Chapter 4). In addition, the effects of meal frequency on metabolic profiles and substrate partitioning in lean healthy males were investigated (Chapter 5). Then, the meal frequency study was repeated in subjects with impaired glucose tolerance (IGT). Furthermore, the effects of meal frequency were investigated on gene expression profiles in PBMCs and muscle tissue (Chapter 6). In Chapter 7 the main results and conclusions described in previous chapters are discussed and implications for future research are addressed. 


\section{REFERENCES}

1. Howarth NC, Huang TT, Roberts SB, Lin BH, McCrory MA: Eating patterns and dietary composition in relation to $\mathrm{BMI}$ in younger and older adults. Int J Obes (Lond) 2007;31:675-684

2. Gannon MC, Nuttall FQ: Control of blood glucose in type 2 diabetes without weight loss by modification of diet composition. Nutrition \& metabolism 2006;3:16

3. Devkota S, Layman DK: Increased ratio of dietary carbohydrate to protein shifts the focus of metabolic signaling from skeletal muscle to adipose. Nutrition \& metabolism 2011;8:13

4. Solomon TP, Chambers ES, Jeukendrup AE, Toogood AA, Blannin AK: The effect of feeding frequency on insulin and ghrelin responses in human subjects. $\mathrm{Br} \mathrm{J}$ Nutr 2008;100:810-819

5. Saltiel AR, Kahn CR: Insulin signalling and the regulation of glucose and lipid metabolism. Nature 2001;414:799-806

6. Martyn JA, Kaneki M, Yasuhara S: Obesity-induced insulin resistance and hyperglycemia: etiologic factors and molecular mechanisms. Anesthesiology 2008;109:137-148

7. Kiens B, Richter EA: Types of carbohydrate in an ordinary diet affect insulin action and muscle substrates in humans. Am J Clin Nutr 1996;63:47-53

8. Blaak EE, Hul G, Verdich C, Stich V, Martinez A, Petersen M, Feskens EF, Patel K, Oppert JM, Barbe P, Toubro S, Anderson I, Polak J, Astrup A, Macdonald IA, Langin D, Holst C, Sorensen TI, Saris WH: Fat oxidation before and after a high fat load in the obese insulin-resistant state. J Clin Endocrinol Metab 2006;91:1462-1469

9. Ludwig DS: Dietary glycemic index and obesity. J Nutr 2000;130:280S-283S

10. Brand-Miller JC, Holt SH, Pawlak DB, McMillan J: Glycemic index and obesity. Am J Clin Nutr 2002;76:281S-285S

11. Saris WH: Sugars, energy metabolism, and body weight control. Am J Clin Nutr 2003;78:850S-857S

12. Eckel $\mathrm{RH}$ : Insulin resistance: an adaptation for weight maintenance. Lancet 1992;340:1452-1453

13. Tremblay A, Boule N, Doucet E, Woods SC: Is the insulin resistance syndrome the price to be paid to achieve body weight stability? Int J Obes (Lond) 2005;29:1295-1298

14. Ambrosini GL, Oddy WH, Huang RC, Mori TA, Beilin LJ, Jebb SA: Prospective associations between sugar-sweetened beverage intakes and cardiometabolic risk factors in adolescents. Am J Clin Nutr 2013;98:327-334

15. Te Morenga L, Mallard S, Mann J: Dietary sugars and body weight: systematic review and meta-analyses of randomised controlled trials and cohort studies. BMJ 2013;346:e7492

16. Sievenpiper JL, de Souza RJ: Are sugar-sweetened beverages the whole story? Am J Clin Nutr 2013;98:261-263

17. Malhotra A: The dietary advice on added sugar needs emergency surgery. BMJ 2013;346:f3199

18. Cottrell RC, Wittekind A: Conclusions of review of dietary sugars and body weight are unwarranted. BMJ 2013;346:f1238 
19. Layman DK, Boileau RA, Erickson DJ, Painter JE, Shiue H, Sather C, Christou DD: A reduced ratio of dietary carbohydrate to protein improves body composition and blood lipid profiles during weight loss in adult women. J Nutr 2003;133:411-417

20. Skov AR, Toubro S, Ronn B, Holm L, Astrup A: Randomized trial on protein vs carbohydrate in ad libitum fat reduced diet for the treatment of obesity. Int J Obes Relat Metab Disord 1999;23:528-536

21. Larsen TM, Dalskov SM, van Baak M, Jebb SA, Papadaki A, Pfeiffer AF, Martinez JA, Handjieva-Darlenska T, Kunesova M, Pihlsgard M, Stender S, Holst C, Saris WH, Astrup A: Diets with high or low protein content and glycemic index for weight-loss maintenance. N Engl J Med 2010;363:2102-2113

22. Brand-Miller J, McMillan-Price J, Steinbeck K, Caterson I: Dietary glycemic index: health implications. J Am Coll Nutr 2009;28 Suppl:446S-449S

23. van Loon LJ, Saris WH, Verhagen $\mathrm{H}$, Wagenmakers AJ: Plasma insulin responses after ingestion of different amino acid or protein mixtures with carbohydrate. Am J Clin Nutr 2000;72:96-105

24. Manders RJ, Wagenmakers AJ, Koopman R, Zorenc AH, Menheere PP, Schaper NC, Saris $\mathrm{WH}$, van Loon LJ: Co-ingestion of a protein hydrolysate and amino acid mixture with carbohydrate improves plasma glucose disposal in patients with type 2 diabetes. Am J Clin Nutr 2005;82:76-83

25. Layman DK, Baum JI: Dietary protein impact on glycemic control during weight loss. J Nutr 2004;134:968S-973S

26. Holt SH, Miller JC, Petocz P: An insulin index of foods: the insulin demand generated by 1000-kJ portions of common foods. Am J Clin Nutr 1997;66:1264-1276

27. Zemel MB: The role of dairy foods in weight management. J Am Coll Nutr 2005;24:537S-546S

28. Zemel MB: Mechanisms of dairy modulation of adiposity. J Nutr 2003;133:252S$256 \mathrm{~S}$

29. Leidy HJ, Campbell WW: The effect of eating frequency on appetite control and food intake: brief synopsis of controlled feeding studies. J Nutr 2011;141:154-157

30. Flint A, Raben A, Blundell JE, Astrup A: Reproducibility, power and validity of visual analogue scales in assessment of appetite sensations in single test meal studies. Int J Obes Relat Metab Disord 2000;24:38-48

31. Cummings DE, Overduin J: Gastrointestinal regulation of food intake. The Journal of clinical investigation 2007;117:13-23

32. Karhunen LJ, Juvonen KR, Huotari A, Purhonen AK, Herzig KH: Effect of protein, fat, carbohydrate and fibre on gastrointestinal peptide release in humans. Regulatory peptides 2008;149:70-78

33. Bowen J, Noakes M, Trenerry C, Clifton PM: Energy intake, ghrelin, and cholecystokinin after different carbohydrate and protein preloads in overweight men. J Clin Endocrinol Metab 2006;91:1477-1483

34. Lejeune MP, Westerterp KR, Adam TC, Luscombe-Marsh ND, Westerterp-Plantenga MS: Ghrelin and glucagon-like peptide 1 concentrations, 24-h satiety, and energy and substrate metabolism during a high-protein diet and measured in a respiration chamber. Am J Clin Nutr 2006;83:89-94

35. Degen L, Oesch S, Casanova M, Graf S, Ketterer S, Drewe J, Beglinger C: Effect of peptide YY3-36 on food intake in humans. Gastroenterology 2005;129:1430-1436 


\section{Chapter 1}

36. Alberts B, Bray D, Lewis J, Raff M, Roberts K, Watson JD: Molecular Biology of The Cell. New York: Garland Publishing 1994;3rd ed.

37. Brouwer $\mathrm{E}$ : On simple formulae for calculating the heat expenditure and the quantities of carbohydrate and fat oxidized in metabolism of men and animals, from gaseous exchange (Oxygen intake and carbonic acid output) and urine-N. Acta Physiol Pharmacol Neerl 1957;6:795-802

38. Ravussin E, Bogardus C: Relationship of genetics, age, and physical fitness to daily energy expenditure and fuel utilization. Am J Clin Nutr 1989;49:968-975

39. Muller M, Kersten S: Nutrigenomics: goals and strategies. Nature reviews Genetics 2003;4:315-322

40. Afman L, Muller M: Nutrigenomics: from molecular nutrition to prevention of disease. Journal of the American Dietetic Association 2006;106:569-576

41. Bouwens $M$, Afman LA, Muller M: Fasting induces changes in peripheral blood mononuclear cell gene expression profiles related to increases in fatty acid betaoxidation: functional role of peroxisome proliferator activated receptor alpha in human peripheral blood mononuclear cells. Am J Clin Nutr 2007;86:1515-1523

42. Kussmann M, Rezzi S, Daniel H: Profiling techniques in nutrition and health research. Current opinion in biotechnology 2008;19:83-99 


\section{CHAPTER 2}

Body weight regulation and obesity:

dietary strategies to improve the metabolic profile

MJM Munsters and WHM Saris

Annu. Rev. Food Sci. Technol. 2014.5:1.1-1.13 


\section{Chapter 2}

\section{ABSTRACT}

This review discusses dietary strategies that may improve the metabolic profile and body weight regulation in obesity. Recent evidence demonstrated that long-term health effects seem to be more beneficial for low-glycemic index (GI) diets compared to high-protein diets. Still, these results need to be confirmed by other prospective cohort studies and long-term clinical trials, and the discrepancy between these study designs needs to be explored in more detail. Furthermore, the current literature is mixed with regard to the efficacy of increased meal frequency (or snacking) regimens in causing metabolic alterations, particularly in relation to body weight control. In conclusion, a growing body of evidence suggests that dietary strategies with the aim to reduce postprandial insulin response and increase fat oxidation, and that tend to restore metabolic flexibility have a place in the prevention and treatment of obesity and associated metabolic disorders. 


\section{INTRODUCTION}

Overweight and obesity represent a worldwide increasing health problem that seriously raises the risk for the development of severe metabolic disorders such as type 2 diabetes (T2D) mellitus and cardiovascular diseases (1; 2). As with increasing obesity, insulin action decreases, and the system usually compensates by increasing $\beta$ cell function and consequently insulin secretion (3). Euglycemia is therefore maintained. Overt hyperglycemia does not develop until later stages, when pancreatic $\beta$-cells can no longer compensate for the high levels of insulin resistance in peripheral tissues (4). Moreover, Erdmann et al.'s (2008) study demonstrated for the first time that insulin resistance already develops during weight gain within the normal range of body weight (4).

Genetic factors are suggested to play an important role in body weight regulation. Nevertheless, the major contributing factors to the increase of obesity in both developed and developing countries are the increased fat intake and energy density of the diet, together with lower physical activity levels (5). The high-fat content of Western diets has been associated with a higher energy intake and body mass index (6). In particular, high-fat foods tend to be very palatable and are highly energy dense, which may encourage passive overeating resulting in a higher energy intake $(7 ; 8)$. In addition, metabolic flexibility, defined as the capacity to increase fat oxidation upon increased fatty acid availability and to switch between fat and glucose as the primary fuel source after a meal, may play an important role in body weight regulation and associated metabolic disorders (9). Next to fat intake, energy drinks, which are mostly from sugary origin, have a weak feedback on satiety and therefore are a risk for overfeeding and weight gain (10).

Despite many scientific advances over the years about the role of dietary intake in energy balance, many questions remain about how people should eat to prevent weight gain or to maintain weight loss (11). For that reason, there is an urgent need to introduce several simple habitual lifestyle changes that can be adopted by several subjects in the population and that can have a significant effect in correcting early metabolic factors that contribute to obesity, insulin resistance, and diabetes (12).

In this review, we first discuss the concepts of body weight regulation, substrate partitioning, and the role of hyperglycemia and hyperinsulinemia on these concepts. Second, we address potential dietary strategies to reduce hyperglycemia and hyperinsulinemia and to achieve and maintain a healthy body weight.

\section{CONCEPT OF BODY WEIGHT REGULATION AND SUBSTRATE PARTITIONING}

In general, dietary carbohydrate intake stimulates insulin release, a response, which serves to limit the rise in glycemia. The increase in plasma insulin concentration promotes glucose uptake in insulin-sensitive tissues and inhibits hepatic glucose 
production (3). Insulin stimulates glucose transport in muscle and glycogen synthesis in both muscle and liver. In addition, insulin decreases the release of free fatty acids (FFA) from adipose tissue by inhibiting hormone-sensitive lipase and stimulates triacylglycerol uptake in adipose tissue by activating lipoprotein lipase. The postprandial rise in glycemia and in insulinemia, in combination with a reduced plasma FFA concentration, results in an increase in carbohydrate oxidation and in a decrease in fat oxidation in the whole body $(13 ; 14)$. The combination of substrates (fat, carbohydrates, protein) oxidized may also influence the energy balance and therefore body weight regulation, which is explained next.

The traditional concept of energy balance states that obesity and overweight develops when energy intake exceeds energy expenditure. Long-term weight maintenance in normal and obese subjects requires that energy intake equals energy expenditure and when the macronutrient composition of the diet is modified, fuel oxidation will be adjusted to achieve a new equilibrium (15). Protein and carbohydrate balances seem to be strictly controlled compared to fat balance; an increase in fat intake does not stimulate its oxidation to the same extent as carbohydrate and protein (16). The rate at which these adjustments are achieved is faster in the transition from a lowcarbohydrate to high-carbohydrate diet ( 2 days). Nevertheless, fat oxidation can take more than one week to match fat intake in response to a higher dietary fat intake (17). In addition, dietary fat is stored very efficiently as body fat but is not efficient in stimulating satiety (18).

Therefore, the limited ability to increase fat oxidation to fat intake may translate into a positive fat balance and, consequently, to weight gain over time, as suggested by Flatt and colleagues $(16 ; 19 ; 20)$. Flatt introduced the concept of body weight regulation with a two-compartment model. This model suggests that weight maintenance can be achieved by a regulation of food intake to maintain stable glycogen levels, which are an integration of carbohydrate and lipid fluxes. Failure to adjust fat oxidation in response to excess dietary fat intake may result in an increased depletion of the glycogen stores, which may stimulate food intake. Expansion of the adipose tissue to enhance fat oxidation to a rate equal to dietary fat intake is one of the mechanisms for adapting to a high-fat diet. Nevertheless, this positive correlation between adipose tissue and 24-h fat oxidation (fasting) could not be confirmed in all studies $(21 ; 22)$.

\section{Defense mechanism to obesity: hyperglycemia and hyperinsulinemia}

As mentioned before, insulin is the principal hormone of glucose homeostasis; it stimulates glucose influx into muscle, glycogen synthesis in the liver and muscle, protein synthesis, and fat deposition in adipocytes, and thereby increases carbohydrate oxidation and decreases fat oxidation $(4 ; 23)$. With regard to the duration over which the difference in serum insulin concentration is maintained, it 
usually peaks in a relatively short time, although its effects may prevail much longer via effect on gene expression of metabolically relevant proteins (24). In a situation of frequent daily insulinemia, fat oxidation is suppressed (25). Reduced fat oxidation can result in weight gain in the long term. Moreover, a growing body of theoretical and experimental work suggests that diets designed to lower the insulin response to ingested carbohydrate may improve access to stored metabolic fuels, decrease hunger, and promote weight loss. Additionally, the risks for various conditions associated with hyperinsulinemia may be lowered, such as diabetes mellitus (26). A higher insulinemic response is linked to weight gain, although the scientific debate is still ongoing $(27 ; 28)$.

Despite hyperinsulinemia, however, alterations in insulin action may be, to a variable extent, present in obesity. This variability could predict whether weight will stabilize or further increase. Insulin resistance can be physiological, but most often is associated with metabolic disorders such as obesity. The reduction in insulin action seen in insulin-resistant states affects metabolic substrate partitioning in a way that would prevent additional weight gain and as such recovers body weight stability. Partitioning of lipid fuels is directed from storage in adipose tissue to immediate or delayed oxidation in skeletal muscle. Despite the potential adverse effects of cardiovascular risk factors that accompany insulin resistance, reductions in insulin action may well be necessary to prevent additional weight gain in humans who eat excessively and are inactive $(29 ; 30)$.

\section{Metabolic inflexibility}

As explained before, metabolic flexibility is defined as the capacity to increase fat oxidation upon increased fatty acid availability and to switch between fat and glucose as the primary fuel source after a meal (9). The metabolism of healthy persons can switch quickly and completely; this is called a flexible metabolism. A growing body of evidence demonstrates a blunted substrate switching from low- to high-fat oxidation in obese individuals, and in the pre-obese and post-obese, and this metabolic inflexibility may be a genetically determined trait (31). Prospective studies identified that Pima Indians with a habitually high 24-h respiratory quotient (RQ) are more prone to gain weight over time (32). In addition, a significant positive association between resting $R Q$ and subsequent weight gain was found in the Baltimore Longitudinal Study on Aging, by Seidell et al. (1992) (33).

Dietary changes and weight loss may improve metabolic flexibility in skeletal muscle (9), because it accounts for $75-80 \%$ of whole-body insulin-stimulated glucose uptake (34), and thereby contribute to the prevention of obesity and T2D. The reduced capacity of obese persons to mobilize and subsequently oxidize fat has been mentioned as a consequence of long-term hyperinsulinemia; however, whether a 
direct link exists is questionable (28). Hyperglycemia and hyperinsulinemia are often accompanied by increased circulation of FFA and/or triacylglycerides due to a loss of buffering capacity of the adipose tissue, even though fat oxidation is diminished (35). This process is referred to as lipid overflow. The oversupply of lipids causes a redistribution of fat from adipose tissue to nonadipose tissues such as skeletal muscle, liver, and pancreas (ectopic fat accumulation). Additionally, impairments in the regulation of fatty acids uptake, storage and/or oxidation may result in muscle lipid accumulation (36). However, the role of FFA in lipid overflow and insulin resistance has recently been revised as studies demonstrated that FFA levels were only slightly increased or not increased at all in the obese, insulin-resistant state $(37 ; 38)$. The slightly increased FFA levels may be explained largely by a mass effect of expanding adipose tissue and that hyperinsulinemia in obesity may occur as a compensation to prevent further increase in plasma FFA levels (39; 40). Furthermore, the lipocentric view depicts the hyperglycemia of $T 2 D$, and the underlying insulin resistance and $\beta$-cell loss, as being secondary to the metabolic trauma caused by lipotoxicity or ectopic lipid deposition (41). Dietary strategies that increase fat oxidation and tend to restore metabolic flexibility may have a place in the prevention and treatment of obesity (31).

\section{Insulin resistance and disturbed skeletal muscle fatty acid handling}

Several factors have been suggested as contributing to the development of skeletal muscle insulin resistance, including disturbances in fatty acid metabolism. Recent evidence suggests that the intermediates of intramuscular triglyceride metabolism are more closely linked to insulin resistance (42). However, Randle et al. (1963) described another potential concept explaining the relationship between insulin resistance and disturbed fatty acid handling (43). The concept of the glucose-fatty-acid cycle suggests that increased fat oxidation leads to reduced glucose oxidation. According to this concept, the increased availability of FFA stimulates FFA oxidation. The enhanced FFA oxidation produces an increased concentration of acetyl CoA and citrate that respectively inhibit pyruvate dehydrogenase and phosphofructokinase. Consequently, glucose-6-phosphate concentration increases, and therefore hexokinase is inhibited, finally resulting in impaired glucose uptake and glucose oxidation (43). In addition, it was established that increased glucose concentrations may inhibit fatty acid oxidation via increased intracellular malonyl-CoA concentrations and subsequent inhibition of CPT-1, thereby confirming the coordinated balance between glucose and fatty acid oxidation (44).

\section{DIETARY STRATEGIES TO MODULATE THE GLUCOSE AND INSULIN PROFILES}

The dietary factors involved in metabolic disorders such as obesity and T2D have yet to be fully identified (45). The search for specific factors that increase the risk of obesity is 
a quest for factors that undermine the innate regulatory control of body weight. Research has shown very few clear nutrient- or food-based determinants of obesity. Meta-analyses and a large-scale, long-term dietary intervention trials show that a reduction in dietary fat causes a reduction in energy intake and may produce a modest weight loss in overweight subjects (31). Although some studies show a protective effect of a high proportion of carbohydrate versus low fat, many others found no association. The evidence relating the intake of sugar per se to weight change is inconsistent (46). A review of studies (intervention, prospective, and cross-sectional) on the relationship between sugars, insulin resistance, and diabetes concluded that all these studies failed to demonstrate an obvious relationship between total simple carbohydrate intake and glycemic control, insulin resistance, or risk to develop T2D $(45 ; 47)$. Also, the only long-term randomized controlled trial (RCT) on the effect of simple versus complex carbohydrates executed in our lab did not demonstrate a significant effect on body weight (48). However, the search for nutrient- or food-based determinants of obesity needs to continue, and for that reason other potential dietary strategies to reduce hyperglycemia and hyperinsulinemia are discussed next.

\section{Glycemic index}

The glycemic index (GI) is suggested as a useful strategy for achieving and maintaining a healthy body weight and reducing the risk of T2D and cardiovascular diseases (49; 50). The rate of carbohydrate absorption after a meal is illustrated by the GI (51). The $\mathrm{Gl}$ of a food is defined as the incremental area under the 2-h plasma glucose response curve of a 50-g carbohydrate portion of a test food expressed as a percentage of the response to the same amount of carbohydrate from a reference food: either white bread or glucose (52). In addition, the glycemic load (GL) was developed to improve the prediction of the glycemic response. The GL of a specific food can be determined by combining the $\mathrm{Gl}$ of the food and the amount of carbohydrates in a serving. In this manner, the overall GL of a meal or an entire diet can be calculated (53). Nevertheless, food processing, food matrix, nutrient bioavailability, and the interaction of nutrients within the meal itself are factors that influence the actual GI of a diet, together with the rate and capacity of digestion and absorption. Digestive and absorptive mechanisms are tightly regulated by hormonal responses, such as cholecystokinin, insulin, and glucagon like peptide-1 (50).

Carbohydrate-rich foods with a lower GI (lower induced postprandial glucose and insulin levels) may assist in weight management via several mechanisms such as providing greater access to fatty acids as a source of fuel by reducing insulinemia, blunting the counter regulatory response that occurs with high blood glucose and insulin swings, maintaining insulin sensitivity, and promoting satiety and greater fat oxidation. In contrast, high-GI meals have been associated with appetite stimulation, 
higher energy intake, and higher fat storage. Additionally, the increased stimulation of glucose and insulin secretion may lead to postprandial hyperinsulinemia, possibly continuing a vicious cycle with peripheral cell insulin receptor downregulation $(27 ; 54$; 55).

\section{Glycemic index and obesity}

Although low-GI diets showed beneficial effects in diabetes, the role of $\mathrm{Gl}$ in body weight control remains controversial. The possible usefulness of low-GI foods in the management of obesity has been reviewed extensively $(27 ; 56$; 57). Raben (2002) concluded that there is no evidence that low-Gl foods are superior to high-GI foods in regard to long-term body weight control (58). Furthermore, a Cochrane Review (49) and a meta-analysis by Livesey et al. (2008) (59), showed that body weight fell with reduction in GI and GL. However, in these studies, food intake was ad libitum or food intake control was limited. The beneficial effect was not observed in studies where food intake was controlled (59). New studies, in particular the recent RCT on protein and GI by (60), confirm the results of the two meta-analyses, as pointed out in a recent review by van Baak \& Astrup (2009) (47). These authors concluded that an effect of low-GI/GL diets on body weight is likely to be small and of limited practical and clinical importance.

\section{High protein and dairy versus vegetable protein source}

Next to low-GI diets, energy-restricted, high-protein diets have been found to improve insulin sensitivity, body composition, lipid profiles, and body weight loss $(61 ; 62)$. Additionally, after weight loss, extra protein intake was found to reduce weight regain (63). Recently, the RCT Diogenes study demonstrated that a modest increase in protein content and a modest reduction in the Gl improved maintenance of weight loss in overweight subjects (60). This beneficial effect of high-protein diets has been attributed to reduced energy efficiency and/or increased thermogenesis $(64 ; 65)$ and a higher satiating effect of proteins $(66 ; 67)$. These effects could be related to reduced glucose disposal, higher endogenous glucose output (54), and the insulin-stimulating effect of proteins that has been described in both healthy (68) and diabetic subjects (69). Dairy proteins such as whey protein isolate, in particular, are relatively rich in branch chain amino acids (70) and therefore have strong insulinotropic effects (71). Moreover, dairy products, and in particular calcium, have shown to have an antiobesity effect (72), despite the higher postprandial insulin levels that are associated with insulin resistance and weight gain (26). Data suggest that both calcium and other dairy product components may contribute to alterations in the metabolic partitioning of dietary energy, resulting in modulation of body weight, body fat, and the insulinresistance syndrome (73). 
Furthermore, a low-fat, plant-based nutritional approach also has been suggested to improve body weight control, glycemia, and cardiovascular risk (74). These foods are nutrient dense and good sources of dietary fiber. However, foods containing soy (vegetable proteins) are proposed as being as good as any other protein source for promoting weight loss (75).

So far, the evidence suggests that a moderate increase of dietary protein may improve weight loss and weight maintenance following weight loss.

\section{Low-glycemic-index versus high-protein diets}

Both dietary strategies are associated with a lower postprandial glucose response, but with a different postprandial insulin response. Short-term studies have been shown to be beneficial for body weight control; nevertheless the long-term health effects may be different. The RCT Diogenes study recently showed that a slightly higher protein content and a lower Gl improved study completion and weight loss maintenance in overweight subjects over a 26 -week period (60). Although lower-carbohydrate, higherprotein diets increase the rate of weight loss, cohort studies and meta-analyses of clinical trials suggest the potential for increased mortality (54). The European Prospective Investigation into Cancer and Nutrition study followed subjects for a mean of 6.5 years for individual dietary information and anthropometric measures. Researchers concluded that a higher intake of total protein, and protein from animal sources, seemed to be positively associated with long-term weight gain (76). Conflicting results are found between RCTs showing a beneficial effect of a highprotein intake on weight maintenance and observational studies suggesting the opposite effect. This might be a consequence of the study designs, although the two study designs often obtain similar results results (77-79). The discrepancy between trials and cohort studies could be explained by the fact that the participants in the trials are a subset of the population that on average might be more resistant to weight loss by a high protein diet. Thus, mimicking a trial with observational data might be a way to reconcile this opposing evidence, as demonstrated before to be a useful method $(80 ; 81)$.

Brand-Miller et al. (2009) concluded in a recent review that a large body of evidence provides robust support for low-Gl carbohydrate diets in the prevention of obesity, diabetes, and cardiovascular disease. Moreover, low-Gl diets may be more behaviorally sustainable because they do not restrict either fat or carbohydrate, or specific food groups (54).

In conclusion, long-term health effects of both dietary strategies seem to be more beneficial for low-Gl diets compared to high-protein diets. Still, these results need to be confirmed by other prospective cohort studies and long-term clinical trials, and the discrepancy between these study designs needs to be explored in more detail. 


\section{Chapter 2}

Furthermore, the discrepancy between the theory that (dairy) proteins have a positive effect on body weight control and the assumption that the high postprandial insulin levels (insulinotropic effects of protein) are associated with insulin resistance and consequently weight gain warrants further investigation (26) (Fig. 1).

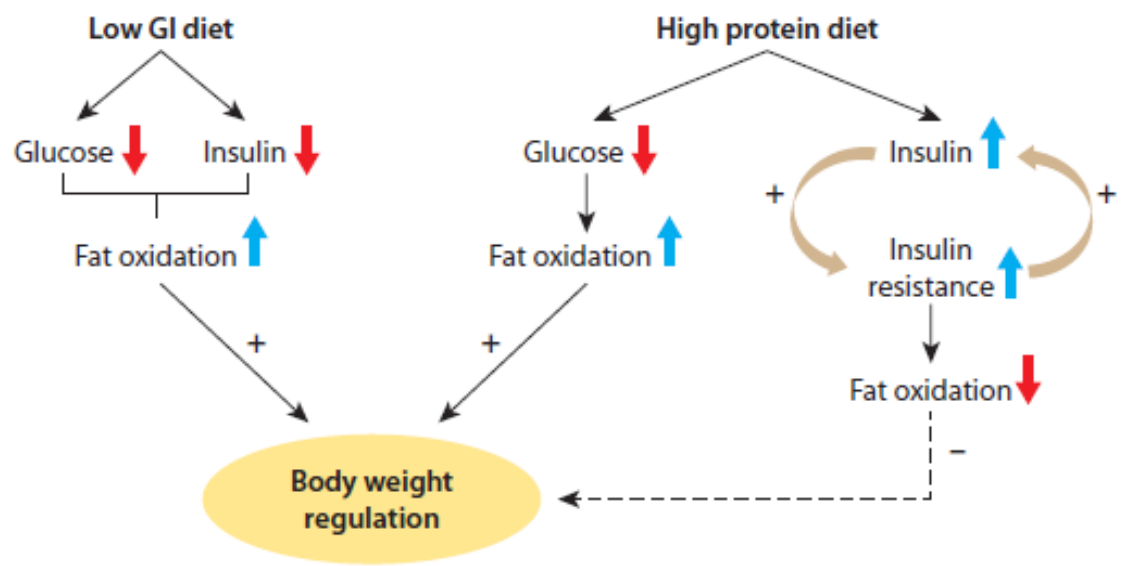

Figure 1. Body weight regulation: A low-glycemic-index (GI) diet induces lower postprandial glucose and insulin levels, which may result in higher fat oxidation and thereby increase body weight regulation. This demonstrates the discrepancy between the theory that proteins have a positive effect on body weight control by reducing postprandial glucose levels and the assumption that the high postprandial insulin levels are associated with insulin resistance and consequently weight gain.

\section{Meal frequency}

Although consumption of three meals a day is the most common pattern of eating in industrialized countries, a scientific rationale for this meal frequency with respect to optimal health is lacking (26). Epidemiological evidence indicates a clear increasing trend in recent years of dietary snacking and increased meal frequency $(82 ; 83)$. The pattern of food intake is often cited as one of the variables that can influence energy balance and substrate metabolism. When the daily energy intake is consumed in several large meals (gorging pattern), relatively more energy has to be stored than with a feeding pattern of several small meals (nibbling pattern; 6--8 meals/day) (84). A gorging pattern (1--2 meals a day) of food intake has been shown to enhance lipogenesis, increase body weight, and reduce glucose tolerance (85), whereas another study showed the opposite (86).

Additionally, eating several small meals is suggested to lead to increased glucose and insulin levels, resulting in a continuous postprandial status thereby inhibiting fat oxidation, which can have a harmful effect on body weight control and metabolic flexibility (14). Solomon et al. (2008) demonstrated that 2 meals per day led to greater fluctuations in glucose, insulin, and ghrelin responses (i.e., greater peaks and lower 
troughs), compared with 12 meals per day assessed throughout an 8-h period (87). Experimental and cross-sectional epidemiological studies to date, in which energy intake underreporting is taken into consideration, suggest that increasing meal frequency may promote positive energy balance in free-living adults (88; 89). However, well-controlled intervention studies do not support an association between meal frequency and body weight (84; 89-91). It is important that 24-h profiles be taken into consideration, as substrate oxidation differences during the day can be compensated during the night, and for that reason no 24-h effects are observed (92).

To conclude, the current literature is mixed with regard to the efficacy of increased meal frequency (or snacking) regimens in causing metabolic alterations, particularly in relation to body weight control (87). Therefore, the possible association between the current increase in meal frequency (snacking) and the rising obesity epidemic requires further investigation by well-controlled trials.

\section{FUTURE RESEARCH}

The discrepancy between the theory that proteins (especially dairy proteins) have a positive effect on body weight control and the assumption that insulinemia as a modulator of insulin resistance and consequently substrate partitioning leading to weight gain warrants further investigation (26). It is suggested that the low-GI property of protein leads to glycemic improvements resulting in a better body weight control despite the stronger insulinotropic effects comparable to high-GI foods. Insulin sensitivity may be improved due to the insulinotropic effect of high-protein diets.

The effect of (dairy) proteins on postprandial insulinemia and consequently substrate partitioning has not been explored previously, because insulin secretion is largely assumed to be proportional to postprandial glycemia as with carbohydrate intake (71). Therefore, the effects of carbohydrate intake (high-glucose and high-insulin levels) versus (dairy) protein intake (low-glucose and high-insulin levels) on the metabolic profile and body weight control need to be investigated in more detail.

\section{SUMMARY AND CONCLUSIONS}

Obesity and T2D mellitus are associated with hyperglycemia and hyperinsulinemia as a result of insulin resistance and can be accompanied by a reduced fat oxidation and metabolic inflexibility. Dietary strategies may improve metabolic flexibility and increase fat oxidation. Low-Gl and high-protein diets are both associated with a lower postprandial glucose response but with different postprandial insulin responses. Longterm health effects of both dietary strategies seem to be more beneficial for low-GI diets than for high-protein diets. Still, these results need to be confirmed by other prospective cohort studies and long-term clinical trials, and the discrepancy between these study designs needs to be explored in more detail. In conclusion, a growing body 


\section{Chapter 2}

of evidence suggests that dietary strategies with the aim to reduce postprandial insulin response and increase fat oxidation, and that tend to restore metabolic flexibility have a place in the prevention and treatment of obesity and associated metabolic disorders.

\section{ACKNOWLEDGMENTS}

We acknowledge funding support via a grant from the Dutch Dairy Association.

The authors are not aware of any affiliations, memberships, funding, or financial holdings that might be perceived as affecting the objectivity of this review. 


\section{REFERENCES}

1. Erdmann J, Kallabis B, Oppel U, Sypchenko O, Wagenpfeil S, Schusdziarra V: Development of hyperinsulinemia and insulin resistance during the early stage of weight gain. Am J Physiol Endocrinol Metab 2008;294:E568-575

2. Klein S, Burke LE, Bray GA, Blair S, Allison DB, Pi-Sunyer X, Hong Y, Eckel RH: Clinical implications of obesity with specific focus on cardiovascular disease: a statement for professionals from the American Heart Association Council on Nutrition, Physical Activity, and Metabolism: endorsed by the American College of Cardiology Foundation. Circulation 2004;110:2952-2967

3. Stumvoll M, Goldstein BJ, van Haeften TW: Type 2 diabetes: principles of pathogenesis and therapy. Lancet 2005;365:1333-1346

4. Martyn JA, Kaneki M, Yasuhara S: Obesity-induced insulin resistance and hyperglycemia: etiologic factors and molecular mechanisms. Anesthesiology 2008;109:137-148

5. James WP: The epidemiology of obesity: the size of the problem. J Intern Med 2008;263:336-352

6. Hill JO, Peters JC: Environmental contributions to the obesity epidemic. Science 1998;280:1371-1374

7. Lissner L, Levitsky DA, Strupp BJ, Kalkwarf HJ, Roe DA: Dietary fat and the regulation of energy intake in human subjects. Am J Clin Nutr 1987;46:886-892

8. Drewnowski A, Greenwood MR: Cream and sugar: human preferences for high-fat foods. Physiol Behav 1983;30:629-633

9. Corpeleijn E, Saris WH, Blaak EE: Metabolic flexibility in the development of insulin resistance and type 2 diabetes: effects of lifestyle. Obes Rev 2009;10:178-193

10. Mattes RD: Dietary compensation by humans for supplemental energy provided as ethanol or carbohydrate in fluids. Physiol Behav 1996;59:179-187

11. McCrory MA, Campbell WW: Effects of eating frequency, snacking, and breakfast skipping on energy regulation: symposium overview. J Nutr 2011;141:144-147

12. Brynes AE, Adamson J, Dornhorst A, Frost GS: The beneficial effect of a diet with low glycaemic index on $24 \mathrm{~h}$ glucose profiles in healthy young people as assessed by continuous glucose monitoring. The British journal of nutrition 2005;93:179-182

13. Jequier E, Tappy L: Regulation of body weight in humans. Physiol Rev 1999;79:451480

14. Frayn K: Metabolic regulation: a human perspective. Oxford, Wiley-Blackwell, 2010

15. Galgani J, Ravussin E: Energy metabolism, fuel selection and body weight regulation. Int J Obes (Lond) 2008;32 Suppl 7:S109-119

16. Flatt JP, Ravussin E, Acheson KJ, Jequier E: Effects of dietary fat on postprandial substrate oxidation and on carbohydrate and fat balances. The Journal of clinical investigation 1985;76:1019-1024

17. Schrauwen P, Wagenmakers AJ, van Marken Lichtenbelt WD, Saris WH, Westerterp KR: Increase in fat oxidation on a high-fat diet is accompanied by an increase in triglyceride-derived fatty acid oxidation. Diabetes 2000;49:640-646

18. Pereira-Lancha LO, Coelho DF, de Campos-Ferraz PL, Lancha AH, Jr.: Body fat regulation: is it a result of a simple energy balance or a high fat intake? J Am Coll Nutr 2010;29:343-351 
19. Flatt JP: The difference in the storage capacities for carbohydrate and for fat, and its implications in the regulation of body weight. Ann N Y Acad Sci 1987;499:104-123 20. Flatt JP: Dietary fat, carbohydrate balance, and weight maintenance: effects of exercise. Am J Clin Nutr 1987;45:296-306

21. Blaak EE, Hul G, Verdich C, Stich V, Martinez A, Petersen M, Feskens EF, Patel K, Oppert JM, Barbe P, Toubro S, Anderson I, Polak J, Astrup A, Macdonald IA, Langin D, Holst C, Sorensen TI, Saris WH: Fat oxidation before and after a high fat load in the obese insulin-resistant state. J Clin Endocrinol Metab 2006;91:1462-1469

22. Astrup A, Buemann B, Western P, Toubro S, Raben A, Christensen NJ: Obesity as an adaptation to a high-fat diet: evidence from a cross-sectional study. Am J Clin Nutr 1994;59:350-355

23. Saltiel AR, Kahn CR: Insulin signalling and the regulation of glucose and lipid metabolism. Nature 2001;414:799-806

24. Diaz EO, Galgani JE, Aguirre CA: Glycaemic index effects on fuel partitioning in humans. Obes Rev 2006;7:219-226

25. Kiens B, Richter EA: Types of carbohydrate in an ordinary diet affect insulin action and muscle substrates in humans. Am J Clin Nutr 1996;63:47-53

26. Ludwig DS: Dietary glycemic index and obesity. J Nutr 2000;130:280S-283S

27. Brand-Miller JC, Holt SH, Pawlak DB, McMillan J: Glycemic index and obesity. Am J Clin Nutr 2002;76:281S-285S

28. Saris WH: Sugars, energy metabolism, and body weight control. Am J Clin Nutr 2003;78:850S-857S

29. Eckel RH: Insulin resistance: an adaptation for weight maintenance. Lancet 1992;340:1452-1453

30. Tremblay A, Boule N, Doucet E, Woods SC: Is the insulin resistance syndrome the price to be paid to achieve body weight stability? Int J Obes (Lond) 2005;29:1295-1298

31. Astrup A: The relevance of increased fat oxidation for body-weight management: metabolic inflexibility in the predisposition to weight gain. Obes Rev 2011;12:859-865

32. Zurlo F, Lillioja S, Esposito-Del Puente A, Nyomba BL, Raz I, Saad MF, Swinburn BA, Knowler WC, Bogardus C, Ravussin E: Low ratio of fat to carbohydrate oxidation as predictor of weight gain: study of 24-h RQ. Am J Physiol 1990;259:E650-657

33. Seidell JC, Muller DC, Sorkin JD, Andres R: Fasting respiratory exchange ratio and resting metabolic rate as predictors of weight gain: the Baltimore Longitudinal Study on Aging. Int J Obes Relat Metab Disord 1992;16:667-674

34. DeFronzo RA, Jacot E, Jequier E, Maeder E, Wahren J, Felber JP: The effect of insulin on the disposal of intravenous glucose. Results from indirect calorimetry and hepatic and femoral venous catheterization. Diabetes 1981;30:1000-1007

35. Smith U: Carbohydrates, fat, and insulin action. Am J Clin Nutr 1994;59:686S-689S

36. Roden M: Muscle triglycerides and mitochondrial function: possible mechanisms for the development of type 2 diabetes. Int J Obes (Lond) 2005;29 Suppl 2:S111-115

37. van Hees AM, Jans A, Hul GB, Roche HM, Saris WH, Blaak EE: Skeletal muscle fatty acid handling in insulin resistant men. Obesity (Silver Spring) 2011;19:1350-1359

38. Karpe F, Dickmann JR, Frayn KN: Fatty acids, obesity, and insulin resistance: time for a reevaluation. Diabetes 2011;60:2441-2449

39. Jocken JW, Langin D, Smit E, Saris WH, Valle C, Hul GB, Holm C, Arner P, Blaak EE: Adipose triglyceride lipase and hormone-sensitive lipase protein expression is 
decreased in the obese insulin-resistant state. J Clin Endocrinol Metab 2007;92:22922299

40. Bickerton AS, Roberts R, Fielding BA, Tornqvist $H$, Blaak EE, Wagenmakers AJ, Gilbert M, Humphreys SM, Karpe F, Frayn KN: Adipose tissue fatty acid metabolism in insulin-resistant men. Diabetologia 2008;51:1466-1474

41. Unger RH: Reinventing type 2 diabetes: pathogenesis, treatment, and prevention. JAMA 2008;299:1185-1187

42. Schrauwen $P$, Hesselink MK: Oxidative capacity, lipotoxicity, and mitochondrial damage in type 2 diabetes. Diabetes 2004;53:1412-1417

43. Randle PJ, Garland PB, Hales CN, Newsholme EA: The glucose fatty-acid cycle. Its role in insulin sensitivity and the metabolic disturbances of diabetes mellitus. Lancet 1963;1:785-789

44. McGarry JD, Mannaerts GP, Foster DW: A possible role for malonyl-CoA in the regulation of hepatic fatty acid oxidation and ketogenesis. The Journal of clinical investigation 1977;60:265-270

45. Laville M, Nazare JA: Diabetes, insulin resistance and sugars. Obes Rev 2009;10 Suppl 1:24-33

46. Jebb SA: Dietary determinants of obesity. Obes Rev 2007;8 Suppl 1:93-97

47. van Baak MA, Astrup A: Consumption of sugars and body weight. Obes Rev 2009;10 Suppl 1:9-23

48. Saris WH, Astrup A, Prentice AM, Zunft HJ, Formiguera X, Verboeket-van de Venne WP, Raben A, Poppitt SD, Seppelt B, Johnston S, Vasilaras TH, Keogh GF: Randomized controlled trial of changes in dietary carbohydrate/fat ratio and simple vs complex carbohydrates on body weight and blood lipids: the CARMEN study. The Carbohydrate Ratio Management in European National diets. Int J Obes Relat Metab Disord 2000;24:1310-1318

49. Thomas DE, Elliott EJ, Baur L: Low glycaemic index or low glycaemic load diets for overweight and obesity. Cochrane Database Syst Rev 2007:CD005105

50. Burton-Freeman BM, Keim NL: Glycemic index, cholecystokinin, satiety and disinhibition: is there an unappreciated paradox for overweight women? Int J Obes (Lond) 2008;32:1647-1654

51. Jenkins DJ, Wolever TM, Taylor RH, Barker H, Fielden H, Baldwin JM, Bowling AC, Newman HC, Jenkins AL, Goff DV: Glycemic index of foods: a physiological basis for carbohydrate exchange. Am J Clin Nutr 1981;34:362-366

52. Brouns F, Bjorck I, Frayn KN, Gibbs AL, Lang V, Slama G, Wolever TM: Glycaemic index methodology. Nutr Res Rev 2005;18:145-171

53. Liu S, Willett WC: Dietary glycemic load and atherothrombotic risk. Curr Atheroscler Rep 2002;4:454-461

54. Brand-Miller J, McMillan-Price J, Steinbeck K, Caterson I: Dietary glycemic index: health implications. J Am Coll Nutr 2009;28 Suppl:446S-449S

55. Esfahani A, Wong JM, Mirrahimi A, Srichaikul K, Jenkins DJ, Kendall CW: The glycemic index: physiological significance. J Am Coll Nutr 2009;28 Suppl:439S-445S

56. Pawlak DB, Ebbeling CB, Ludwig DS: Should obese patients be counselled to follow a low-glycaemic index diet? Yes. Obes Rev 2002;3:235-243

57. Ludwig DS: The glycemic index: physiological mechanisms relating to obesity, diabetes, and cardiovascular disease. Jama 2002;287:2414-2423 
58. Raben A: Should obese patients be counselled to follow a low-glycaemic index diet? No. Obes Rev 2002;3:245-256

59. Livesey G, Taylor R, Hulshof T, Howlett J: Glycemic response and health--a systematic review and meta-analysis: relations between dietary glycemic properties and health outcomes. Am J Clin Nutr 2008;87:258S-268S

60. Larsen TM, Dalskov SM, van Baak M, Jebb SA, Papadaki A, Pfeiffer AF, Martinez JA, Handjieva-Darlenska T, Kunesova M, Pihlsgard M, Stender S, Holst C, Saris WH, Astrup A: Diets with high or low protein content and glycemic index for weight-loss maintenance. N Engl J Med 2010;363:2102-2113

61. Layman DK, Boileau RA, Erickson DJ, Painter JE, Shiue H, Sather C, Christou DD: A reduced ratio of dietary carbohydrate to protein improves body composition and blood lipid profiles during weight loss in adult women. J Nutr 2003;133:411-417

62. Skov AR, Toubro S, Ronn B, Holm L, Astrup A: Randomized trial on protein vs carbohydrate in ad libitum fat reduced diet for the treatment of obesity. Int J Obes Relat Metab Disord 1999;23:528-536

63. Lejeune MP, Kovacs EM, Westerterp-Plantenga MS: Additional protein intake limits weight regain after weight loss in humans. The British journal of nutrition 2005;93:281289

64. Raben A, Agerholm-Larsen L, Flint A, Holst JJ, Astrup A: Meals with similar energy densities but rich in protein, fat, carbohydrate, or alcohol have different effects on energy expenditure and substrate metabolism but not on appetite and energy intake. Am J Clin Nutr 2003;77:91-100

65. Lejeune MP, Westerterp KR, Adam TC, Luscombe-Marsh ND, Westerterp-Plantenga MS: Ghrelin and glucagon-like peptide 1 concentrations, 24-h satiety, and energy and substrate metabolism during a high-protein diet and measured in a respiration chamber. Am J Clin Nutr 2006;83:89-94

66. Westerterp-Plantenga MS, Lejeune MP: Protein intake and body-weight regulation. Appetite 2005;45:187-190

67. Paddon-Jones D, Westman E, Mattes RD, Wolfe RR, Astrup A, WesterterpPlantenga M: Protein, weight management, and satiety. Am J Clin Nutr 2008;87:1558S$1561 S$

68. van Loon LJ, Saris WH, Verhagen $\mathrm{H}$, Wagenmakers AJ: Plasma insulin responses after ingestion of different amino acid or protein mixtures with carbohydrate. Am J Clin Nutr 2000;72:96-105

69. Manders RJ, Wagenmakers AJ, Koopman R, Zorenc AH, Menheere PP, Schaper NC, Saris $\mathrm{WH}$, van Loon $\mathrm{L}$ : Co-ingestion of a protein hydrolysate and amino acid mixture with carbohydrate improves plasma glucose disposal in patients with type 2 diabetes. Am J Clin Nutr 2005;82:76-83

70. Layman DK, Baum JI: Dietary protein impact on glycemic control during weight loss. J Nutr 2004;134:968S-973S

71. Holt SH, Miller JC, Petocz P: An insulin index of foods: the insulin demand generated by 1000-kJ portions of common foods. Am J Clin Nutr 1997;66:1264-1276

72. Zemel MB: The role of dairy foods in weight management. J Am Coll Nutr 2005;24:537S-546S

73. Zemel MB: Mechanisms of dairy modulation of adiposity. J Nutr 2003;133:252S$256 \mathrm{~S}$ 
74. Trapp CB, Barnard ND: Usefulness of vegetarian and vegan diets for treating type 2 diabetes. Curr Diab Rep 2010;10:152-158

75. Cope MB, Erdman JW, Jr., Allison DB: The potential role of soyfoods in weight and adiposity reduction: an evidence-based review. Obes Rev 2008;9:219-235

76. Halkjaer J, Olsen A, Overvad K, Jakobsen MU, Boeing H, Buijsse B, Palli D, Tognon G, Du $\mathrm{H}$, van der AD, Forouhi NG, Wareham NJ, Feskens EJ, Sorensen TI, Tjonneland A: Intake of total, animal and plant protein and subsequent changes in weight or waist circumference in European men and women: the Diogenes project. Int J Obes (Lond) 2011;35:1104-1113

77. Golder S, Loke YK, Bland M: Meta-analyses of adverse effects data derived from randomised controlled trials as compared to observational studies: methodological overview. PLoS Med 2011;8:e1001026

78. Benson K, Hartz AJ: A comparison of observational studies and randomized, controlled trials. N Engl J Med 2000;342:1878-1886

79. Concato J, Shah N, Horwitz RI: Randomized, controlled trials, observational studies, and the hierarchy of research designs. N Engl J Med 2000;342:1887-1892

80. Hernan MA, Alonso A, Logan R, Grodstein F, Michels KB, Willett WC, Manson JE, Robins JM: Observational studies analyzed like randomized experiments: an application to postmenopausal hormone therapy and coronary heart disease. Epidemiology 2008;19:766-779

81. Tannen RL, Weiner MG, Xie D: Use of primary care electronic medical record database in drug efficacy research on cardiovascular outcomes: comparison of database and randomised controlled trial findings. BMJ 2009;338:b81

82. Samuelson G: Dietary habits and nutritional status in adolescents over Europe. An overview of current studies in the Nordic countries. European journal of clinical nutrition 2000;54 Suppl 1:S21-28

83. Berteus Forslund H, Torgerson JS, Sjostrom L, Lindroos AK: Snacking frequency in relation to energy intake and food choices in obese men and women compared to a reference population. Int J Obes (Lond) 2005;29:711-719

84. Verboeket-van de Venne WP, Westerterp KR: Influence of the feeding frequency on nutrient utilization in man: consequences for energy metabolism. European journal of clinical nutrition 1991;45:161-169

85. Bertelsen J, Christiansen C, Thomsen C, Poulsen PL, Vestergaard S, Steinov A, Rasmussen LH, Rasmussen O, Hermansen K: Effect of meal frequency on blood glucose, insulin, and free fatty acids in NIDDM subjects. Diabetes Care 1993;16:4-7

86. Farshchi HR, Taylor MA, Macdonald IA: Regular meal frequency creates more appropriate insulin sensitivity and lipid profiles compared with irregular meal frequency in healthy lean women. European journal of clinical nutrition 2004;58:10711077

87. Solomon TP, Chambers ES, Jeukendrup AE, Toogood AA, Blannin AK: The effect of feeding frequency on insulin and ghrelin responses in human subjects. The British journal of nutrition 2008;100:810-819

88. Chapelot D: The role of snacking in energy balance: a biobehavioral approach. J Nutr 2011;141:158-162

89. McCrory MA, Howarth NC, Roberts SB, Huang TT: Eating frequency and energy regulation in free-living adults consuming self-selected diets. J Nutr 2011;141:148-153 


\section{Chapter 2}

90. Palmer MA, Capra S, Baines SK: Association between eating frequency, weight, and health. Nutrition reviews 2009;67:379-390

91. Munsters MJ, Saris WH: Effects of meal frequency on metabolic profiles and substrate partitioning in lean healthy males. PLoS One 2012;7:e38632

92. Saris WH, Schrauwen P: Substrate oxidation differences between high- and lowintensity exercise are compensated over 24 hours in obese men. Int J Obes Relat Metab Disord 2004;28:759-765 


\section{CHAPTER 3}

The effect of sugar-sweetened beverages intake on energy intake in an ad libitum 6 months low-fat high carbohydrate diet

MJM Munsters and WHM Saris Annals of Nutrition \&Metabolism 2010;57(2):116-23 


\section{ABSTRACT}

Background/Aims: The increased incidence of obesity coincides with an increased consumption of sugar-sweetened beverages (SSBs). This study investigated the effect of SSB intake on energy intake in an ad libitum 6-month low-fat high-carbohydrate diet in a reanalysis of the CARMEN data.

Methods: Forty-seven overweight-to-obese men and women participated in the Maastricht centre of the randomized controlled CARMEN study. They were allocated to a control (habitual) diet group (CD), a low-fat (-10 energy percent, En\%) high simple carbohydrate (SCHO) or low-fat high complex carbohydrate group (CCHO) (SCHO vs. CCHO: 1.5 vs. 0.5 ) using a controlled laboratory shop system. Reanalyses were made for the energy, amount and density of all drinks and in particular of sweetened beverages (SBs). The $\mathrm{SCHO}$ and $\mathrm{CD}$ group could select nondiet $\mathrm{SBs}$, including soft drinks and fruit juices, while the $\mathrm{CCHO}$ group received $\mathrm{SB}$ alternatives.

Results: Energy intake decreased in the $\mathrm{CCHO}$ and $\mathrm{SCHO}$ groups versus the $\mathrm{CD}$ group ($2.7 \pm 0.4 \mathrm{MJ} /$ day $\mathrm{CCHO}$ group vs. $-0.2 \pm 0.5 \mathrm{MJ} /$ day $\mathrm{CD}$ group, $\mathrm{p}<0.01 ;-1.4 \pm 0.4$ $\mathrm{MJ} /$ day $\mathrm{SCHO}$ group, not significant). Simple carbohydrate intake increased significantly in the $\mathrm{SCHO}$ group versus the $\mathrm{CCHO}$ and $\mathrm{CD}$ groups $(+10.8 \pm 1.6$ vs. $-2.0 \pm$ 0.9 and $-0.5 \pm 1.1 \mathrm{En} \% ; \mathrm{p}<0.001)$. In the SCHO and CD groups, energy intake from SBs increased significantly $(+187 \pm 114$ and $+101 \pm 83 \mathrm{~kJ} /$ day, respectively; $-432 \pm 72$ $\mathrm{kJ} /$ day in the $\mathrm{CCHO}$ group; $\mathrm{p}<0.001)$.

Conclusion: Simple carbohydrate intake increased through enhanced intake of nondiet $\mathrm{SBs}$ in the SCHO group. Fat reduction combined with only diet SBs in an ad libitum situation has a greater impact on energy intake than fat reduction combined with nondiet SBs. 


\section{INTRODUCTION}

Worldwide, the incidence of overweight and obesity has continued to rise relentlessly since the early 1980s. In particular, the increasing incidence of childhood obesity has been recognized as a growing threat in both developed and developing countries (1). Overweight and obesity are associated with an increased risk of developing dietrelated diseases such as diabetes type 2 , cancer and cardiovascular diseases. It is generally accepted that energy-dense diets, that is high-fat diets, are a major factor in excess energy intake leading to weight gain (2). Besides fat intake, sugar-sweetened beverages (SSBs) and products of high glycemic index (GI) have been suggested as important dietary factors causing overfeeding leading to excess weight (3-6).

A high Gl, mostly based on refined carbohydrates, indicates rapid digestion and absorption of carbohydrate-containing meals resulting in high postprandial blood glucose and insulin concentrations. This is in contrast with low Gl products, mostly based on unrefined carbohydrates, which result in low postprandial (maximal) blood glucose and insulin responses (7). Moreover, the increased incidence of obesity has coincided with increased SSB consumption in the United States (8). Thus, more attention has been paid to the role of SSBs, such as soft drinks and fruit drinks, in the development of obesity (9). A proposed mechanism through which consumption of sugar-sweetened drinks could lead to obesity is imprecise and incomplete compensation for energy consumed in liquid form (6). Energy in a liquid food matrix is absorbed and metabolized more efficiently than energy in a solid food matrix (10). The development of sports drinks was based on this principle of a fast gastric emptying and absorption in the gut. In addition, studies have shown that higher liquid carbohydrate consumption did not result in a reduction of solid food consumption $(11 ; 12)$. It has also been suggested that fluids are less efficient in inducing satiety and suppressing food intake compared with solid foods $(13 ; 14)$. Based on these studies, it has been suggested that liquid carbohydrates may promote excess energy intake and, consequently, result in weight gain and obesity. However, critical reviews of the literature on the association between SSB consumption and weight gain have come to different conclusions. Several investigators found that a greater SSB intake resulted in an increased energy intake and body weight $(15 ; 16)$. However, other meta-analyses and review articles concluded that this association was weak or equivocal $(9 ; 17-20)$. All review articles indicated a lack of randomized controlled long-term studies. Therefore, the aim of the present study was to investigate the effect of a 6-month ad libitum intake of SSBs on energy intake in overweight-obese individuals in a reanalysis of the data obtained from one of the centers in the Carbohydrate Ratio Management in European National diets (CARMEN) study (21). In the randomized controlled CARMEN trial, subjects followed a 6-month strictly controlled diet using the laboratory shop system with either a low-fat high simple carbohydrate diet, a low-fat high 
complex carbohydrate diet or a control diet including SSBs or diet sweetened beverage (SB) alternatives.

\section{MATERIALS AND METHODS}

\section{Study population}

Subjects were 47 overweight to obese men and women participating in the Maastricht centre of the CARMEN study (21), because the food-specific dietary record data of the whole cohort was not available anymore. Their mean age was $39 \pm 1.3$ years (range 20 - 55 years), with a mean BMI of $29.0 \pm 0.3$ (range $25.4-35.0$ ) and a mean body fat of $34.6 \pm 1.2 \%$ (range $17.6-48.7 \%$ ). The subjects were all healthy as assessed by medical history, blood and urine chemistry. Exclusion criteria were: weight loss of more than 5 $\mathrm{kg}$ in the preceding 6 months; use of prescribed or slimming diets; high-intensity exercise for more than $7 \mathrm{~h}$ weekly; excess alcohol intake ( $>28$ drinks weekly for men, > 21 for women); pregnancy; lactation. This study was conducted according to the guidelines laid down in the Declaration of Helsinki and the Medical Ethical Committee of the University Hospital Maastricht approved all procedures involving human subjects. Written informed consent was obtained from all subjects.

\section{Study design}

The aim, design and results of the complete CARMEN study were described in detail previously (21). The CARMEN study was a multicentre randomized ad libitum feeding trial in 5 EU countries, Denmark, UK, Germany, Spain and the Netherlands, that tested the effects of altering the ratio of fat to carbohydrate as well as simple to complex carbohydrate per se, on body weight and blood lipids in overweight individuals. A laboratory shop system with the provision of foods was used to maximize dietary compliance in an otherwise community-based population. During a 5-week run-in period, subjects were provided with a selection of about 150 commercially available food products, of typical macronutrient composition, using a validated laboratory shop system (22). The selection of the food products was intended to achieve $70 \%$ coverage of total fat intake and $50 \%$ of total carbohydrate intake from the shop. A computer program was developed which ensured selection of the appropriate food items by means of a barcode scanner system. After the run-in period, subjects were randomly assigned to 1 of 3 experimental groups, stratified by age, sex, tertile of simple to complex carbohydrate intake and fat intake, as measured during the last week of the run-in period. Throughout an intervention period of 6 months, subjects in the control group (CD) were provided with a variety of products of typical macronutrient composition leading to a macronutrient intake, which was representative for the Netherlands. Subjects in the low-fat high simple carbohydrate ( $\mathrm{SCHO}$ ) group and the 
low-fat high complex carbohydrate $(\mathrm{CCHO})$ group were provided with a variety of fatreduced alternatives and products with a high respectively low ratio of simple to complex carbohydrates, in order to reduce fat intake by 10 energy percent (En\%) and, at the same time, to increase either simple or complex carbohydrate intake resulting in a simple to complex $\mathrm{CHO}$ ratio of the habitual intake of about $1.0-1.5$ and 0.5 , respectively.

\section{Measurements}

Total food intake, that is consumption of food items provided via the laboratory shop and consumption of food items bought in conventional supermarkets, was recorded at baseline, at the end of the run-in period and after 1, 2, 4 and 6 month(s) of intervention, using 3- or 7-day weighed dietary records and checked with the individually laboratory shop record inclusive return of not used products. Energy and macronutrient intakes were calculated using a computerized Dutch food composition table (23). Simple carbohydrates are based on mono- and disaccharides such as sucrose while complex carbohydrates are calculated from the polysaccharides levels as tabulated in the national food table. Additionally, subanalyses were made in this study for the energy, amount and energy density of all drinks and in particular of SBs. Energy intake of all drinks included SBs (non-diet and diet) and alcoholic drinks, and excluded dairy liquid products. The SCHO and CD groups were able to select nondiet (sugar) SBs, including soft drinks and fruit juices from the shop, while the $\mathrm{CCHO}$ group received diet (artificially) SB alternatives. Body weight, fat mass and percentage of body fat were also measured before and at the end of the 6-month intervention. Furthermore, Creactive protein (CRP) levels were measured before and at the end of the 6 month intervention to investigate the effect of the three diets on chronic low-grade inflammation, because the cross-sectional study of Liu et al. (24) showed in healthy overweight women that dietary GI and glycemic load were positively associated with plasma CRP concentration, which is a sensitive marker for systemic inflammation.

\section{Statistical analysis}

Results are presented as mean \pm standard error of the mean. Homogeneity was checked with the Kolmogorov-Smirnov test. Regarding the 6-month dietary intervention, analysis of variance was used as a global test for differences in the degree of change from values at the start of the intervention among groups. Additionally, post hoc comparisons were made with Bonferroni adjustment of significance levels, when analysis of variance indicated a significant difference between the groups $(p<0.05)$. Simple regression analysis was used to compare the changes in macronutrients and energy derived from all drinks and SBs with the changes in weight 
(kg) and the changes in body fat percentage during the 6-month intervention for all subjects.

\section{RESULTS}

Subject characteristics of each group at the start of the dietary intervention period are shown in Table 1. Subject characteristics were not significantly different between the three intervention groups.

Table 1. Baseline characteristics of subjects completing the 6 month intervention, according to study group.

\begin{tabular}{lllll}
\hline $\begin{array}{l}\text { Baseline } \\
\text { characteristics }\end{array}$ & $\begin{array}{l}\text { SCHO group } \\
(\mathrm{n}=14)\end{array}$ & $\begin{array}{l}\text { CCHO group } \\
(\mathrm{n}=15)\end{array}$ & $\begin{array}{l}\text { CD Group } \\
(\mathrm{n}=18)\end{array}$ & p-value \\
\hline Male, \% & 50.0 & 46.7 & 55.6 & 0.702 \\
Age, years & $39.8 \pm 0.6$ & $38.9 \pm 0.6$ & $37.2 \pm 0.5$ & 0.882 \\
Body weight, $\mathrm{kg}$ & $85.3 \pm 2.5$ & $83.2 \pm 2.4$ & $88.5 \pm 2.7$ & 0.328 \\
BMI, kg/m ${ }^{2}$ & $28.6 \pm 0.4$ & $28.3 \pm 0.4$ & $29.9 \pm 0.7$ & 0.076 \\
Body fat, \% & $35.2 \pm 2.2$ & $33.3 \pm 2.0$ & $35.2 \pm 1.9$ & 0.760 \\
\hline
\end{tabular}

Values are expressed as mean \pm SEM. P-values were derived by analysis of variance and denote the overall significance of differences among the 3 groups. P-values for comparisons between groups have been adjusted for three pair-wise comparisons (Bonferroni's adjustment).

\section{Diets}

Analysis of variance revealed no significant differences in start intervention values between the three groups (Table 2). Over the 6-month intervention period, total energy intake was significantly reduced only in the $\mathrm{CCHO}$ group compared with the $\mathrm{CD}$ group (Table 3 ). The energy intake decrease was nearly twice as high in the CCHO group in comparison with the $\mathrm{SCHO}$ group (not significant). Protein intake significantly increased in the $\mathrm{CCHO}$ group compared with the $\mathrm{SCHO}$ and $\mathrm{CD}$ groups. As designed, both low-fat groups decreased En\% from fat significantly compared with the CD group. In the SCHO group, total and simple carbohydrate En\% increased significantly compared with the $\mathrm{CCHO}$ and $\mathrm{CD}$ groups. In the $\mathrm{CCHO}$ group En\% from total carbohydrates was significantly higher compared with the $C D$ group. Both low-fat groups increased En\% from complex carbohydrates compared with the CD group. Fiber and alcohol intake showed no significant differences among the three groups. Total energy density decreased in the $\mathrm{SCHO}$ and $\mathrm{CCHO}$ groups compared with the $\mathrm{CD}$ group by $-0.9 \pm 0.1$ and $-1.1 \pm 0.1 \mathrm{~kJ} / \mathrm{g}$, respectively, versus $-0.2 \pm 0.2 \mathrm{~kJ} / \mathrm{g}$ in the $\mathrm{CD}$ group $(\mathrm{p}<$ 0.001 ). The CD group showed a similar food intake at the end of the intervention than at the start, as was planned. 
Table 2. Start intervention values for variables related to the diet, according to study group.

\begin{tabular}{lccc}
\hline Variable & $\begin{array}{c}\text { SCHO group } \\
(\mathrm{n}=14)\end{array}$ & $\begin{array}{c}\text { CCHO group } \\
(\mathrm{n}=15)\end{array}$ & $\begin{array}{c}\text { CD group } \\
(\mathrm{n}=18)\end{array}$ \\
\hline Energy intake, MJ/day & $11.1 \pm 0.7$ & $11.7 \pm 0.7$ & $11.9 \pm 0.7$ \\
Protein intake, En\% & $15.0 \pm 0.6$ & $13.4 \pm 0.4$ & $13.5 \pm 0.4$ \\
Fat intake, En\% & $40.1 \pm 1.4$ & $39.0 \pm 1.4$ & $38.9 \pm 1.3$ \\
Total carbohydrate intake, En\% & $42.4 \pm 1.5$ & $44.9 \pm 1.5$ & $45.2 \pm 1.6$ \\
Simple carbohydrate intake, En\% & $19.0 \pm 1.7$ & $21.2 \pm 1.2$ & $21.7 \pm 1.6$ \\
Complex carbohydrate intake, En\% & $23.0 \pm 0.9$ & $23.5 \pm 1.2$ & $23.4 \pm 0.9$ \\
Alcohol intake, En\% & $2.5 \pm 1.1$ & $2.7 \pm 0.9$ & $2.4 \pm 0.7$ \\
Fibre intake, g/d & $19.0 \pm 1.5$ & $17.7 \pm 1.7$ & $18.1 \pm 1.2$ \\
Total energy density, kJ/g & $4.2 \pm 0.2$ & $4.4 \pm 0.8$ & $4.2 \pm 0.8$ \\
Energy intake all drinks, kJ/day & $914 \pm 164$ & $1136 \pm 243$ & $1213 \pm 159$ \\
Amount all drinks, g/day & $1263.0 \pm 129.5$ & $1334.9 \pm 149.2$ & $1508.5 \pm 119.5$ \\
Density all drinks, kJ/g & $0.75 \pm 0.11$ & $0.82 \pm 0.08$ & $0.83 \pm 0.09$ \\
Energy intake SBs, kJ/day & $461 \pm 97$ & $633 \pm 77$ & $744 \pm 100$ \\
Amount SBs, g/day & $295.0 \pm 65.6$ & $391.1 \pm 47.3$ & $464.8 \pm 64.2$ \\
Density SBs, kJ/g & $1.36 \pm 0.16$ & $1.61 \pm 0.12$ & $1.54 \pm 0.11$ \\
Simple CHO intake SBs, g/day & $27.0 \pm 5.7$ & $37.0 \pm 4.5$ & $43.7 \pm 5.9$ \\
\hline
\end{tabular}

Values are expressed as mean \pm SEM.

\section{Sweetened beverages}

The intake of SBs in all groups was around 5.3 En\% at the start of the intervention and reflects average SB intake in the Netherlands. Energy intake of all drinks increased significantly in the $\mathrm{SCHO}$ and $\mathrm{CD}$ groups compared with the $\mathrm{CCHO}$ group during the intervention (Table 3). The increase in SB (soft drinks and fruit juices) intake in the $\mathrm{SCHO}$ group during the study resulted in a total energy intake from SB of $648 \mathrm{~kJ} / \mathrm{day}$ (6.7 En\%), an increase of $187 \mathrm{~kJ} /$ day compared with the start of the intervention (Table 3). The CD group increased SB intake by $101 \mathrm{~kJ} /$ day during the intervention period, which resulted in a total SB energy intake of $844 \mathrm{~kJ} /$ day (7.2 En\%). When only diet SBS were provided to the $\mathrm{CCHO}$ group, SB intake decreased by $432 \mathrm{~kJ} /$ day to a total energy intake from SB of $201 \mathrm{~kJ} /$ day (2.2 En\%). Energy density of all drinks increased significantly in the $\mathrm{SCHO}$ and $\mathrm{CD}$ groups compared with the $\mathrm{CCHO}$ group. In the $\mathrm{SCHO}$ and $C D$ groups, energy intake and total simple carbohydrate intake from SBs increased significantly compared with the $\mathrm{CCHO}$ group (Fig. 1). Although the $\mathrm{SCHO}$ group showed the highest and the $\mathrm{CCHO}$ group the lowest SB consumption, no significant difference was found between the three groups in the amount of SBs consumed. Additionally, energy density of SBs increased significantly in the SCHO group compared with the CCHO group (+0.64 vs. $-0.98 \mathrm{~kJ} / \mathrm{g}$, respectively; $\mathrm{p}<0.01$ ) (Table 3 ). 
Table 3. Changes for variables related to the diet after the 6 months intervention period, according to study group.

\begin{tabular}{|c|c|c|c|c|}
\hline \multirow[t]{3}{*}{ Variable } & \multicolumn{3}{|c|}{$\begin{array}{l}\text { Change after } 6 \text { months of intervention compared with } \\
\text { start }\end{array}$} & \multirow[t]{3}{*}{ p-value } \\
\hline & $\mathrm{SCHO}$ group & $\mathrm{CCHO}$ group & CD group & \\
\hline & $(n=14)$ & $(n=15)$ & $(n=18)$ & \\
\hline Energy intake, MJ/day & $-1.4 \pm 0.4$ & $-2.7 \pm 0.4$ & $-0.2 \pm 0.5^{++}$ & 0.0024 \\
\hline Protein intake, En\% & $+0.8 \pm 0.5$ & $+3.6 \pm 0.7^{* *}$ & $-0.5 \pm 0.5^{++}$ & 0.0001 \\
\hline Fat intake, En\% & $-15.1 \pm 1.7$ & $-6.9 \pm 2.1 * *$ & $+1.6 \pm 1.2^{* * *,++}$ & 0.0001 \\
\hline Total carbohydrate intake, En\% & $+13.8 \pm 1.7$ & $+2.9 \pm 1.4^{* * *}$ & $-2.0 \pm 1.1^{* * *,+}$ & 0.0001 \\
\hline Simple carbohydrate intake, En\% & $+10.8 \pm 1.6$ & $-2.0 \pm 0.9 * * *$ & $-0.5 \pm 1.1 * * *$ & 0.0001 \\
\hline Complex carbohydrate intake, En\% & $+2.7 \pm 0.6$ & $+4.7 \pm 1.6$ & $-1.5 \pm 1.1^{*^{,++}}$ & 0.0013 \\
\hline Alcohol intake, En\% & $+0.5 \pm 0.5$ & $+0.5 \pm 0.4$ & $+1.0 \pm 0.5$ & 0.6412 \\
\hline Fibre intake, $\mathrm{g} / \mathrm{d}$ & $-5.0 \pm 1.1$ & $-3.9 \pm 1.5$ & $0.8 \pm 1.2$ & 0.0606 \\
\hline Total energy density, kJ/g & $-0.9 \pm 0.1$ & $-1.1 \pm 0.1$ & $-0.2 \pm 0.2^{* * *,+++}$ & 0.0001 \\
\hline Energy intake all drinks, kJ/day & $+193 \pm 123$ & $-463 \pm 111^{* *}$ & $+292 \pm 136^{+++}$ & 0.0002 \\
\hline Amount all drinks, g/day & $+296.5 \pm 114.5$ & $+142.0 \pm 93.2$ & $+184.5 \pm 103.4$ & 0.5856 \\
\hline Density all drinks, kJ/g & $-0.01 \pm 0.09$ & $-0.41 \pm 0.06$ & $+0.02 \pm 0.07^{+++}$ & 0.0001 \\
\hline Energy intake SBs, kJ/day & $+187 \pm 114$ & $-432 \pm 72 * * *$ & $+101 \pm 83^{+++}$ & 0.0001 \\
\hline Amount SBs, g/day & $+133.4 \pm 72.2$ & $-0.7 \pm 64.8$ & $+79.2 \pm 47.4$ & 0.3225 \\
\hline Density SBs, kJ/g & $+0.64 \pm 0.53$ & $-0.98 \pm 0.12^{* *}$ & $+0.01 \pm 0.11$ & 0.0016 \\
\hline Simple $\mathrm{CHO}$ intake SBs, g/day & $+11.3 \pm 6.8$ & $-26.6 \pm 4.1^{* * *}$ & $+5.7 \pm 5.0^{+++}$ & 0.0001 \\
\hline
\end{tabular}

Values are expressed as mean \pm SEM. $* \mathrm{P}<0.05, * * \mathrm{P}<0.01, * * * \mathrm{P}<0.001$ compared with the SCHO group; ${ }^{+} \mathrm{P}<0.05,{ }^{++} \mathrm{P}<0.01,{ }^{+++} \mathrm{P}<0.001$ compared with the $\mathrm{CCHO}$ group. $\mathrm{P}$-values were derived by analysis of variance and denote the overall significance of differences among the 3groups. P-values for comparisons between groups have been adjusted for three pair-wise comparisons (Bonferroni's adjustment).

Table 4. Start intervention values and changes after 6 months dietary intervention for body weight and body composition, according to study group.

\begin{tabular}{llllll}
\hline Characteristics & \multicolumn{2}{l}{ Change after 6 months compared with start } & & $p$-value \\
& $\begin{array}{l}\text { Start } \\
\text { intervention }\end{array}$ & $\begin{array}{l}\text { SCHO } \\
\text { Group }\end{array}$ & $\begin{array}{l}\text { CCHO } \\
\text { Group }\end{array}$ & $\begin{array}{l}\text { CD } \\
\text { Group }\end{array}$ & \\
& value $(\mathrm{n}=47)$ & $(\mathrm{n}=14)$ & $(\mathrm{n}=15)$ & $(\mathrm{n}=18)$ & \\
\hline Body weight, kg & $85.85 \pm 1.5$ & $+0.67 \pm 0.8$ & $-0.87 \pm 0.7$ & $+1.12 \pm 0.5$ & 0.086 \\
BMI, kg/m & $29.00 \pm 0.3$ & $+0.23 \pm 0.3$ & $-0.28 \pm 0.2$ & $+0.39 \pm 0.2$ & 0.097 \\
Fat mass, kg & $29.51 \pm 1.0$ & $+0.01 \pm 0.6$ & $-0.87 \pm 0.5$ & $+0.14 \pm 0.9$ & 0.592 \\
Body fat, \% & $34.61 \pm 1.2$ & $-0.40 \pm 0.6$ & $-0.74 \pm 0.6$ & $-0.32 \pm 0.9$ & 0.909 \\
\hline
\end{tabular}

Values are expressed as mean \pm SEM. P-values were derived by analysis of variance and denote the overall significance of differences among the three groups. P-values for comparisons between groups have been adjusted for three pair-wise comparisons (Bonferroni's adjustment). 


\section{Liquid and total simple carbohydrate intake}

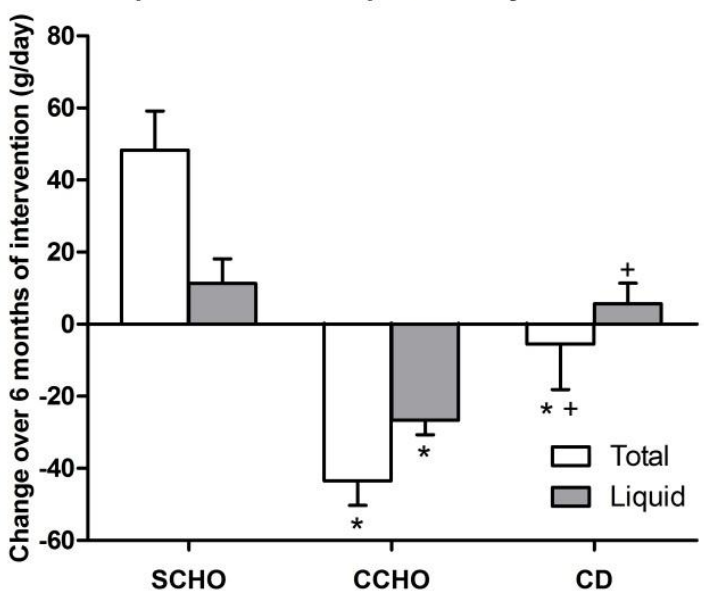

Figure. 1: The change in liquid and solid simple carbohydrate intake during 6-month intervention period in the $\mathrm{SCHO}, \mathrm{CCHO}$ and $\mathrm{CD}$ groups. ${ }^{*} \mathrm{P}<0.05$ compared with the $\mathrm{SCHO}$ group. ${ }^{+} \mathrm{P}<0.05$ compared with the $\mathrm{CCHO}$ group.

\section{Body weight and body composition}

Analysis of variance showed no significant differences for body weight and composition at the start of the intervention period among the three groups (Table 4). After 6 months of intervention, body weight $(p=0.086)$ and BMI $(p=0.097)$ tended to be lower in the $\mathrm{CCHO}$ group when compared with the $\mathrm{CD}$ group, although differences did not reach statistical significance (Table 4). During the intervention period no significant relation was observed between changes in macronutrient intake, energy derived from all drinks and SBs as well as changes in body weight and body fat (data not shown). Results showed no significant differences in CRP levels between the three groups at the start of the intervention ( $\mathrm{SCHO}, 3.2 \pm 0.8 ; \mathrm{CCHO}, 2.9 \pm 0.7 ; \mathrm{CD}, 2.8 \pm 0.8$ $\mathrm{mg} / \mathrm{L}$ ) and no significant differences in changes of CRP levels were observed during the intervention period (SCHO: $-0.1 \pm 0.9$; CCHO: $-0.4 \pm 0.3$; $\mathrm{CD}:+0.2 \pm 0.7 \mathrm{mg} / \mathrm{L}$ ).

\section{DISCUSSION}

The present study was executed in a subsample of the multi-randomized 6-month ad libitum low-fat high carbohydrate diet trial CARMEN (21) to gain a better insight into the role of energy derived from SSBs in a situation where specific SB diet alternatives were used to create a difference in simple carbohydrate intake over a relatively long period ( 6 months). As in the overall trial, in this subsample the rise of SB intake also created a significant difference in simple carbohydrate intake between the $\mathrm{SCHO}$ and $\mathrm{CCHO}$ groups. Analyses of the data from the National Health and Nutrition Examination Survey (from 1999-2001) in the US showed that SSB intake accounted for $12.3 \%$ of 
daily energy in the 19- to 39-year-olds age group and accounted for $6.2 \%$ of daily energy in the 40- to 59-year-olds age group (25). The approximate mean of both age groups, 9.3 En\%, was used as reference because subjects' age ranged from 20 to 55 years in this study. It can be concluded that the results of this study where nondiet SBS were used to create a difference in simple carbohydrate intake over a relatively long period are higher compared with the average SB intake in the Netherlands (6.7 vs. 5.3 En\%), respectively and somewhat lower compared with the US (9.3 En\%). Thus, results from this well-controlled study give a good indication about effects of changes in the diet and, in particular, SBs in relation to the normal consumption of SBs in the Dutch population.

It is expected that with a higher En\% intake from SBs in the population, an even better reduction in energy coming from SBs could be achieved using diet alternatives. Although we observed a significant positive effect of consuming only diet SB on energy intake and a trend in body weight change in this study, it has to be taken into consideration that this effect was observed under a relatively controlled setting despite the ad libitum study design. The Dutch National Institute of Health (DNIH) has studied the possible relationship between the consumption of several common diet products and overweight in a normal setting (26). Young adults and households who are overweight more often use diet products than people with a normal weight, such as artificially sweetened beverages (41 vs. $26 \%, p<0.001$, for young adults and 76 vs. $64 \%, p<0.001$, for households), artificial sweeteners (21 vs. $9 \%, p<0.001$, for young adults) and low-fat crisps (16 vs. $12 \%, p<0.05$, for households). At the same time, the overweight group uses the same or even more nondiet products than people with a healthy weight. Replacing all nondiet SBs with diet alternatives appears a good strategy to reduce energy intake through drinks and prevent overweight. However, in the study by the DNIH, it was observed that users of artificially sweetened beverages and low-fat crisps consume or buy more beverages and crisps in total (that is diet and nondiet collectively). Such eating behavior could result in a daily lifestyle with a similar or even higher energy intake. These findings suggest that artificially sweetened beverages and low-fat crisps are used partly or completely in addition to the nondiet products. Therefore, the consumption of diet products can only be effective when accompanied with a drastic reduction in the consumption of nondiet products.

The aim of the complete CARMEN study was to investigate the effects on carbohydrates as well as the type of carbohydrate intake under ad libitum condition when fat content of the diet was reduced with low fat alternatives. Under the condition of a lower fat intake, carbohydrate intake increases both in relative terms as well as in absolute terms. Therefore, the comparable decrease in total energy density in both the $\mathrm{SCHO}$ and $\mathrm{CCHO}$ groups is significant because it is claimed that the replacement of fat by sugar or refined carbohydrates in low-fat foods leads to highenergy dense foods (27). However, the outcome of the complete CARMEN study as 
well as this subanalysis of the CARMEN data, with considerable use of low-fat, high simple carbohydrate foods, does not confirm this statement (21). The relationship between low-fat and high simple carbohydrate intake may be less of a concern than previously suggested because of the trend in lower energy intake and significantly lower energy density of the low-fat high simple carbohydrate diet. This study has demonstrated that the type of carbohydrates (simple or complex carbohydrates) does not seem to have much impact on body weight regulation due to the lower energy density of both low-fat groups.

Several observational studies found an inverse relationship between energy intake from fat and from sugar, but not between fat and starch intake (28). In our study, the $\mathrm{SCHO}$ group increased the intake of nondiet SBs and, therefore, simple carbohydrate intake (En\%) and total carbohydrate intake (En\%) although overall energy intake tended to decrease because of fat intake reduction (-15.1 En\% fat). The study by Raben et al. (29) also found no difference in an ad libitum energy intake between the high-fat diet and the high-sugar low-fat diet after 14 days (10.2 and 10.3 MJ/day, respectively). Sugar intake reduces intake of fat simultaneously and subsequently reduces energy intake, because of the lower energy density. In contrast, a reduction in sugar intake could result in an increased fat intake. Furthermore, dietary sugar may increase acceptance of a low-fat diet, which could lead to increased long-term compliance as shown in a study by Drummond and Kirk (30).

Additionally, after the 6-month dietary intervention period, no significant relation was observed between changes in the diet and change in body weight, BMI and body fat in the overweight subjects. These results are in line with a meta-analysis by Forshee et al. (9) and reviews (17-20), which all concluded that the association was equivocal between intake of SSBs and BMI in children and adolescents. Evidence linking beverage consumption to the global obesity epidemic is still weak (31). Furthermore, Liu and colleagues found a positive association between dietary GI, glycemic load and CRP levels, although our results cannot confirm this observation.

While this study showed interesting results about the effects of SBs consumption, it has certain limitations. No difference was found in complex carbohydrate intake (En\%) between the low-fat groups. The low-fat, high complex carbohydrate diet tended to result in a reduced body weight and $\mathrm{BMI}$, although none of these effects were significant (table 4). Although the body weight and complex carbohydrate intake changes were not significant, the trends are the same compared with the results of the complete CARMEN trial since the dietary characteristics from this subgroup of the CARMEN trial are highly comparable to the diet characteristics in the main study. The lack of significance in body weight changes is related to the underpowered analyses (table 1). The Carmen study was powered about 5 times greater to detect body weight changes. Therefore the results should be interpreted with some caution. 


\section{Chapter 3}

In summary, a significantly lower energy intake was achieved when diet SBs were consumed instead of nondiet SBs. However, in daily life, diet SBs are used partly or completely in addition to nondiet products. Consequently, the consumption of diet products can only be effective when accompanied by a drastic reduction in the consumption of nondiet products. Replacement of fat by low-fat, simple/complex carbohydrates in foods did not lead to higher energy-dense foods as suggested before. The relationship between low-fat and high simple carbohydrate intake may be less of a concern than previously suggested because of the lower energy density of the low-fat high simple carbohydrate diet.

\section{Disclosure Statement}

Supported by a grant from the EU-FAIR program PL95-0809 and by a grant from the Dutch Sugar Bureau. 


\section{REFERENCES}

1. WHO: Obesity: preventing and managing the global epidemic. Report of a WHO consultation. World Health Organ Tech Rep Ser 2000;894:i-xii, 1-253

2. Rolls BJ: The relationship between dietary energy density and energy intake. Physiol Behav 2009;97:609-615

3. Willett WC: Is dietary fat a major determinant of body fat? Am J Clin Nutr 1998;67:556S-562S

4. Ludwig DS, Majzoub JA, Al-Zahrani A, Dallal GE, Blanco I, Roberts SB: High glycemic index foods, overeating, and obesity. Pediatrics 1999;103:E26

5. Ludwig DS: Dietary glycemic index and obesity. J Nutr 2000;130:280S-283S

6. Ludwig DS, Peterson KE, Gortmaker SL: Relation between consumption of sugarsweetened drinks and childhood obesity: a prospective, observational analysis. Lancet 2001;357:505-508

7. Brand-Miller JC, Holt SH, Pawlak DB, McMillan J: Glycemic index and obesity. Am J Clin Nutr 2002;76:281S-285S

8. Bray GA, Nielsen SJ, Popkin BM: Consumption of high-fructose corn syrup in beverages may play a role in the epidemic of obesity. Am J Clin Nutr 2004;79:537-543

9. Forshee RA, Anderson PA, Storey ML: Sugar-sweetened beverages and body mass index in children and adolescents: a meta-analysis. Am J Clin Nutr 2008;87:1662-1671

10. Saris WH: Athletics. In Human Nutrition and Dietetics Garrow JS JW, Ralph A Ed. London, Churchill Livingstone, 2000, p. pp 471-480

11. Schulze MB, Manson JE, Ludwig DS, Colditz GA, Stampfer MJ, Willett WC, Hu FB: Sugar-sweetened beverages, weight gain, and incidence of type 2 diabetes in young and middle-aged women. JAMA 2004;292:927-934

12. Raben A, Vasilaras TH, Moller AC, Astrup A: Sucrose compared with artificial sweeteners: different effects on ad libitum food intake and body weight after 10 wk of supplementation in overweight subjects. Am J Clin Nutr 2002;76:721-729

13. Mattes RD: Dietary compensation by humans for supplemental energy provided as ethanol or carbohydrate in fluids. Physiol Behav 1996;59:179-187

14. Soenen S, Westerterp-Plantenga MS: No differences in satiety or energy intake after high-fructose corn syrup, sucrose, or milk preloads. Am J Clin Nutr 2007;86:15861594

15. Vartanian LR, Schwartz MB, Brownell KD: Effects of soft drink consumption on nutrition and health: a systematic review and meta-analysis. Am J Public Health 2007;97:667-675

16. Malik VS, Schulze MB, Hu FB: Intake of sugar-sweetened beverages and weight gain: a systematic review. Am J Clin Nutr 2006;84:274-288

17. Bachman CM, Baranowski T, Nicklas TA: Is there an association between sweetened beverages and adiposity? Nutrition reviews 2006;64:153-174

18. Forshee RA, Storey ML, Allison DB, Glinsmann WH, Hein GL, Lineback DR, Miller SA, Nicklas TA, Weaver GA, White JS: A critical examination of the evidence relating high fructose corn syrup and weight gain. Crit Rev Food Sci Nutr 2007;47:561-582

19. Pereira MA: The possible role of sugar-sweetened beverages in obesity etiology: a review of the evidence. Int J Obes (Lond) 2006;30:28-36 
20. van Baak MA, Astrup A: Consumption of sugars and body weight. Obes Rev 2009;10 Suppl 1:9-23

21. Saris WH, Astrup A, Prentice AM, Zunft HJ, Formiguera X, Verboeket-van de Venne WP, Raben A, Poppitt SD, Seppelt B, Johnston S, Vasilaras TH, Keogh GF: Randomized controlled trial of changes in dietary carbohydrate/fat ratio and simple vs complex carbohydrates on body weight and blood lipids: the CARMEN study. The Carbohydrate Ratio Management in European National diets. Int J Obes Relat Metab Disord 2000;24:1310-1318

22. Skov AR, Toubro S, Raben A, Astrup A: A method to achieve control of dietary macronutrient composition in ad libitum diets consumed by free-living subjects. European journal of clinical nutrition 1997;51:667-672

23. Becel voedingsprogramma: Een professioneel programma voor de personal computer. Rotterdam, Nederlandse Unilever Bedrijven B.V., 1994

24. Liu S, Manson JE, Buring JE, Stampfer MJ, Willett WC, Ridker PM: Relation between a diet with a high glycemic load and plasma concentrations of high-sensitivity Creactive protein in middle-aged women. Am J Clin Nutr 2002;75:492-498

25. Nielsen SJ, Popkin BM: Changes in beverage intake between 1977 and 2001. Am J Prev Med 2004;27:205-210

26. Berg WE OM, Boer JMA: Consumptie van een aantal lightproducten in relatie tot overgewicht. Bilthoven, RIVM, 2006

27. Katan MB, Grundy SM, Willett WC: Should a low-fat, high-carbohydrate diet be recommended for everyone? Beyond low-fat diets. N Engl J Med 1997;337:563-566; discussion 566-567

28. Kirk TR: Role of dietary carbohydrate and frequent eating in body-weight control. Proc Nutr Soc 2000;59:349-358

29. Raben A, Macdonald I, Astrup A: Replacement of dietary fat by sucrose or starch: effects on $14 \mathrm{~d}$ ad libitum energy intake, energy expenditure and body weight in formerly obese and never-obese subjects. Int J Obes Relat Metab Disord 1997;21:846859

30. Drummond S, Kirk T: Assessment of advice to reduce dietary fat and non-milk extrinsic sugar in a free-living male population. Public Health Nutr 1999;2:187-197

31. Drewnowski A, Bellisle F: Liquid calories, sugar, and body weight. Am J Clin Nutr 2007;85:651-661 


\section{CHAPTER 4}

Effects of different protein and glycemic index diets on metabolic profiles and substrate partitioning in lean healthy males

MJM Munsters, MCP Geraedts, WHM Saris Applied Physiology Nutrition and Metabolism 2013;38:1-8 


\section{Chapter 4}

\section{ABSTRACT}

Introduction: Dietary glycemic index (GI) and protein affects postprandial insulin responses and consequently $24 \mathrm{~h}$ glucose metabolism and therefore substrate partitioning. This study investigated the mechanistic effects of different protein and GI diets on $24 \mathrm{~h}$ profiles of metabolic markers and substrate partitioning.

Methods: After 3 days of diet and physical activity standardization 10 healthy male subjects (BMI: $22.5 \pm 0.6 \mathrm{~kg} / \mathrm{m}^{2}$ ) stayed in a respiration chamber 4 times for $36 \mathrm{~h}$ each time to measure substrate partitioning. All subjects randomly received four isoenergetic diets with either a normal (15 En\%) dairy protein, low GI (< 40 units) (NDP-LGI) diet; a high (25 En\%) dairy protein, low GI (HDP-LGI) diet; a normal vegetable protein, low GI (NVP-LGI) diet or a normal dairy protein, high GI (> 60 units) (NDP-HGI) diet. During the day blood was sampled at fixed time points for the measurement of metabolic markers and satiety hormones.

Results: The HDP-LGI diet increased $24 \mathrm{~h}$ protein oxidation and sleeping metabolic rate (SMR) compared with the NDP-LGI diet $(p<0.002)$. No significant differences in $24 \mathrm{~h}$ carbohydrate and fat oxidation (day and night) were found between all intervention diets. Net incremental area under the curve (net iAUC) of $24 \mathrm{~h}$ plasma glucose decreased in the HDP-LGI diet compared with the NDP-LGI diet $(p<0.01)$, but no effect was observed on insulin levels.

Conclusion: No difference in appetite profiles were observed between all intervention diets. The lower $24 \mathrm{~h}$ glycemic profile as a result of a high dairy protein diet did not lead to changes in $24 \mathrm{~h}$ substrate partitioning in lean healthy subjects with a normal insulin sensitivity. 


\section{INTRODUCTION}

Both dietary glycemic index (GI) and protein affect postprandial insulin responses and consequently $24 \mathrm{~h}$ glucose metabolism and substrate partitioning. Therefore, these factors are suggested to play an important role in body weight control. The claim that low GI foods have a positive effect on obesity is partly based on the assumption that reduction of postprandial glucose and insulin responses will decrease carbohydrate oxidation and fat storage and increase fat oxidation (1-3). Furthermore, lower and slower postprandial blood glucose and insulin responses are believed to promote satiety and suppress hunger, because large fluctuations in blood glucose and insulin may induce hypoglycemia, which could lead to increased hunger (1-3). However, inconsistencies about the effects of Gl also exist, most likely because of lack in standardization of human diets, such as isocaloric feeding, proportion and types of carbohydrates, fiber, protein, fat, food matrix, and method of preparation. All have profound effects on the postprandial glucose response (4).

In addition, studies have found that modestly increasing the proportion of protein in the diet may improve body composition, facilitate fat loss, promote satiety, and improve body weight maintenance after weight loss $(5 ; 6)$. Interestingly, proteins, protein hydrolysates, and amino acids can generate a substantial increase in insulin response of up to $200 \%$ (7), particularly branch-chain amino acids (BCAA) such as leucine. Dairy proteins, such as whey protein isolate, are relatively rich in BCAA (8). McCarron first pointed out the inverse relation between dairy intake (in particular, calcium and protein intake) and body weight (9). Dairy products have a very low GI, and except for cheese, all these products have potent insulinotropic effects (10). This gives a puzzling physiological mechanistic profile with the notion of the positive weight regulatory aspects of dairy (protein) intake on one hand and the hypothesis that insulinemia, as a modulator of insulin resistance and consequently substrate partitioning, leads to weight gain on the other hand (11). It is suggested that the low GI property of (dairy) protein causes glycemic improvements leading to a better body weight control despite the stronger insulinotropic effects, which are comparable to high GI foods. This hints at an improvement of insulin sensitivity due to the stimulatory insulin secretion effect using diets in high dairy protein.

The extent to which dairy factors affect postprandial insulinemia has not been investigated previously, because insulin secretion is largely assumed to be proportional to postprandial glycemia (10). Therefore, the purpose of the present study was to investigate the mechanistic effects of different proteins (content and source) and GI diets on the $24 \mathrm{~h}$ profiles of metabolic markers (main focus on glucose and insulin levels) and substrate partitioning in lean healthy males. 


\section{MATERIAL AND METHODS}

\section{Subjects}

Ten healthy non-smoking men aged $28 \pm 1.8 \mathrm{y}$, with a mean BMI of $22.5 \pm 0.6 \mathrm{~kg} / \mathrm{m}^{2}$ and a mean percentage body fat of $17.9 \pm 2.7 \%$ were recruited from local educational institutions. Inclusion criteria were as follows: weight stable over the past 3 months, no known metabolic abnormalities, BMI $<25 \mathrm{~kg} / \mathrm{m}^{2}$; alcohol intake $1<28$ drinks weekly). At screening subjects completed a medical history questionnaire and performed an Oral Glucose Tolerance Test (OGTT). The results of the OGTT were mean fasting glucose level of $5.2 \pm 0.2 \mathrm{mmol} / \mathrm{L}$, a fasting insulin level of $9.2 \pm 0.8 \mathrm{mU} / \mathrm{L}$ and mean $2 \mathrm{~h}$ glucose level after the OGTT of $4.2 \mathrm{mmol} / \mathrm{L}$. Given that energy expenditure (EE) declines with increasing age, a maximal age of 40 years was set to form a homogeneous adult group. For homogeneity reasons, as well as to avoid menstrual cycle effects on EE, only Caucasian males were included. This study was conducted according to the guidelines laid down in the Declaration of Helsinki (12), and the Medical Ethical Committee of the University Hospital Maastricht approved all procedures involving human subjects. All subjects signed an informed consent form.

\section{Study design}

This study had a randomized, single-blind, four-way crossover design. The four isoenergetic interventions consisted of 30\% energy (En\%) from fat and 45 or $55 \mathrm{En} \%$ from carbohydrates (higher protein is compensated by lower carbohydrates) and: (1) normal (15 En\%) dairy protein (DP) and low GI (GI < 40) (NDP-LGI); (2) high (25 En\%) dairy protein and low GI (GI < 40) (HDP-LGI); (3) normal (15 En\%) vegetable protein (VP) and low GI (GI < 40) (NVP-LGI); and (4) normal (15 En\%) dairy protein and high GI $(G I>60)$ (NDP-HGI). A diet consisting of $100 \%$ dairy protein was not possible to produce, consequently the predominantly dairy protein diets consisted of $70 \%$ animal protein (of which $70 \%$ was dairy protein) and $30 \%$ vegetable protein. The vegetable protein diet consisted of $100 \%$ vegetable protein; predominantly gluten, nuts, and soy. Subjects consumed the four different diets randomly and water and tea were provided ad libitum. The diet consisted of breakfast at $09.00 \mathrm{~h}$, lunch at $13.00 \mathrm{~h}$, dinner at 18.00 $\mathrm{h}$, and a potential snack at $21.30 \mathrm{~h}$ when subjects were not in energy balance (for calculation see later). The dietary content of the intervention diets is described in detail in Table 1. The diets were adapted from the Diogenes multicenter trial and were changed accordingly (13). The GI of each diet was calculated at the beginning of the study using the international GI tables, however in this article the new more appropriate GI values of individual food components from the Diogenes $\mathrm{Gl}$ database were used. The Diogenes GI database contains GI levels of typical foods per country, which became available when the study was already underway. 


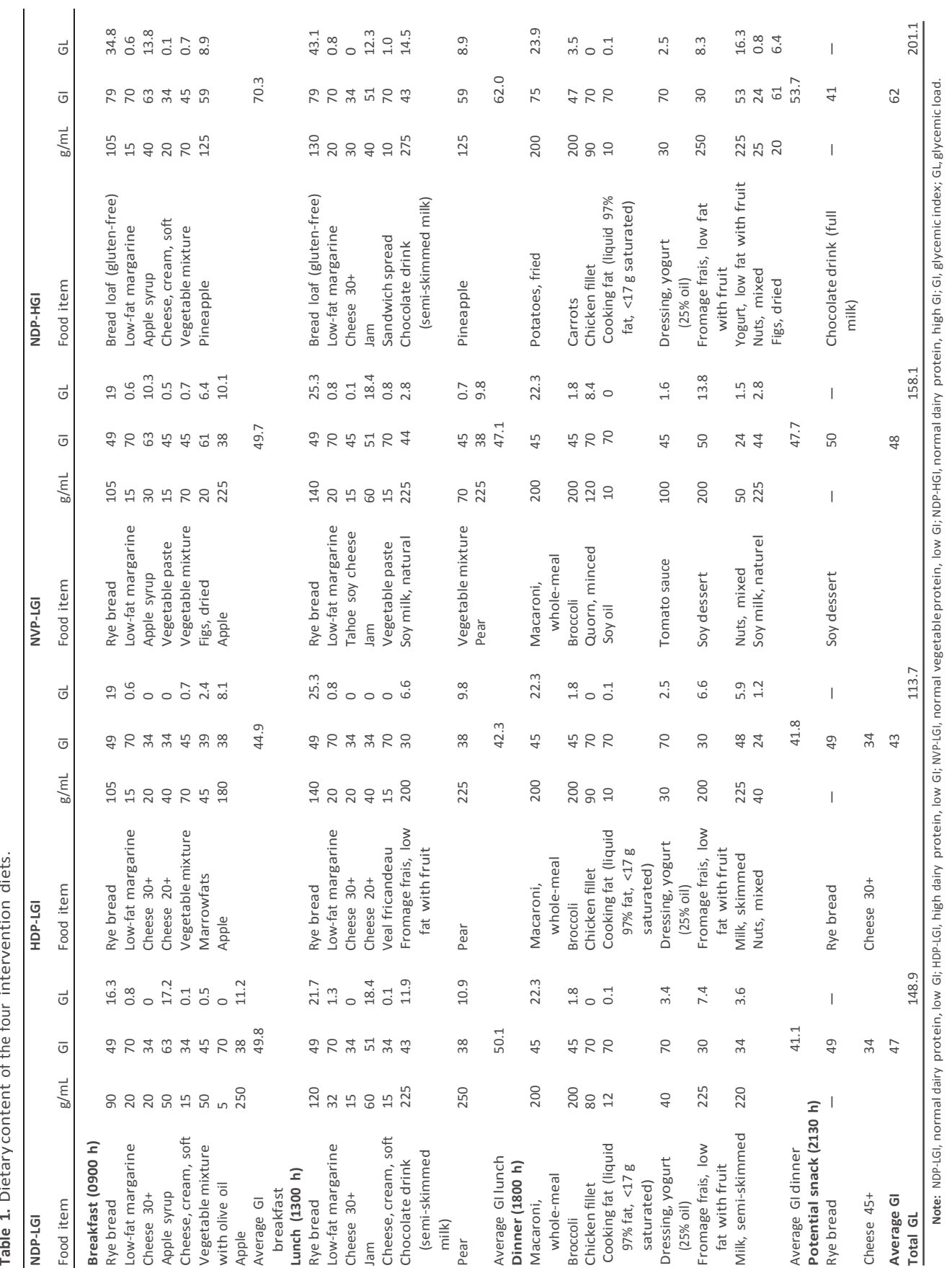


Before each intervention, subjects had to standardize their food intake and physical activity (PA) to have the same baseline condition. Food intake and PA diaries were completed for 3 days prior the first intervention and repeated precisely before subsequent interventions. The interventions started at $21.00 \mathrm{~h}$ when subjects entered the respiration chamber and finished $36 \mathrm{~h}$ later at $09.00 \mathrm{~h}$. The system of the respiration chamber is described in detail by Schoffelen et al. (1997) (14). The subjects were maintained in energy balance by carefully controlling energy intake and expenditure, which was based on individually measured and calculated requirements. In the respiration chamber, PA was prescribed by means of a standardized PA protocol, three repetitions of stepping (15 min each). The sleeping metabolic rate (SMR) was assessed throughout the first night in the respiration chamber. The SMR is defined as the lowest EE (measured in 30-min intervals) over three consecutive sleeping hours. The total daily EE was estimated by multiplying the SMR with a physical activity index (PAI) of 1.55 (15). This level of EE was used subsequently as the energy intake level for all four $24 \mathrm{~h}$ intervention days.

\section{Continuous glucose monitoring}

Before each intervention, a MiniMed sensor and MiniMed Continuous Glucose Monitoring System Gold (CGMS) were used to measure subcutaneous interstitial fluid glucose levels (Medtronic MiniMed, Northridge, California, USA). The monitor sampled the signals once every $10 \mathrm{~s}$ and recorded an average signal every $5 \mathrm{~min}$. The monitor was calibrated with four separate capillary finger prick glucose readings using a glucose meter (Glucocard Memory PC; A. Menarini Diagnostics, Florence, Italy). Although the sensors recorded data for $36 \mathrm{~h}$, only the last $24 \mathrm{~h}$ data (monitored between $09.00 \mathrm{~h}$ on day 2 and $09.00 \mathrm{~h}$ on day 3) were used for analysis. Continuous overall net glycemic action (CONGA) was used to measure the intraday glycemic variability (16). CONGAn was defined as the standard deviation of the differences in glucose concentration between current observation and the observation $n$ hours previous. CONGA1, CONGA2, and CONGA4 were calculated indicating intraday glycemic variability based on 1, 2 and $4 \mathrm{~h}$ time periods. Higher CONGA values indicate greater glycemic variation, values above 1.5 indicate glycemic lability (16). The coefficient of variability (CV) is defined as the SD divided by the mean of the glucose values (17).

\section{Blood sampling}

In the morning, a catheter was placed into an antecubital vein for blood withdrawal. Blood was sampled just before ingestion of the three experimental meals, and 30,60, 120 and 240 min postprandially for determination of plasma levels of insulin, glucose, free fatty acids (FFA), and triglycerides (TG). At $\mathrm{T}=0$ (baseline $09.00 \mathrm{~h}$ ) and $60 \mathrm{~min}$ after 
ingestion of the three experimental meals, C-peptide and the satiety-related hormones glucagon-like peptide-1 (GLP-1) active and ghrelin-active were sampled. On the next morning at $09.00 \mathrm{~h}(\mathrm{~T}=24)$, fasting blood samples were taken to measure all of the markers described above.

Standard $10 \mathrm{~mL}$, ice-cooled vacutainer tubes containing EDTA to prevent clotting were used to collect blood samples. Plasma was obtained by low-speed centrifugation within $1 \mathrm{~h}$ after blood sampling, frozen in liquid nitrogen, and stored at $-80{ }^{\circ} \mathrm{C}$ until further analysis. Blood samples were mixed with $60 \mu \mathrm{l}$ of dipeptidyl peptidase IV inhibitor (DPP-IV) for GLP-1 active measurements (Linco Research Inc., St. Charles, Missouri, USA). Phenylmethylsofonyl fluoride was added to the active ghrelin plasma samples. Plasma insulin, active ghrelin, and GLP-1 active concentrations were measured by radioimmunoassay (Millipore, Billerica, Mass., MA, USA). An enzymelinked immunosorbent assay (ELISA) was used to assess C-peptide levels (Mercodia, Uppsala, Sweden). Plasma glucose, FFA, and TG concentrations were measured with the use of an enzymatic colorimetric method on a CobasFara spectrophotometer (Roche Diagnostics, Basel, Switzerland).

\section{Visual analogue scales}

Hunger, fullness, satiety, thirst, and desire to eat were measured by anchored $100-\mathrm{mm}$ visual analogue scales (VAS) to assess appetite profiles (18). These scales were completed by the subjects just before, 30, and 60 min after breakfast, lunch, and dinner, and the next morning at $09.00 \mathrm{~h}$.

\section{Indirect calorimetry}

EE was calculated by means of $\mathrm{O}_{2}$ consumption, $\mathrm{CO}_{2}$ production, and urine nitrogen excretion according to Brouwer (19). The $24 \mathrm{~h}$ urine nitrogen concentration was used to calculate total daily nitrogen excretion, which was measured with a nitrogen analyzer (CHN-O-Rapid; Heraeus, Hanau, Germany). Nitrogen loss by evaporation was prevented by adding $10 \mathrm{~mL}$ of $\mathrm{HCL}$ to the urine containers. PA was monitored using a radar system, which is based on the Doppler principle. The $24 \mathrm{~h}$ EE was calculated from $09.00 \mathrm{~h}$ (first morning) to $09.00 \mathrm{~h}$ (second morning). Diet induced thermogenesis (DIT) was calculated by plotting EE against radar output; both averaged over 30-min periods. The radar output during exercise was excluded, because it was not reliable. The intercept of the regression line at the lowest radar output represents the EE in the inactive state (resting metabolic rate; RMR), consisting of DIT and SMR. DIT was determined by subtracting SMR from RMR. Activity-induced EE (AEE) was determined by subtracting SMR and DIT from $24 \mathrm{~h}$ EE. PAI was calculated by dividing $24 \mathrm{~h}$ EE by $\operatorname{SMR}(20 ; 21)$. 


\section{Body composition}

In the fasted state, body density was measured by underwater weighing. Lung volume was assessed simultaneously by the helium dilution technique using a spirometer (Volugraph 2000; Mijnhardt, Bunnik, the Netherlands). Body weight was determined on a digital balance, accurate to $0.001 \mathrm{~kg}$ (IDI plus; Mettler Toledo, Tiel, the Netherlands). Underwater, body weight was measured on a digital balance, accurate to $0.01 \mathrm{~kg}$ (EC240; Mettler Toledo, Tiel, the Netherlands). Body fat percentage was calculated using the equation of Siri (22).

\section{Statistical analyses}

The primary endpoint for this study was the postprandial glucose response, and the results of Manders et al. (2006) (23) were used for power calculation (power of 90\%). That study examined postprandial plasma glucose responses after co-ingestion of an insulinotropic protein (Pro) hydrolysate without additional free leucine with a single bolus of carbohydrate (Cho). SPSS software (version 15 for windows; SPSS) was used for data entry and analysis. Data are reported as means \pm standard error of the mean (SEM). Homogeneity of the data was checked with the Kolmogorov-Smirnov test, and In transformation was applied when data were not normally distributed. The total area under the curve (AUC) and the net incremental area under the curve (net iAUC), which includes all iAUC, together with the area below the fasting concentration were calculated using the trapezoidal rule for all data except for indirect calorimetry data. CGMS data, EE, substrate partitioning, and (net i)AUCs (i.e. both net iAUC and AUC) were compared between the four intervention diets with one-way repeated measures ANOVA. Mixed-model ANOVA was used to compare the intervention diets at the different time points for VAS scales and the metabolic markers. Outcomes were corrected for multiple testing. Statistical significance was set at $p<0.05$.

\section{RESULTS}

\section{Normal vs. high dairy protein}

The HDP-LGI diet showed a higher SMR compared with the NDP-LGI diet $(p<0.001)$ (Table 2). As expected, the HDP-LGI diet increased $24 \mathrm{~h}$ protein oxidation compared with the other three diets $(\mathrm{p}<0.05)$. Overall, net iAUC of $24 \mathrm{~h}$ glucose levels and AUC of $2 \mathrm{~h}$ glucose levels after lunch were significantly lower in the HDP-LGI diet compared with the NDP-LGI diet $(p<0.01)$ and NDP-HGI diet $(p<0.05)$ (Fig. 1 and Table 3). FFA levels increased in the NDP-LGI diet compared with the HDP-LGI diet, particularly after lunch and dinner. Changes in the TG profiles are less pronounced, however the HDPLGI diet showed a higher TG level. GLP-1 active levels showed no significant differences between the intervention diets (data not shown). Surprisingly, CGMS data 
demonstrated that glucose levels tended to be higher in the HDP-LGI diet during the night (NS) compared with the NDP-LGI diet respectively, with $5.5 \pm 0.3$ vs. $5.3 \pm 0.2$ $\mathrm{mmol} / \mathrm{L}$ (Fig. 2).
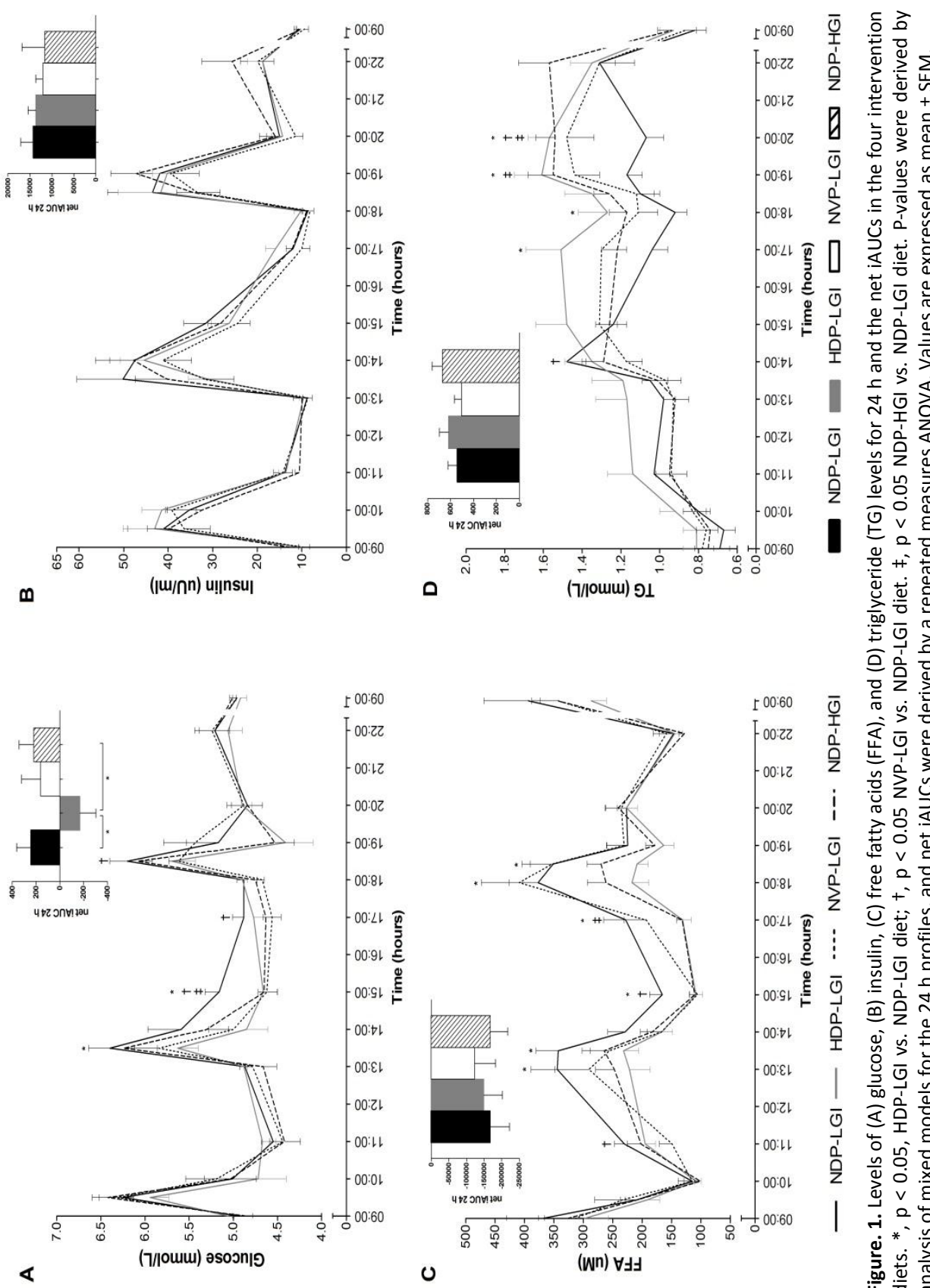

可高家

웅

ग्र

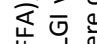

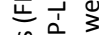

$\stackrel{n}{i} \sum y$

is

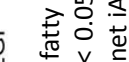

\& 2 일

(i)

Ōi

s.

जे

.

鱼

ì

ठํ

$\frac{10}{10}$

○ 区잉

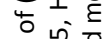

능 힝

ये

i 24

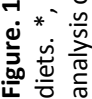


Table 2. Total energy expenditure, components of energy expenditure, and substrate partitioning, according to the four intervention diets (24 h).

\begin{tabular}{llllll}
\hline & NDP-LGI & HDP-LGI & NVP-LGI & NDP-HGI & p-value \\
\hline El (MJ/day) & $11.4 \pm 0.4$ & $11.4 \pm 0.4$ & $11.4 \pm 0.4$ & $11.4 \pm 0.4$ & - \\
TEE (MJ/day) & $11.9 \pm 0.4 \mathrm{ab}$ & $12.1 \pm 0.4 \mathrm{ab}$ & $12.0 \pm 0.4 \mathrm{a}$ & $11.5 \pm 0.4 \mathrm{~b}$ & 0.016 \\
EB (MJ/day) & $-0.5 \pm 0.2 \mathrm{ab}$ & $-0.6 \pm 0.2 \mathrm{ab}$ & $-0.6 \pm 0.2 \mathrm{a}$ & $-0.1 \pm 0.1 \mathrm{~b}$ & 0.016 \\
RMR (MJ/day) & $8.1 \pm 0.2 \mathrm{ab}$ & $8.6 \pm 0.2 \mathrm{a}$ & $8.3 \pm 0.2 \mathrm{ab}$ & $8.1 \pm 0.1 \mathrm{~b}$ & 0.005 \\
SMR (MJ/day) & $7.0 \pm 0.1 \mathrm{a}$ & $7.3 \pm 0.1 \mathrm{bc}$ & $7.3 \pm 0.1 \mathrm{~b}$ & $7.1 \pm 0.1 \mathrm{ac}$ & 0.000 \\
DIT (MJ/day) & $1.1 \pm 0.2$ & $1.3 \pm 0.2$ & $1.0 \pm 0.2$ & $1.0 \pm 0.1$ & 0.2 \\
AEE (MJ/day) & $3.8 \pm 0.3$ & $3.5 \pm 0.3$ & $3.8 \pm 0.3$ & $3.5 \pm 0.3$ & 0.2 \\
PAI & $1.69 \pm 0.04$ & $1.66 \pm 0.04$ & $1.65 \pm 0.05$ & $1.63 \pm 0.04$ & 0.1 \\
RQ & $0.90 \pm 0.01$ & $0.90 \pm 0.00$ & $0.91 \pm 0.01$ & $0.91 \pm 0.00$ & 0.4 \\
Protein oxidation & $72.3 \pm 6.8 \mathrm{a}$ & $97.6 \pm 4.6 \mathrm{~b}$ & $74.8 \pm 3.8 \mathrm{a}$ & $77.1 \pm 4.1 \mathrm{a}$ & 0.002 \\
(g/day) & & & & & \\
Carbohydrate & $421.5 \pm 18.2$ & $432.6 \pm 16.2$ & $448.6 \pm 27.7$ & $430.6 \pm 20.8$ & 0.6 \\
oxidation (g/day) & & & & & \\
Fat oxidation (g/day) & $83.1 \pm 7.3$ & $70.6 \pm 5.7$ & $76.9 \pm 9.5$ & $69.2 \pm 4.9$ & 0.2
\end{tabular}

Note: NDP-LGI, normal dairy protein, low Gl; HDP-LGI, high dairy protein, low GI; NVP-LGI, normal vegetable protein, low GI; NDP-HGI, normal dairy protein, high GI; El, energy intake; TEE, total energy expenditure; EB, energy balance; RMR, resting metabolic rate; SMR, sleeping metabolic rate; DIT, diet induced thermogenesis; AEE, activity-induced energy expenditure; PAI, physical activity index; RQ, respiratory quotient. Values are expressed as mean $\pm \mathrm{SEM}$; P-values were derived by analysis of repeated measures variance and denote the overall significance of differences among the four diets; P-values are corrected for multiple testing (Bonferroni adjustment). Within each row any values with the same letter do not differ significantly $(p>0.05)$.

\section{Vegetable vs. dairy protein}

SMR increased in the NVP-LGI diet compared with the NDP-LGI diet $(p<0.001)$ (Table 2 ). At some time points throughout the day, glucose levels were lower in the NVP-LGI diet compared with the NDP-LGI diet $(p<0.05)$ (Fig. 2). Two hours after breakfast and lunch FFA levels decreased in the NVP-LGI diet compared with the NDP-LGI diet.

\section{Low vs. high GI}

There was a higher TG level throughout the day for the NDP-HGI diet compared with the NDP-LGI diet.

\section{Energy expenditure and substrate partitioning}

Subjects received the same amount of energy in each intervention diet (Table 2). Given the well-controlled $24 \mathrm{~h}$ activity pattern and total energy intake, total energy expenditure (TEE) and energy balance only significantly differed between the NVP-LGI diet and the NDP-HGI diet $(p<0.05)$. RMR increased in the HDP-LGI diet compared 
with the NDP-HGI diet $(p<0.01)$. The NVP-LGI diet also showed a significantly higher SMR compared with the NDP-HGI diet $(p<0.001)$. No effects on $24 \mathrm{~h}$ DIT, AEE, PAL and $R Q$ were observed between the intervention diets. No significant differences in $24 \mathrm{~h}$ carbohydrate and fat oxidation were found between the intervention diets. Furthermore, no differences in day and night substrate partitioning were observed (data not shown).

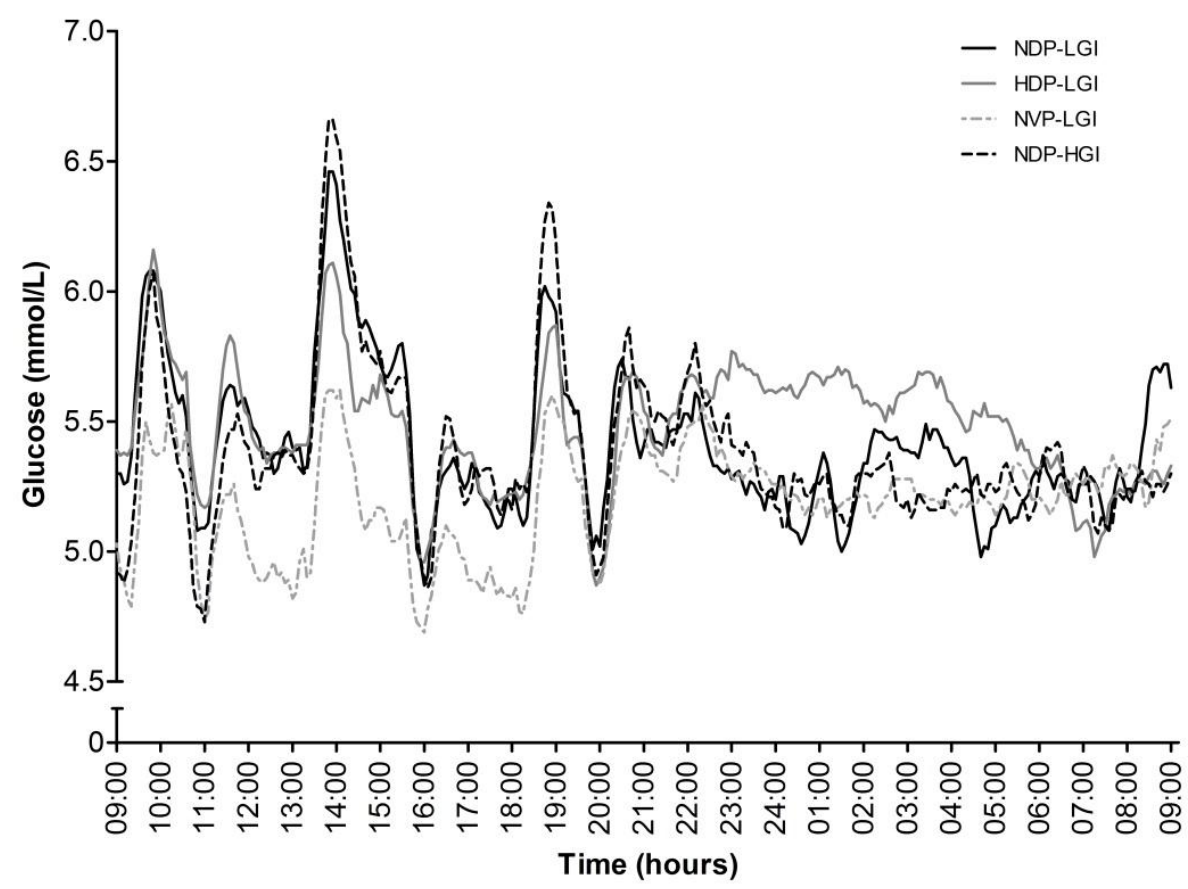

Figure. 2. CGMS glucose levels in the four intervention diets for $24 \mathrm{~h}$. See the text for descriptions of the diets. Values are expressed as mean.

\section{Metabolic markers measured at fixed time points}

Insulin and C-peptide levels, as well as the net iAUC of insulin, and C-peptide, and the iAUCs of $2 \mathrm{~h}$ insulin after each meal, showed no significant differences between the four intervention diets during the day (Table 3 and Fig. 1; c-peptide levels not shown). No correlations between net iAUCs of glucose and the GL of each intervention diet were found (data not shown). No significant differences were found in plasma levels of ghrelin-active between the four intervention diets (data not shown). During the day, there was an increase in ghrelin-active levels for all four diets. 
Table 3. iAUC $2 \mathrm{~h}$ after each meal for glucose and insulin levels, according to the four intervention diets.

\begin{tabular}{|c|c|c|c|c|c|}
\hline & NDP-LGI & HDP-LGI & NVP-LGI & NDP-HGI & $\begin{array}{l}p- \\
\text { value }\end{array}$ \\
\hline $\begin{array}{l}\text { iAUC, glucose, } 2 \text { h } \\
\text { after breakfast }\end{array}$ & $42.5 \pm 0.7$ & $26.5 \pm 7.8$ & $49.2 \pm 9.4$ & $48.7 \pm 8.3$ & 0.106 \\
\hline $\begin{array}{l}\text { iAUC, glucose, } 2 \mathrm{~h} \\
\text { after lunch }\end{array}$ & $60.2 \pm 9.5 a$ & $27.6 \pm 7.7 b$ & $44.0 \pm 10.8 a b$ & $59.7 \pm 14.0 \mathrm{a}$ & 0.007 \\
\hline $\begin{array}{l}\text { iAUC, glucose, } 2 \mathrm{~h} \\
\text { after dinner }\end{array}$ & $50.6 \pm 14.7 a b$ & $25.0 \pm 7.8 a$ & $47.7 \pm 8.0 b$ & $40.7 \pm 4.7 \mathrm{ab}$ & 0.064 \\
\hline ¡AUC, insulin, 2 h & $2214.8 \pm$ & $2554.3 \pm$ & $2278.2 \pm$ & $1892.3 \pm$ & 0.387 \\
\hline after breakfast & 334.8 & 277.8 & 293.9 & 342.4 & \\
\hline iAUC, insulin, $2 \mathrm{~h}$ & $3654.1 \pm$ & $2756.1 \pm$ & $2635.4 \pm$ & $3156.1 \pm$ & 0.153 \\
\hline after lunch & 543.5 & 289.8 & 387.7 & 286.6 & \\
\hline iAUC, insulin, $2 \mathrm{~h}$ & $2730.3 \pm$ & $2424.2 \pm$ & $2264.1 \pm$ & $2693.3 \pm$ & 0.382 \\
\hline after dinner & 325.3 & 359.5 & 262.2 & 282.9 & \\
\hline
\end{tabular}

Note: NDP-LGI, normal dairy protein, low GI; HDP-LGI, high dairy protein, low GI; NVP-LGI, normal vegetable protein, low Gl; NDP-HGI, normal dairy protein, high GI; iAUC, incremental area under the curve. Values are expressed as mean $\pm \mathrm{SEM}$; P-values were derived by analysis of repeated measures variance and denote the overall significance of differences among the four diets; P-values are adjusted for multiple testing (Bonferroni's adjustment). Within each row any values with the same letter do not differ significantly ( $p$ > 0.05).

Table 4. Analyses of the CGMS data compared between the four intervention diets $(n=9)$.

\begin{tabular}{llllll}
\hline & NDP-LGI & HDP-LGl & NVP-LGI & NDP-HGI & $\begin{array}{l}p- \\
\text { value }\end{array}$ \\
\hline Mean, per 24 h (mmol/L) & $5.4 \pm 0.1$ & $5.5 \pm 0.2$ & $5.2 \pm 0.2$ & $5.4 \pm 0.2$ & 0.5 \\
Min, per 24 h (mmol/L) & $4.3 \pm 0.2$ & $4.4 \pm 0.3$ & $4.1 \pm 0.3$ & $4.2 \pm 0.2$ & 0.7 \\
Max, per 24 h (mmol/L) & $6.9 \pm 0.2$ & $6.6 \pm 0.2$ & $6.3 \pm 0.3$ & $7.0 \pm 0.4$ & 0.1 \\
Mean, day (mmol/L) & $5.5 \pm 0.1$ & $5.5 \pm 0.1$ & $5.2 \pm 0.2$ & $5.5 \pm 0.2$ & 0.3 \\
Mean, night (mmol/L) & $5.3 \pm 0.2$ & $5.5 \pm 0.3$ & $5.2 \pm 0.2$ & $5.2 \pm 0.3$ & 0.7 \\
net iAUC, per 24 h & $163.8 \pm 271.7$ & $142.2 \pm 283.6$ & $228.5 \pm 360.8$ & $671.2 \pm 339.8$ & 0.5 \\
net iAUC, day & $171.6 \pm 168.6$ & $104.2 \pm 159.7$ & $120.3 \pm 229.3$ & $503.4 \pm 162.9$ & 0.3 \\
net iAUC, night & $23.7 \pm 81.8$ & $-59.7 \pm 42.9$ & $20.3 \pm 71.9$ & $67.4 \pm 77.5$ & 0.7 \\
CONGA1 & $0.59 \pm 0.07$ & $0.47 \pm 0.04$ & $0.46 \pm 0.05$ & $0.62 \pm 0.09$ & 0.2 \\
CONGA2 & $0.64 \pm 0.08$ & $0.48 \pm 0.04$ & $0.50 \pm 0.05$ & $0.65 \pm 0.11$ & 0.2 \\
CONGA4 & $0.66 \pm 0.09$ & $0.49 \pm 0.05$ & $0.56 \pm 0.04$ & $0.64 \pm 0.09$ & 0.3 \\
CV & $0.09 \pm 0.01$ & $0.08 \pm 0.01$ & $0.09 \pm 0.01$ & $0.10 \pm 0.02$ & 0.6 \\
\hline
\end{tabular}

Note: NDP-LGI, normal dairy protein, low GI; HDP-LGI, high dairy protein, low Gl; NVP-LGI, normal vegetable protein, low Gl; NDP-HGI, normal dairy protein, high Gl; day, 0900-2359 h; night, 0000-0900 h; Mean, mean glucose level; Min., minimal glucose level; Max., maximal glucose level; net iAUC, net incremental area under the curve; CONGA1, CONGA2, CONGA4, continuous overall net glycemic action describing intraday glycemic variability between respectively 1,2 , and $4 \mathrm{~h}$ time periods, respectively, over $24 \mathrm{~h}$; CV, coefficient of variability. Values are expressed as mean \pm SEM; P-values were derived by analysis of repeated measures variance and denote the overall significance of differences among the four diets; P-values are adjusted for 
multiple testing (Bonferroni's adjustment). Within each row any values with the same letter do not differ significantly $(p>0.05)$.

\section{Continuous glucose monitoring}

Sensor failure in one person resulted in complete CGMS data of nine subjects (Fig. 2). Mean, maximum, and minimum glucose concentration, and the (net i)AUCs during the day $(09.00-23.59 \mathrm{~h})$ and during the night $(00.00-09.00 \mathrm{~h})$, and CONGA1, CONGA2, CONGA4, and CV were calculated per diet per $24 \mathrm{~h}$ from the CGMS data and showed no significant differences between the four intervention diets (Table 4, not all data shown). No correlations were found between the (net i)AUC of glucose and CGMS data (data not shown).

\section{Appetite measurements}

The response curves for the appetite sensations (hunger, satiety, fullness, thirst and prospective food consumption) did not reveal any significant differences in appetite profiles between the four diets during the day (data not shown).

\section{DISCUSSION}

The aim of the present study was to investigate whether substantial differences in the $\mathbf{G l}$, the protein content or protein source could affect 24 hours metabolic profiles in lean healthy normoglycemic subjects under highly controlled conditions. Surprisingly, the metabolic profile, in terms of substrate partitioning, was not modified. However, a higher dairy protein intake significantly reduced glucose levels throughout the day (net iAUC) and increased protein oxidation.

\section{Normal vs. high dairy protein}

Our results suggest that the high dairy protein diet leads to glycemic improvements in lean healthy subjects despite the fact that no changes are observed in nutritional partitioning. One can speculate that this profile can lead to a potentially better body weight control over the long term. Gannon et al. (2003) confirmed the improvement of the $24 \mathrm{~h}$ glycemic profile in type 2 diabetics after a high protein diet for 5 weeks (24). We expected that the high dairy protein diet would reduce glucose levels due to the higher insulin response. However, no changes in insulin and C-peptide levels were observed between the intervention diets in these healthy subjects. This could be explained by their normal insulin sensitivity. In our study, insulin secretion might have increased $10 \mathrm{~min}$ postprandially, also called the first-phase insulin secretion. The critical physiologic role of the first-phase of insulin secretion is the maintenance of postmeal glucose homeostasis (25). Consequently, insulin peaks may not have been detected due to blood sampling after $30 \mathrm{~min}$. 
Even though no significant effects of the intervention diets were observed with CGMS data, it is a good method to assess patterns of glycemic excursions of all intervention diets, not to assess the absolute degree of glycemic excursions as deviations in glucose levels between blood and CGMS were observed in our data (16). The CGMS data revealed lower glucose levels during the day and interestingly a tendency for higher glucose levels during the night in the high dairy protein diet. This suggests a glycemia counter regulation mechanism over $24 \mathrm{~h}$. Merl et al. showed that the markedly enhanced epinephrine response to early nighttime hypoglycemia could be clinically important; because this neuroendocrine response is known to play a crucial role in mediating the awareness of and metabolic defensive mechanism against hypoglycemia (26).

It has been suggested that a high protein diet increases EE and DIT $(27 ; 28)$. Our data showed no significant effects of the high dairy protein diet on TEE and DIT. Probably, the low number of subjects to achieve enough power can explain this. In addition, the high dairy protein diet induced a significantly higher SMR and protein oxidation than the normal dairy protein diet. This might be the result of the small storage capacity for protein in the human body. The higher thermic effect of protein is generally attributed to the metabolic costs of peptide-bond synthesis and breakdown, urogenesis and gluconeogenesis (29). Moreover, there is no clear agreement in the literature about the effects of high protein diets on the different components of energy metabolism (30; 31). Recently, Stepien et al. (2010) concluded that the time of adaptation to the diet is critical and may partly explain the discrepancies in the literature. Inhibition of de novo lipogenesis may be the major process that permits a reduction in fat deposition under conditions of high-protein feeding. Still, more research using macronutrient compositions mimicking daily life diets and the time-course of metabolic changes occurring after switching to a high protein diet in humans should be performed to confirm these results (32).

\section{Dairy vs. vegetable protein}

We hypothesized that ingestion of dairy protein would lead to a better metabolic profile compared with vegetable protein, due to the insulinotropic effects of dairy protein. However, glucose levels were lower at several fixed time points in the vegetable protein diet compared with the dairy protein diets. Research to date has demonstrated that a low-fat, plant-based nutritional approach improves control of weight, glycemia, and cardiovascular risk (33). Nonetheless, the lower glucose levels could have been induced by a slightly higher fiber intake in the vegetable protein diet in the present study. The selection of food products on equal fiber content was limited and consequently fiber content was higher in the vegetable protein diet compared with the dairy protein diets. The vegetable protein source in the present study consisted of a combination of gluten, nuts and soy protein. It has previously been demonstrated that glucose and insulin levels are comparable between different 
protein hydrolysates (pea, rice, soy, gluten, whey, and egg) (34), and that foods containing soy are as good as any other protein source for promoting weight loss (35). Additionally, SMR increased in the vegetable protein diet, and the reason for this is unknown; this might be due to a difference in amino acid-specific effects on sympathetic activity (29). However, DIT or TEE were not different between the types of protein. One can conclude that these results must be interpreted carefully and additional evidence is needed.

\section{Low vs. high GI}

The low Gl diet was hypothesized to improve glycemic control, reduce insulin secretion, and increase fat oxidation compared with the high Gl diet. Nevertheless, no significant effect of the Gl was observed on all outcomes, although fat oxidation tended to be higher (20\%) in the low Gl diet than in the high Gl diet ( $p=0.194)$. This observed effect is potentially important because a low Gl diet might contribute to weight loss maintenance or obesity prevention, as suggested by Brand-Miller et al. (2002) (36). Our results are consistent with those of a previous study from Aston et al. (2002), that found no differences in glucose profiles using CGMS between a low or high GI diet for a week. These authors indicated that a difference in dietary GI of 14-15 units is insufficient to alter daylong glycemia (37). In the present study, the difference in $\mathrm{Gl}$ units was calculated at the beginning of the study to be 20 units, but due to new more appropriate GI values, food processing, storage, cooking, food matrix, nutrient bioavailability, and the interaction of nutrients within the meal itself could have influenced the actual GI (38). It is physiologically relevant to observe that even at a substantial difference in GI units (15 to 20 units) a $24 \mathrm{~h}$ glycemic response and substrate partitioning are not affected in healthy individuals with a normal insulin sensitivity. Further studies are needed to determine the stage of insulin resistance at which dietary GI has an effect on glycemic profile and substrate partitioning.

The present study was designed to investigate the acute metabolic responses of dietary protein type and GI. The long-term (6 months) RCT Diogenes study recently showed positive weight maintenance results in overweight subjects with a modest, higher protein diet and to a lesser extent also with a lower GI after a considerable weight loss ( $11 \%$ body weight) (6). Our study represents to a certain extent daily life situations that most other studies are lacking. This is important because it has been shown by Saris et al. (2004) that substrate oxidation differences between equicaloric, high- and low-intensity exercise during the day were compensated for during the night leading to no differences over $24 \mathrm{~h}$ in obese men (15). For that reason, it is of importance to investigate the $24 \mathrm{~h}$ profiles.

\section{Conclusions}

In conclusion, our results indicate that the metabolic profile, in terms of substrate partitioning, was not modified despite substantial differences in protein (content and source) and GI of the diets. We could not observe an insulinotropic effect of (high) 


\section{Chapter 4}

dairy protein, probably because the insulin peak was not detected and, perhaps more importantly, subjects were insulin-sensitive. Nevertheless, our data do show that a high dairy protein diet leads to a lower glycemic profile in lean healthy subjects during the day, which might be of importance for long-term body weight control.

\section{ACKNOWLEDGMENTS}

We gratefully thank all volunteers for their time and motivation and P. Schoffelen, L. Ronden, J. Stegen, H. Aydeniz, G. Hul and W. Sluijsmans for their excellent technical or analytical support. This study was supported by the Dutch Dairy Association.

The authors declare no conflict of interests.

The authors' responsibilities were as follows-MJM: responsible for the design, conduct of the study, data collection and analysis, data interpretation and manuscript writing. MCG: assisted with the practical work of the research and carried out radioimmunoassay's. WHS: responsible for the design of the study, data interpretation and manuscript writing. All authors read and approved the submitted manuscript. 


\section{REFERENCES}

1. Ludwig DS: The glycemic index: physiological mechanisms relating to obesity, diabetes, and cardiovascular disease. Jama 2002;287:2414-2423

2. Roberts SB: High-glycemic index foods, hunger, and obesity: is there a connection? Nutrition reviews 2000;58:163-169

3. Flint A, Moller BK, Raben A, Sloth B, Pedersen D, Tetens I, Holst JJ, Astrup A: Glycemic and insulinemic responses as determinants of appetite in humans. Am J Clin Nutr 2006;84:1365-1373

4. van Schothorst EM, Bunschoten A, Schrauwen P, Mensink RP, Keijer J: Effects of a high-fat, low- versus high-glycemic index diet: retardation of insulin resistance involves adipose tissue modulation. FASEB J 2009;23:1092-1101

5. Paddon-Jones D, Westman E, Mattes RD, Wolfe RR, Astrup A, Westerterp-Plantenga M: Protein, weight management, and satiety. Am J Clin Nutr 2008;87:1558S-1561S

6. Larsen TM, Dalskov SM, van Baak M, Jebb SA, Papadaki A, Pfeiffer AF, Martinez JA, Handjieva-Darlenska T, Kunesova M, Pihlsgard M, Stender S, Holst C, Saris WH, Astrup A: Diets with high or low protein content and glycemic index for weight-loss maintenance. N Engl J Med 2010;363:2102-2113

7. van Loon LJ, Saris WH, Verhagen $\mathrm{H}$, Wagenmakers AJ: Plasma insulin responses after ingestion of different amino acid or protein mixtures with carbohydrate. Am J Clin Nutr 2000;72:96-105

8. Layman DK, Baum JI: Dietary protein impact on glycemic control during weight loss. J Nutr 2004;134:968S-973S

9. McCarron DA: Dietary calcium as an antihypertensive agent. Nutrition reviews 1984;42:223-225

10. Holt SH, Miller JC, Petocz P: An insulin index of foods: the insulin demand generated by 1000-kJ portions of common foods. Am J Clin Nutr 1997;66:1264-1276

11. Ludwig DS: Dietary glycemic index and obesity. J Nutr 2000;130:280S-283S

12. Goodyear MD, Krleza-Jeric K, Lemmens T: The Declaration of Helsinki. BMJ 2007;335:624-625

13. Aston LM, Jackson D, Monsheimer $S$, Whybrow $S$, Handjieva-Darlenska $T$, Kreutzer M, Kohl A, Papadaki A, Martinez JA, Kunova V, van Baak MA, Astrup A, Saris WH, Jebb SA, Lindroos AK: Developing a methodology for assigning glycaemic index values to foods consumed across Europe. Obes Rev 2010;11:92-100

14. Schoffelen PF, Westerterp KR, Saris WH, Ten Hoor F: A dual-respiration chamber system with automated calibration. J Appl Physiol 1997;83:2064-2072

15. Saris WH, Schrauwen P: Substrate oxidation differences between high- and lowintensity exercise are compensated over 24 hours in obese men. Int J Obes Relat Metab Disord 2004;28:759-765

16. McDonnell CM, Donath SM, Vidmar SI, Werther GA, Cameron FJ: A novel approach to continuous glucose analysis utilizing glycemic variation. Diabetes Technol Ther 2005; 7:253-263

17. Wentholt IM, Kulik W, Michels RP, Hoekstra JB, DeVries JH: Glucose fluctuations and activation of oxidative stress in patients with type 1 diabetes. Diabetologia 2008;51:183-190 
18. Flint A, Raben A, Blundell JE, Astrup A: Reproducibility, power and validity of visual analogue scales in assessment of appetite sensations in single test meal studies. Int J Obes Relat Metab Disord 2000;24:38-48

19. Brouwer $\mathrm{E}$ : On simple formulae for calculating the heat expenditure and the quantities of carbohydrate and fat oxidized in metabolism of men and animals, from gaseous exchange (Oxygen intake and carbonic acid output) and urine-N. Acta Physiol Pharmacol Neerl 1957;6:795-802

20. Ravussin E, Lillioja S, Anderson TE, Christin L, Bogardus C: Determinants of 24-hour energy expenditure in man. Methods and results using a respiratory chamber. The Journal of clinical investigation 1986;78:1568-1578

21. Westerterp KR, Wilson SA, Rolland V: Diet induced thermogenesis measured over $24 \mathrm{~h}$ in a respiration chamber: effect of diet composition. Int J Obes Relat Metab Disord 1999;23:287-292

22. Siri WE: The gross composition of the body. Adv Biol Med Phys 1956;4:239-280

23. Manders RJ, Koopman R, Sluijsmans WE, van den Berg R, Verbeek K, Saris WH, Wagenmakers AJ, van Loon $\mathrm{L}$ : Co-ingestion of a protein hydrolysate with or without additional leucine effectively reduces postprandial blood glucose excursions in Type 2 diabetic men. J Nutr 2006;136:1294-1299

24. Gannon MC, Nuttall FQ, Saeed A, Jordan K, Hoover H: An increase in dietary protein improves the blood glucose response in persons with type 2 diabetes. Am J Clin Nutr 2003;78:734-741

25. Del Prato S, Tiengo A: The importance of first-phase insulin secretion: implications for the therapy of type 2 diabetes mellitus. Diabetes Metab Res Rev 2001;17:164-174

26. Merl V, Kern W, Peters A, Oltmanns KM, Gais S, Born J, Fehm HL, Schultes B: Differences between nighttime and daytime hypoglycemia counterregulation in healthy humans. Metabolism 2004;53:894-898

27. Lejeune MP, Westerterp KR, Adam TC, Luscombe-Marsh ND, Westerterp-Plantenga MS: Ghrelin and glucagon-like peptide 1 concentrations, 24-h satiety, and energy and substrate metabolism during a high-protein diet and measured in a respiration chamber. Am J Clin Nutr 2006;83:89-94

28. Crovetti R, Porrini M, Santangelo A, Testolin G: The influence of thermic effect of food on satiety. European journal of clinical nutrition 1998;52:482-488

29. Mikkelsen PB, Toubro S, Astrup A: Effect of fat-reduced diets on 24-h energy expenditure: comparisons between animal protein, vegetable protein, and carbohydrate. Am J Clin Nutr 2000;72:1135-1141

30. Raben A, Agerholm-Larsen L, Flint A, Holst JJ, Astrup A: Meals with similar energy densities but rich in protein, fat, carbohydrate, or alcohol have different effects on energy expenditure and substrate metabolism but not on appetite and energy intake. Am J Clin Nutr 2003;77:91-100

31. Westerterp-Plantenga MS, Lejeune MP, Smeets AJ, Luscombe-Marsh ND: Sex differences in energy homeostatis following a diet relatively high in protein exchanged with carbohydrate, assessed in a respiration chamber in humans. Physiol Behav 2009;97:414-419 
32. Stepien M, Gaudichon C, Azzout-Marniche D, Fromentin G, Tome D, Even P: Postprandial nutrient partitioning but not energy expenditure is modified in growing rats during adaptation to a high-protein diet. J Nutr 2010;140:939-945

33. Trapp CB, Barnard ND: Usefulness of vegetarian and vegan diets for treating type 2 diabetes. Curr Diab Rep 2010;10:152-158

34. Claessens $M$, Calame W, Siemensma AD, van Baak MA, Saris WH: The effect of different protein hydrolysate/carbohydrate mixtures on postprandial glucagon and insulin responses in healthy subjects. European journal of clinical nutrition 2009;63:4856

35. Cope MB, Erdman JW, Jr., Allison DB: The potential role of soyfoods in weight and adiposity reduction: an evidence-based review. Obes Rev 2008;9:219-235

36. Brand-Miller JC, Holt SH, Pawlak DB, McMillan J: Glycemic index and obesity. Am J Clin Nutr 2002;76:281S-285S

37. Aston LM, Laccetti R, Mander AP, Hall R, Moore CS, Jebb SA: No difference in the 24-hour interstitial fluid glucose profile with modulations to the glycemic index of the diet. Nutrition 2010;26:290-295

38. Flint A, Moller BK, Raben A, Pedersen D, Tetens I, Holst JJ, Astrup A: The use of glycaemic index tables to predict glycaemic index of composite breakfast meals. The British journal of nutrition 2004;91:979-989 



\section{CHAPTER 5}

Effects of meal frequency on metabolic profiles and substrate partitioning in lean healthy males

MJM Munsters, WHM Saris

PloSOne. 2012;7(6):e38632 


\section{Chapter 5}

\section{ABSTRACT}

Introduction: The daily number of meals has an effect on postprandial glucose and insulin responses, which may affect substrate partitioning and thus weight control. This study investigated the effects of meal frequency on $24 \mathrm{~h}$ profiles of metabolic markers and substrate partitioning.

Methods: Twelve (BMI: $21.6 \pm 0.6 \mathrm{~kg} / \mathrm{m}^{2}$ ) healthy male subjects stayed after 3 days of food intake and physical activity standardization $2 \times 36$ hours in a respiration chamber to measure substrate partitioning. All subjects randomly received two isoenergetic diets with a Low meal Frequency $(3 \mathrm{x} ; \mathrm{LFr})$ or a High meal Frequency $(14 \mathrm{x} ; \mathrm{HFr})$ consisting of 15 En\% protein, 30 En\% fat, and 55 En\% carbohydrates. Blood was sampled at fixed time points during the day to measure metabolic markers and satiety hormones.

Results: Glucose and insulin profiles showed greater fluctuations, but a lower AUC of glucose in the LFr diet compared with the HFr diet. No differences between the frequency diets were observed on fat and carbohydrate oxidation. Though, protein oxidation and RMR (in this case SMR + DIT) were significantly increased in the LFr diet compared with the HFr diet. The LFr diet increased satiety and reduced hunger ratings compared with the HFr diet during the day.

Conclusion: The higher rise and subsequently fall of insulin in the LFr diet did not lead to a higher fat oxidation as hypothesized. The LFr diet decreased glucose levels throughout the day (AUC) indicating glycemic improvements. RMR and appetite control increased in the LFr diet, which can be relevant for body weight control on the long term. 


\section{INTRODUCTION}

The escalating obesity trend in man is due to an imbalance between energy intake and energy expenditure. Energy intake is influenced by the effect of food's energy density, total energy content and meal frequency and the extent to which these alter satiety. Of these factors, meal frequency has received least attention (1).

Epidemiological evidence indicates increasing trends in recent years of dietary snacking and increased meal frequency $(2 ; 3)$. The current literature is mixed with regard to the efficacy of increased meal frequency (or snacking) regimens in causing metabolic alterations, particularly in relation to weight management (1). Increasing eating frequency has been postulated to increase metabolism, reduce hunger and food cravings (better appetite control), improve glucose and insulin control, and reduce body weight and body fat storage (4). However, there are suggestions from experimental studies to date as well as from cross-sectional epidemiological studies, in which energy intake underreporting is taken into account, that greater eating frequency (snacking) may promote positive energy balance in free-living adults $(5 ; 6)$. On the other hand, well-controlled intervention studies do not support an association between eating frequency and body weight $(6 ; 7)$.

Eating three meals a day is suggested to result in a higher postprandial insulin peak due to the higher carbohydrate $(\mathrm{CHO})$ intake and thereby increasing cellular glucose uptake and oxidation. As a consequence, dietary fat is primarily stored in the adipose tissue (insulin stimulated activation of lipo-protein lipase) during the postprandial phase. In between meals, the fasting state, when insulin levels are decreased and lipolysis is activated this substrate flux is reversed $(8 ; 9)$.

Given the inconclusive evidence in the literature regarding meal frequency and its metabolic implications, very well-controlled trials are necessary to resolve speculation that the current increase in snacking habits contribute by its metabolic changes during the day to the escalating obesity epidemic. For that reason, the aim of the present study was to investigate the mechanistic effects of meal frequency on $24 \mathrm{~h}$ insulin, glucose profiles, appetite profiles and substrate partitioning under well-controlled energy balance conditions. We hypothesized that in an energy balanced situation eating 3 meals a day gives better opportunities to turn the metabolic flux into a prolonged fasting state with a higher fat oxidation compared to eating 14 meals a day where subjects remain in a continuous postprandial status. 


\section{MATERIALS AND METHODS}

\section{Study population}

The study was conducted between $21^{\text {th }}$ October 2009 and $19^{\text {th }}$ March 2010 on 12 adults. Subjects were recruited by advertisements at local educational institutions. All subjects were healthy as assessed by a medical history questionnaire, blood pressure measurement and an Oral Glucose Tolerance Test (OGTT). Subjects had to be weight stable over the past 3 months. Exclusion criteria were: $\mathrm{BMI}>25 \mathrm{~kg} / \mathrm{m}^{2}$; metabolic abnormalities and excess alcohol intake (> 28 drinks weekly). Given that energy expenditure declines with increasing age, a maximal age of 40 years was set to form a homogeneous adult group. Only males were included to avoid menstrual cycle effects on energy expenditure. In addition, only males of European descent were included for homogeneity reasons. This study was conducted according to the guidelines laid down in the Declaration of Helsinki (10). The Medical Ethical Committee of the University Hospital Maastricht approved all procedures involving human subjects. Written informed consent was obtained from all subjects.

\section{Screening}

All subjects performed an OGTT before inclusion. Subjects came to university in the morning after an overnight fast. A catheter was placed into an antecubital vein and a fasting blood sample was taken. Next a bolus of $75 \mathrm{~g}$ glucose (dissolved in $250 \mathrm{ml}$ water) was ingested ( $\mathrm{T}=0 \mathrm{~min}$ ). Blood was sampled every 30 minutes until $\mathrm{T}=120 \mathrm{~min}$. Plasma glucose levels were measured to determine glucose tolerance. In addition, plasma glucose and insulin levels were used to assess insulin sensitivity using the oral glucose insulin sensitivity (OGIS)-index for a $2 \mathrm{~h}$ OGTT as described by Mari et al (11). Insulin sensitivity in the basal state was determined by the homeostasis model assessment insulin resistant $\left(\mathrm{HOMA}_{\mathrm{R}}\right)(12)$.

\section{Study design}

This study had a randomized, 2-way crossover design with a wash-out period of at least one week to avoid interaction between the two interventions. Each intervention lasted 36 hours in the respiration chamber (13). All subjects randomly received the same diet with a Low meal Frequency (3x; LFr) or a High meal Frequency (14x; HFr) with a constant macronutrient composition of 15 energy\% (En\%) dairy protein, $30 \mathrm{En \%}$ fat, and 55 En\% carbohydrates in each meal. The protein consisted of $70 \%$ dairy protein and $30 \%$ vegetable protein. The diet was composed of LU cracottes natural (210 g), milk (semi-skimmed; $1540 \mathrm{ml}$ ), yoghurt drink (Vifit natural; $200 \mathrm{ml}$ ), melon (1500 g), tomato $(640 \mathrm{~g})$ and olive oil $(47 \mathrm{ml})$ for a $2400 \mathrm{kcal}$ diet. The LFr diet consisted 
of breakfast at $08.00 \mathrm{~h}$, lunch at $12.00 \mathrm{~h}$, and dinner at $17.00 \mathrm{~h}$. In the HFr diet meals were consumed every hour from $08.00 \mathrm{~h}$ until $21.00 \mathrm{~h}$. The choice of 14 meals was made to ensure that subjects were in a continuous postprandial status and in the range of the published high meal frequencies studies (1); six to seventeen.

Subjects were allowed to consume water and tea after $18.00 \mathrm{~h}$ ad libitum, because after that time point no VAS questionnaires had to be completed. Subjects were fed isoenergetic based on the individual energy requirements. For measurement and calculation see description respiration chambers. Subjects standardized their food intake and activity for 3 days before each test to have the same baseline condition. Food-intake and activity diaries had to be filled out before the first test and subjects were instructed to follow the same regime preceding the second test.

Subjects entered the respiration chamber at $20.00 \mathrm{~h}$ and finished the intervention $36 \mathrm{~h}$ later at $8.00 \mathrm{~h}$. Physical activity was prescribed by means of a standardized physical activity protocol, three times of stepping (15 minutes). It was carefully controlled that subjects were fed in energy balance, which was based on individually measured and calculated requirements. During the first night in the respiration chamber the sleeping metabolic (SMR) rate was assessed. The SMR is defined as the lowest energy expenditure (measured in $\mathbf{3 0}$ minutes intervals) over three consecutive sleeping hours. Based on the SMR (multiplied with a physical activity index (PAI) of 1.55), the total daily energy expenditure (EE) was estimated (14). This level of EE was used subsequently as energy intake level for both $24 \mathrm{~h}$ intervention days in the respiration chamber.

\section{CGMS}

Each respiration chamber visit started after placement of a MiniMed sensor and MiniMed Continuous Glucose Monitoring System Gold (CGMS ${ }^{\mathrm{TM}}$ ) to measure subcutaneous interstitial fluid glucose levels over $36 \mathrm{~h}$ (Medtronic Minimed, Northridge, USA). The glucose monitor sampled the signals once every 10 seconds and recorded an average signal every five minutes, providing as many as 288 Sensor readings in a $24 \mathrm{~h}$ period. The monitor was calibrated with four separate capillary finger prick glucose readings using a glucose meter (Glucocard Memory PC; A. Menarini Diagnostics, Florence, Italy). Although the sensors recorded data for $36 \mathrm{~h}$, only the last $24 \mathrm{~h}$ data (monitored between 08.00 hours on day 2 and 08.00 hours on day 3) were used for analysis. Continuous overall net glycemic action (CONGA), a novel method described by McDonnell et al (15), was used to assess intra-day glycemic variability. CONGAn was defined as the standard deviation of the differences in glucose concentration between current observation and the observation $n$ hours previous. CONGA1, CONGA2, and CONGA4, were calculated indicating intra-day glycemic variability based on $1 \mathrm{~h}, 2 \mathrm{~h}$ and $4 \mathrm{~h}$ time periods. Higher CONGA values indicate 
greater glycemic variation, values above 1.5 indicate glycemic lability (15). The coefficient of variability (CV) is defined as the SD divided by the mean of the glucose values (16).

\section{Blood Sampling}

In the morning, while staying in the chamber, a catheter was placed into an antecubital vein using an airtight sleeve for the withdrawal of blood. Blood was sampled just before ingestion of the first meal (baseline), 30 minutes postprandially, and subsequently every hour until $21.30 \mathrm{~h}$ for the determination of plasma levels of insulin, glucose, free fatty acids (FFA), and triglycerides (TG). At $T=0$ (baseline $08.00 \mathrm{~h}$ ), and 60 minutes postprandially after consumption of the three experimental meals satiety related hormones glucagon-like peptide-1 (GLP-1) active, and ghrelin-active were sampled. Adiponectin levels were sampled at $\mathrm{T}=0$, before lunch $(11.30 \mathrm{~h})$ and at the last blood sampling that day $(21.30 \mathrm{~h})$. The next morning at $08.00 \mathrm{~h}(\mathrm{~T}=24)$, before subjects left the respiration chamber, fasting blood samples were taken to assess all the markers mentioned above. Blood was collected in standard $10 \mathrm{ml}$ ice-cooled vacutainer blood collection tubes containing EDTA to prevent clotting. Plasma was obtained by low-speed centrifugation within one hour after blood sampling, frozen in liquid nitrogen, and stored at $-80{ }^{\circ} \mathrm{C}$ until further analysis. Phenylmethylsofonyl fluoride was added to the active ghrelin plasma samples. For GLP-1 active measurements blood was mixed with $60 \mu$ dipeptidyl peptidase IV inhibitor (DPP-IV) (Linco Research Inc., St Charles, Missouri, USA). Plasma insulin, active ghrelin, adiponectin, GLP-1 active concentrations were measured by radioimmunoassay (Millipore, Billerica, MA, U.S.A). Plasma glucose, FFA, and TG concentrations were measured with the use of an enzymatic colorimetric method on a CobasFara spectrophotometer (Roche Diagnostica, Basel, Switzerland).

\section{Visual analogue scales}

Appetite profiles were measured using anchored 100-mm visual analogue scales (VAS) with words at each end that expressed the most extreme rating to measure hunger, fullness, satiety, thirst, and prospective food consumption (17). Subjects completed these questionnaires just before, 30 , and 60 minutes after consumption of the three experimental meals in the LFr diet, and the next morning at $08.00 \mathrm{~h}$. At the similar time points, questionnaires were completed in the HFr diet.

\section{Indirect calorimetry}

The respiration chamber is a $14 \mathrm{~m}^{3}$ room and is furnished with a bed, chair, table, television, radio, telephone, computer, wash-bowl, intercom, and a deep-freeze toilet. 
Air locks are used for exchange of food and urine. EE was determined from the measurements of $\mathrm{O}_{2}$ consumption, $\mathrm{CO}_{2}$ production, and urine nitrogen excretion according to Brouwer (18). The chamber is ventilated with fresh air at a rate of $70-80$ $1 /$ min. The ventilation rate was measured with a dry gas meter (type 4; Schlumberger; Dordrecht, The Netherlands). The concentrations of $\mathrm{O}_{2}$ and $\mathrm{CO}_{2}$ were measured using a paramagnetic $\mathrm{O}_{2}$ analyser (OA184A; Servomex, Crowborough, UK) and an infrared $\mathrm{CO}_{2}$ analyzer (Uras 3G; Hartmann \& Braun, Frankfurt am Main, Germany). Ingoing air was analysed one every 15 minutes and outgoing air once every 5 minutes. The gas sample to be measured was selected by a computer, which also stored and processed the data. Physical activity was monitored using a radar system, which is based on the Doppler principle. $24 \mathrm{~h}$ urine samples were collected in containers with $10 \mathrm{ml} \mathrm{HCL}$ to prevent nitrogen loss by evaporation. The $24 \mathrm{~h}$ urine nitrogen concentration was used to calculate total daily nitrogen excretion, which was measured with a nitrogen analyzer (CHN-O-Rapid; Heraeus, Hanau, Germany). 24 h EE was calculated from 08.00 hours (first morning) to 08.00 hours (second morning). Diet induced thermogenesis (DIT) was calculated by plotting EE against radar output; both averaged over 30 minutes periods. The radar output during stepping has been excluded, because it is not reliable measurement for the $24 \mathrm{~h}$ EE components calculation. The intercept of the regression line at the lowest radar output represents the $E E$ in the inactive state (resting metabolic rate; RMR), consisting of DIT and SMR. DIT was determined by subtracting SMR from RMR. Activity-induced EE was determined by subtracting SMR and DIT from $24 \mathrm{~h}$ EE. PAI was calculated by dividing $24 \mathrm{~h}$ EE by SMR (19; 20).

\section{Body composition}

In the fasted state, body density was determined by underwater weighing for baseline characteristics. Lung volume was measured simultaneously using the helium dilution technique. Body weight was determined on a digital balance, accurate to $0.001 \mathrm{~kg}$ (IDI plus; Mettler Toledo, Tiel, the Netherlands). Under water, body weight was measured using a digital balance, accurate to $0.01 \mathrm{~kg}$ (EC240; Mettler Toledo, Tiel, the Netherlands). Lung volume was measured using a spirometer (Volugraph 2000; Mijnhardt, Bunnik, the Netherlands). Body fat percentage was calculated using the equation of Siri (21).

\section{Statistical analyses}

SPSS software (version 15 for windows; SPSS) was used for data entry and analysis. All data is reported as means \pm standard error mean (SEM). Homogeneity of the data was checked with the Kolmogorov-Smirnov test, In transformation was applied when data were not normally distributed. CGMS and EE data were calculated per 24 hour, during the day $(8 \mathrm{am}-23 \mathrm{pm})$ and during the night ( $23 \mathrm{pm}-8 \mathrm{am})$. CGMS data, EE, substrate 
partitioning, and (net incremental) area under the curves ((net i)AUCs) calculated using the trapezoid method, were compared between the two intervention diets with a paired t-test. Mixed-model ANOVA (22) was used to compare the intervention diets at the different time points for VAS scales and the metabolic markers. Outcomes were corrected for multiple testing. Statistical significance was set at $p<0.05$.

Table 1. Subject characteristics at baseline.

\begin{tabular}{|c|c|}
\hline Subject characteristics & Group ( $n=12)$ \\
\hline Age (yrs) & $23 \pm 1.2(18-31)$ \\
\hline $\mathrm{BMI}\left(\mathrm{kg} / \mathrm{m}^{2}\right)$ & $21.6 \pm 0.6(19.1-24.6)$ \\
\hline Fat free mass (kg) & $62.1 \pm 1.3(52.1-67.8)$ \\
\hline Body fat (\%) & $14.1 \pm 1.4(5.1-21.6)$ \\
\hline Systolic blood pressure (mm/Hg) & $114 \pm 2.9(98-133)$ \\
\hline Diastolic blood pressure $(\mathrm{mm} / \mathrm{Hg})$ & $69 \pm 2.3(59-83)$ \\
\hline Fasting glucose level (mmol/L) & $5.2 \pm 0.1(4.8-5.7)$ \\
\hline $2 \mathrm{~h}$ glucose level after OGTT ( $\mathrm{mmol} / \mathrm{L})$ & $4.1 \pm 0.3(3.2-7.1)$ \\
\hline Fasting insulin level (mU/L) & $13.4 \pm 2.9(5.9-44.6)$ \\
\hline $\mathrm{OGIS}_{120}\left(\mathrm{ml} / \mathrm{min} / \mathrm{m}^{2}\right)$ & $455.1 \pm 8.5(396-495)$ \\
\hline $\mathrm{HOMA}_{\mathrm{IR}}$ & $2.4 \pm 0.7(1.3-11.2)$ \\
\hline
\end{tabular}

Values are expressed as mean \pm SEM.

\section{RESULTS}

\section{Subject characteristics}

Twelve healthy non-smoking men aged $23 \pm 1.2 \mathrm{y}$, with a mean body mass index (BMI) of $21.6 \pm 0.6 \mathrm{~kg} / \mathrm{m}^{2}$ and with a mean percentage body fat of $14.1 \pm 1.4 \%$ participated in this study. Subject characteristics at baseline are shown in Table 1.

\section{Energy expenditure and substrate partitioning}

Energy intake was similar by design in both intervention diets $(12.0 \pm 0.3 \mathrm{MJ} / \mathrm{d})$ (Table 2). Total energy expenditure (TEE) and energy balance were not significantly different between both diets. The LFr diet showed a significantly higher RMR (in this case SMR + DIT) compared with the HFr diet ( $8.5 \pm 0.3$ vs. $8.0 \pm 0.2 \mathrm{MJ} / \mathrm{d}$ respectively). SMR and DIT ( $p=0.094$ ) tended to be increased (NS) in the LFr diet. No effect on $24 \mathrm{~h}$ AEE, PAL and $\mathrm{RQ}$ was observed between the intervention diets. Protein oxidation significantly increased in the LFr diet during the day and total $24 \mathrm{~h}(106.9 \pm 7.1 \mathrm{vs} .90 .6 \pm 4.3 \mathrm{~g} / \mathrm{d})$. No significant differences in $24 \mathrm{~h}$, day and night $\mathrm{CHO}$ and fat oxidation were found. 
Table 2. $24 \mathrm{~h}$ total energy intake and expenditure, components of energy expenditure and substrate partitioning, according to Low or High Frequency (LFr and HFr diet resp.) diet.

\begin{tabular}{llll}
\hline & LFr diet & HFr diet & p-value \\
\hline El (MJ/d) & $12.0 \pm 0.3$ & $12.0 \pm 0.3$ & - \\
TEE (MJ/d) & $12.3 \pm 0.3$ & $12.1 \pm 0.3$ & 0.122 \\
EB (MJ/d) & $-0.4 \pm 0.2$ & $-0.1 \pm 0.1$ & 0.116 \\
RMR (MJ/d) & $8.5 \pm 0.3$ & $8.0 \pm 0.2^{*}$ & 0.006 \\
SMR (MJ/d) & $7.2 \pm 0.2$ & $7.0 \pm 0.2$ & 0.154 \\
DIT (MJ/d) & $1.3 \pm 0.1$ & $1.0 \pm 0.1$ & 0.094 \\
AEE (MJ/d) & $3.8 \pm 0.2$ & $4.1 \pm 0.2$ & 0.238 \\
PAI & $1.72 \pm 0.03$ & $1.73 \pm 0.03$ & 0.570 \\
RQ & $0.91 \pm 0.01$ & $0.91 \pm 0.01$ & 0.658 \\
Protein oxidation (g/d) & $106.9 \pm 7.1$ & $90.6 \pm 4.3 *$ & 0.021 \\
Carbohydrate oxidation (g/d) & $455.5 . \pm 16.3$ & $456.8 \pm 17.4$ & 0.946 \\
Fat oxidation (g/d) & $61.9 \pm 5.2$ & $64.6 \pm 4.6$ & 0.647
\end{tabular}

El: energy intake. TEE: total energy expenditure. RMR: resting metabolic rate. DIT: diet induced thermogenesis. AEE: activity-induced energy expenditure. PAl: physical activity index. RQ: respiratory quotient. Values are expressed as mean $\pm \mathrm{SEM}$. ${ }^{*} \mathrm{P}<0.05$ compared with the LFr diet. P-values were derived by paired t-test analysis and denote the overall significance of differences among the two diets.

\section{Metabolic markers measured at fixed time points}

The LFr diet showed significantly higher peaks and lower troughs for glucose and insulin levels compared with the HFr diet during the day (Fig. 1). The AUC of $24 \mathrm{~h}$ glucose was significantly lower in the LFr diet $(7276.1 \pm 149.8 \mathrm{mmol} / \mathrm{L})$ compared with the HFr diet (7664.6 $\pm 184.5 \mathrm{mmol} / \mathrm{L})$, although the AUC of insulin was not significantly different between the two diets. In general, there was a tendency for higher FFA levels in the LFr diet, in particular after dinner compared with the HFr diet (Fig. 1). TG profiles were significantly higher after lunch in the LFr diet, however TG levels were significantly higher in the evening in the HFr diet. GLP-1 active and adiponectin levels showed no significant differences between the intervention diets, but overall levels tended to be higher in LFr diet (Fig. 2). The LFr diet significantly decreased ghrelinactive levels one hour after breakfast, and showed the same trend throughout the day in the LFr diet. 

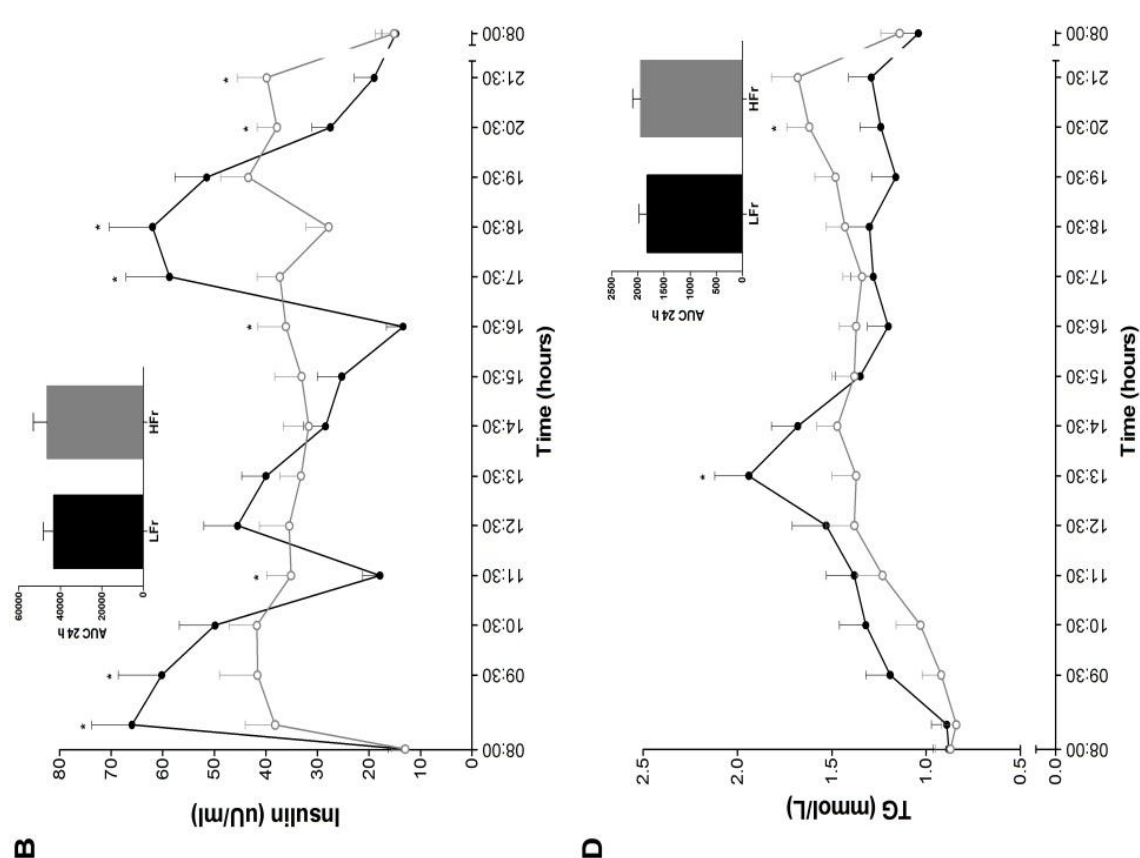

ì

药

올

$\checkmark+1$

*

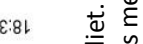

के

Q:L $\quad \frac{\bar{\sigma}}{0}$

of:9l की

\&:gl

act

든

空

ㄷํㅇ

व

$m$

口

立 志

는

芒

웡. 월

实 $\frac{\pi}{0}$

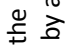

눙 웅

Чั๊

这遂
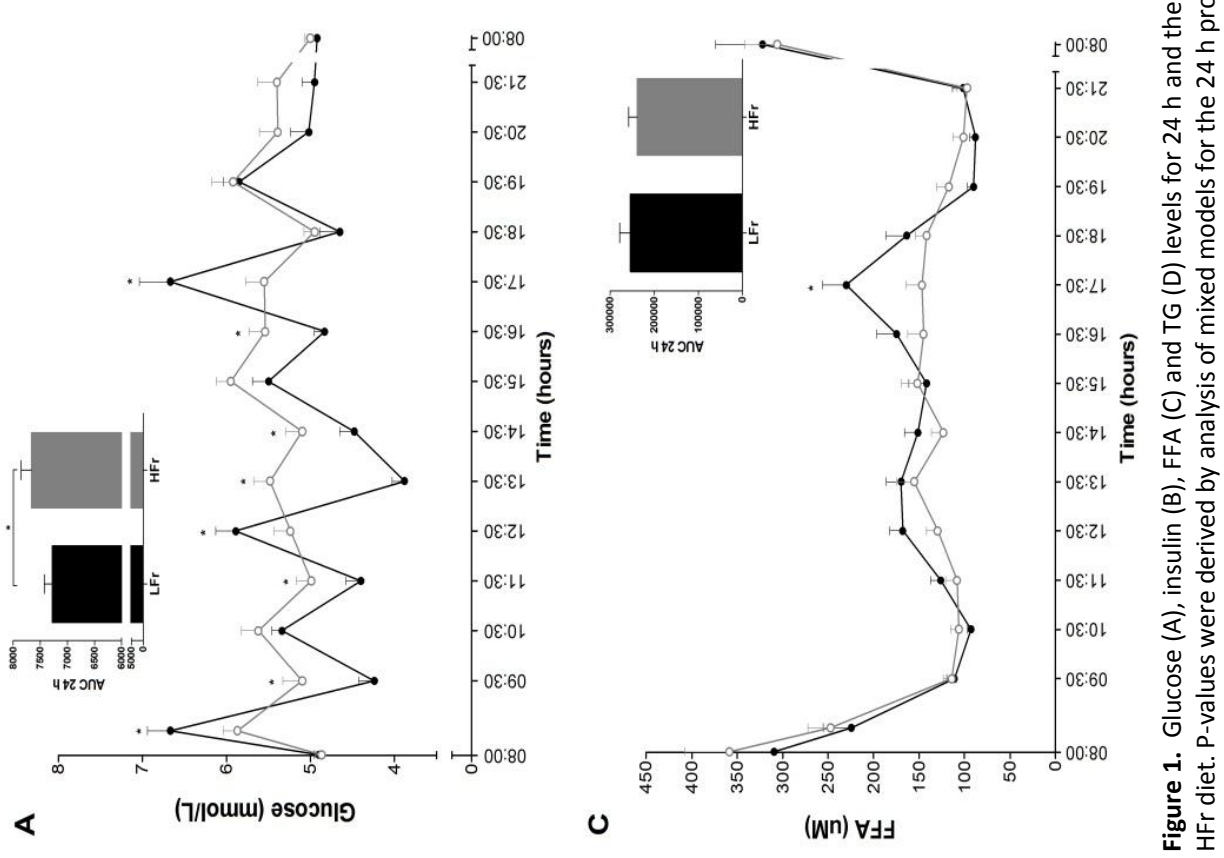
A

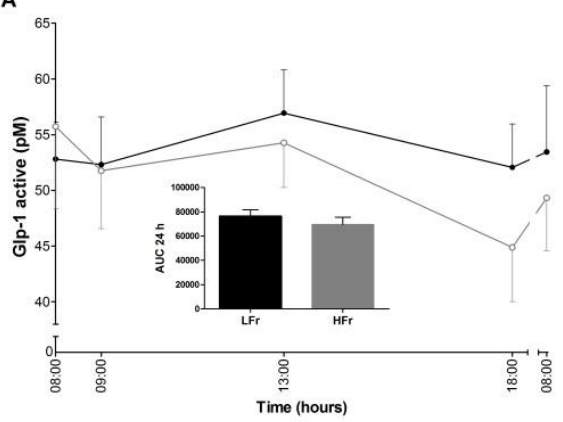

C

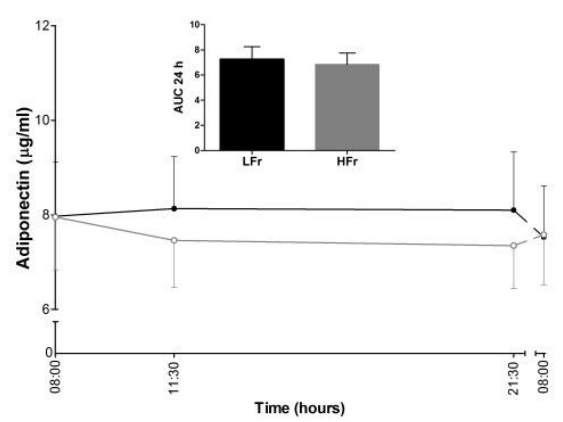

B

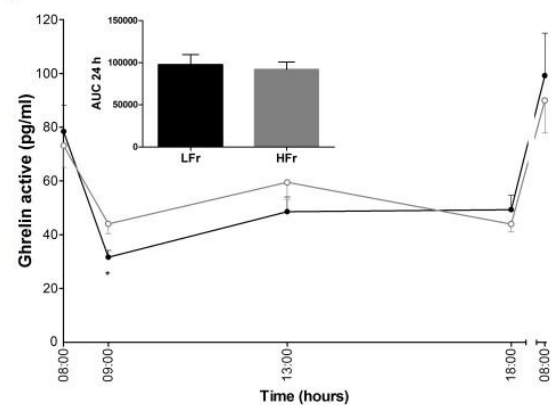

Figure 2. GLP-1 active (A), ghrelin-active (B) and adiponectin (C) levels for $24 \mathrm{~h}$ and the AUCs of the LFr (dense black circle) and $\mathrm{HFr}$ (open gray circle) diet. ${ }^{*} \mathrm{P}<0.05 \mathrm{LFr}$ vs. HFr diet. P-values were derived by analysis of mixed models for the $24 \mathrm{~h}$ profiles and by a paired t-test for the AUCs. Values are expressed as mean \pm SEM.

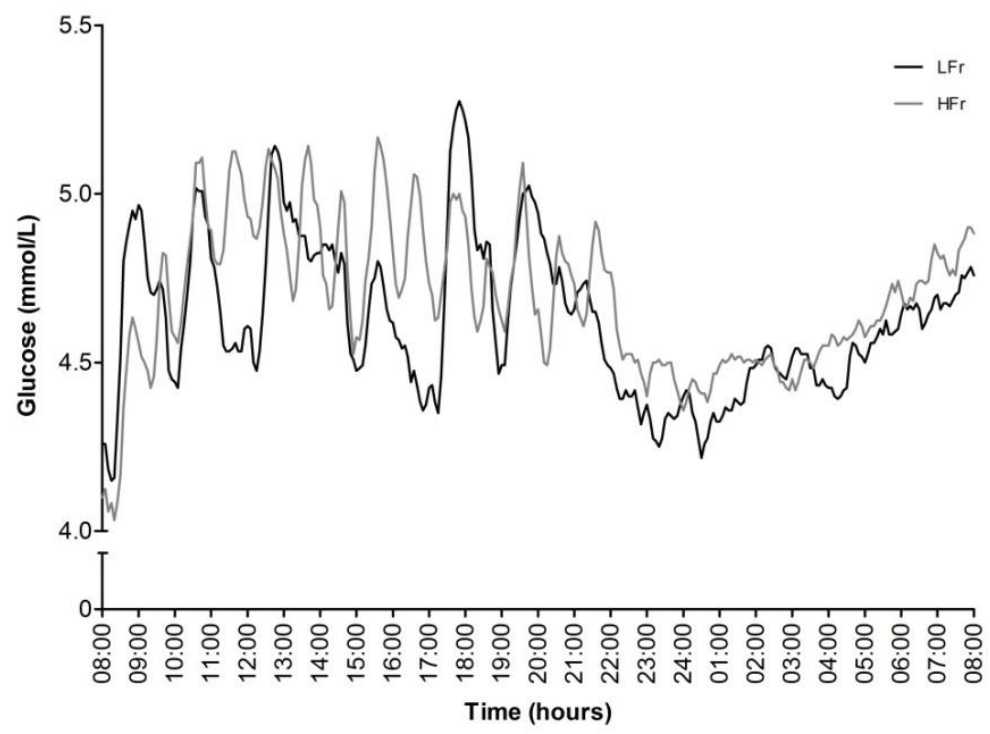

Figure 3. CGMS glucose levels for $24 \mathrm{~h}$ in the LFr and HFr diet. Values are expressed as mean. 


\section{CGMS}

Complete CGMS data of twelve subjects was obtained. Mean, maximum, minimum glucose concentration, and the (net i)AUCs were calculated per diet per 24 hour from the CGMS data, during the day and night and showed no significant differences between the two interventions (Table 3). Nevertheless, the CGMS data clearly showed the different glycemic patterns of the two meal frequency diets (Fig. 3). Glycemic variability (conga 1,2,4 and CV) did not change between both intervention diets (table 3 ). The correlation between the CGMS data and glucose data was significant in the LFr $\operatorname{diet}\left(R^{2}=0.333 ; p=0.05\right)$, and not in the HFr diet.

Table 3. Analyses of the CGMS data compared between the two intervention diets $(n=12)$.

\begin{tabular}{llll}
\hline & LFr diet & HFr diet & p-value \\
\hline Mean 24 h (mmol/L) & $4.6 \pm 0.1$ & $4.7 \pm 0.2$ & 0.614 \\
Min 24 h (mmol/L) & $3.7 \pm 0.2$ & $3.6 \pm 0.2$ & 0.711 \\
Max 24 h (mmol/L) & $5.6 \pm 0.2$ & $5.6 \pm 0.2$ & 0.906 \\
Mean 8-23h (mmol/L) & $4.7 \pm 0.1$ & $4.8 \pm 0.2$ & 0.648 \\
Min 8-23h (mmol/L) & $3.8 \pm 0.2$ & $3.7 \pm 0.2$ & 0.782 \\
Max 8-23h (mmol/L) & $5.6 \pm 0.2$ & $5.6 \pm 0.2$ & 0.806 \\
Mean 23-8h (mmol/L) & $4.5 \pm 0.2$ & $4.6 \pm 0.1$ & 0.587 \\
Min 23-8h (mmol/L) & $4.0 \pm 0.2$ & $4.0 \pm 0.2$ & 0.810 \\
Max 23-8h (mmol/L) & $4.9 \pm 0.2$ & $5.2 \pm 0.2$ & 0.249 \\
AUC 24 h & $6657.3 \pm 198.7$ & $6759.1 \pm 218.5$ & 0.601 \\
AUC 8-23h & $4230.7 \pm 118.3$ & $4288.8 \pm 149.1$ & 0.646 \\
AUC 23-8h & $2448.1 \pm 93.3$ & $2492.3 \pm 74.9$ & 0.584 \\
net iAUC 24 h & $525.3 \pm 242.3$ & $855.1 \pm 223.3$ & 0.191 \\
net iAUC 8-23h & $398.3 \pm 130.1$ & $598.8 \pm 131.6$ & 0.163 \\
net iAUC 23-8h & $108.1 \pm 64.3$ & $80.3 \pm 79.5$ & 0.777 \\
CONGA1 & $0.43 \pm 0.05$ & $0.34 \pm 0.02$ & 0.158 \\
CONGA2 & $0.45 \pm 0.06$ & $0.39 \pm 0.02$ & 0.634 \\
CONGA4 & $0.53 \pm 0.07$ & $0.46 \pm 0.03$ & 0.565 \\
CV & $0.09 \pm 0.01$ & $0.08 \pm 0.01$ & 0.999 \\
\hline Mn: minma & 4.03
\end{tabular}

Min: minimal glucose level. Max: maximal glucose level. AUC: area under the curve. netiAUC: net incremental area under the curve. CONGA1,2,4: continuous overall net glycemic action describing intra-day glycemic variability between respectively 1,2 and $4 \mathrm{~h}$ time periods over $24 \mathrm{~h}$. CV: coefficient of variability. Values are expressed as mean \pm SEM. ${ }^{*} \mathrm{P}<0.05$ compared with the LFr diet. P-values were derived by paired t-test analysis and denote the overall significance of differences among the two diets. 


\section{Appetite measurements}

At fixed time points throughout the day hunger, prospective food consumption and thirst ratings significantly reduced, and satiety and fullness ratings significantly increased in the LFr diet compared with the HFr diet (Fig. 4, graphs of prospective food consumption, thirst and fullness were not shown because of the same trend). The AUCs of all appetite measurements were significantly different between the two diets (only shown for hunger and satiety).
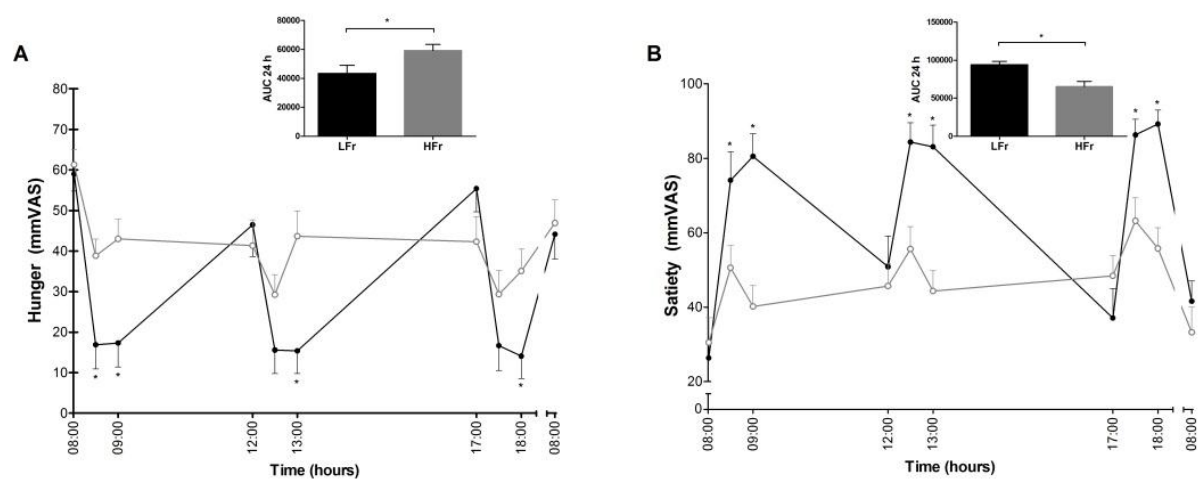

Figure 4. Hunger (A), and satiety (B) levels for $24 \mathrm{~h}$ and the AUCs of the LFr (dense black circle) and HFr (open gray circle) diet. ${ }^{*} \mathrm{P}<0.05 \mathrm{LFr}$ vs. HFr diet. P-values were derived by analysis of mixed models for the $24 \mathrm{~h}$ profiles and by a paired t-test for the AUCs. Values are expressed as mean $\pm \mathrm{SEM}$.

\section{DISCUSSION}

Increasing meal frequency resulted in significantly lower peaks, higher troughs and constant glucose (higher AUC) and insulin values compared with the LFr diet under isoenergetic well-controlled conditions in lean healthy males. Nevertheless, no effect of meal frequency was observed on substrate partitioning of $\mathrm{CHO}$ and fat. Protein oxidation, RMR (in this case SMR + DIT) and appetite control increased significantly in the LFr diet compared with the HFr diet.

Our results are in accordance with findings from Solomon et al. (1), who found that 2 meals per day led to greater fluctuations in glucose, insulin, and ghrelin responses (i.e. greater peaks and lower troughs) compared with the 12 meals per day assessed throughout an 8-h period. Nevertheless, the lower AUC of glucose in the LFr indicates glycemic improvements, we suggest that this can lead to a better body weight control on the long term.

The CGMS data showed the glycemic excursions and clearly indicated the differences between the two diets during the day. However, baseline values are somewhat lower than the glucose levels measured at the fixed time points. The accuracy of the sensor has been discussed and discrepancies occasionally were seen between interstitial 
tissue and blood glucose levels in detecting low glucose values. Therefore, the CGMS is a good method to assess patterns of glycemic excursions and not the absolute degree of glycemic excursions (15).

The higher rise and subsequently fall of insulin in the LFr diet was suggested to result in a higher fat oxidation, which was not observed in this study. These findings are in line with a review by Bellisle (23) and a recent review by Leidy et al(4), who discussed eating frequency and energy regulation in controlled feeding studies. Those reviews also indicated that eating frequency appears to have no effect on energy expenditure. Another explanation might be that the insulin levels did not increase high enough to inhibit fat oxidation in the HFr diet. Maybe a certain threshold has to be reached before substantial inhibition will occur. The half-maximal suppression of lipolysis is seen at around $120 \mathrm{pmol} / \mathrm{l}(17 \mu \mathrm{U} / \mathrm{ml})$ of insulin, and at the peak of insulin after a typical carbohydrate breakfast (400-500 pmol/l; 57-72 $\mu \mathrm{U} / \mathrm{ml})$, adipocytes lipolysis will be maximally suppressed (24). In addition, Mandarino et al. demonstrated with euglycemic insulin infusions that basal rates of FFA and fat oxidation were suppressed by $70-80 \%$ at an insulin level of $20-25 \mu \mathrm{U} / \mathrm{ml}$ and were essentially completely suppressed at insulin concentrations $>50 \mu \mathrm{U} / \mathrm{ml}$ (25). Our data showed insulin levels between 30 and $40 \mu \mathrm{U} / \mathrm{ml}$ in the $\mathrm{HFr}$ diet, which suggests that the threshold for maximal suppression of lipolysis was not reached in these subjects.

Protein oxidation increased significantly in the LFr diet, which could be explained by body's limited capacity to store protein. The larger portion size and thus absolute amount of protein intake at each meal in the LFr diet resulted consequently in a higher protein oxidation. We speculate that the lower protein oxidation in the HFr diet might be a relevant dietary strategy in elderly to increase daily protein uptake and preserve lean tissue, because aging is accompanied by a progressive decline in skeletal muscle mass, also known as sarcopenia (26). Additionally, it is suggested that the postprandial rise in plasma essential amino acids concentration, particularly leucine, defines the subsequent postprandial rate of muscle protein synthesis (27). Nevertheless, observed changes in protein metabolism on whole-body level do not necessarily represent changes on muscle level (28). Therefore, more research is necessary to investigate effects of different meal frequencies in elderly and in particular on muscle protein synthesis.

The trend of a higher DIT $(p=0.094)$ and SMR in the LFr diet is translated into a significantly higher RMR. This is a relevant observation because a low RMR is considered a risk factor for weight gain leading to obesity (29). The higher RMR in the LFr diet might have been stimulated by a plasma insulin induced increase in the activity of the sympathetic nervous system $(30 ; 31)$. Other studies reported that no changes in RMR were observed as a result of increased meal frequency $(32 ; 33)$. However, these studies investigated meal frequency at a range of 2 vs. 7, and our study investigated meal frequency at a larger range (3 vs. 14). 
Consuming the LFr diet resulted in increased feelings of satiety (AUC), and more inhibition of the satiety hormone ghrelin-active after breakfast and decreased feelings of hunger (AUC) throughout the day. Hence, we suggest that the LFr diet resulted in a better appetite control, although subsequent food intake (ad libitum meals) has not been measured in present study. Therefore, the results should be interpreted with caution. On the contrary, studies examining nibbling (small, frequent meals) compared to gorging (large, few meals) under isoenergetic conditions over a range of meal frequencies from 2 to 12 meals/d provided conflicting evidence, but over a narrower range suggest there may be some tendency for a 6-meals/d pattern to improve appetite control relative to a 3-meals/d pattern (34). A point to consider when interpreting the study findings includes the energy level of the study diets (varied from energy restriction to isoenergetic) and resulting meal portions. The differential responses between smaller and larger eating occasions may simply be due to the inability of the body to detect the size of a smaller eating occasion as an adequate physiological load, reducing or eliminating the eating-related responses typically observed when larger eating occasions occur (4).

We designed this study to investigate different meal frequencies under isoenergetic well-controlled conditions, eliminating differences in energy balance as a confounding factor. Furthermore, potential interactions with factors such as dietary composition, food form, nutritional quality, and portion size served were also minimal in this study. A disadvantage of this study design is that the changes in feelings of hunger and satiety could not result in adjustments in subsequent energy intake since the diet was not ad libitum. Accordingly, it is difficult to generalize these metabolic results to a daily life setting. It is unclear what will happen when subjects consume meals with a higher frequency, have ad libitum access to food and how this would affect total energy intake. In addition, in our study a snack was chosen to represent a smaller-sized portion of a typical meal taken more frequently throughout the day. In a free-living situation snacks are generally high-sugar or high-fat foods (1) and therefore total energy intake probably will increase.

The subjects of our study were young and healthy, therefore they have a good capacity to switch between substrates, which indicate a high metabolic flexibility. However, when subjects are overweight, obese or have type 2 diabetes their metabolic flexibility is reduced. For that reason, subjects with metabolic inflexibility could have more difficulties handling a high meal frequency diet and this would be interesting to investigate in the future.

In conclusion, glucose and insulin profiles showed greater fluctuations, but a lower AUC of glucose in the LFr diet compared with the HFr diet. The higher peaks and subsequently lower troughs of insulin in the LFr diet did not lead to a higher fat oxidation as hypothesized. RMR and appetite control increased in the LFr diet, which can be relevant for body weight control on the long term. However, this was studied 


\section{Chapter 5}

for one day in young healthy males, which are very metabolic flexible. Therefore, populations at risk related to substrate partitioning and long-term effects have to be studied before firm conclusions can be made about the mechanistic effects of meal frequency on the metabolic profile and substrate partitioning.

\section{ACKNOWLEDGMENTS}

We would like to thank all the volunteers for their time and motivation and P. Schoffelen, L. Ronden, J. Stegen, H. Aydeniz, and W. Sluijsmans for their excellent technical or analytical support. Also, we would like to thank Veronique Hall for her contribution to the execution of the study.

\section{Author Contributions}

Conceived and designed the experiments: MM WS. Performed the experiments: MM. Analyzed the data: MM. Contributed reagents/materials/analysis tools: MM. Wrote the paper: MM WS. 


\section{REFERENCES}

1. Solomon TP, Chambers ES, Jeukendrup AE, Toogood AA, Blannin AK: The effect of feeding frequency on insulin and ghrelin responses in human subjects. The British journal of nutrition 2008;100:810-819

2. Samuelson G: Dietary habits and nutritional status in adolescents over Europe. An overview of current studies in the Nordic countries. European journal of clinical nutrition 2000;54 Suppl 1:S21-28

3. Berteus Forslund $H$, Torgerson JS, Sjostrom L, Lindroos AK: Snacking frequency in relation to energy intake and food choices in obese men and women compared to a reference population. Int J Obes (Lond) 2005;29:711-719

4. Leidy HJ, Campbell WW: The effect of eating frequency on appetite control and food intake: brief synopsis of controlled feeding studies. J Nutr 2011;141:154-157

5. Chapelot D: The role of snacking in energy balance: a biobehavioral approach. J Nutr 2011;141:158-162

6. McCrory MA, Howarth NC, Roberts SB, Huang TT: Eating frequency and energy regulation in free-living adults consuming self-selected diets. J Nutr 2011;141:148-153

7. Palmer MA, Capra S, Baines SK: Association between eating frequency, weight, and health. Nutrition reviews 2009;67:379-390

8. Miller WC, Lindeman AK, Wallace J, Niederpruem M: Diet composition, energy intake, and exercise in relation to body fat in men and women. Am J Clin Nutr 1990;52:426-430

9. Astrup A, Raben A: Carbohydrate and obesity. Int J Obes Relat Metab Disord 1995;19 Suppl 5:S27-37

10. Goodyear MD, Krleza-Jeric K, Lemmens T: The Declaration of Helsinki. BMJ 2007;335:624-625

11. Mari A, Pacini G, Murphy E, Ludvik B, Nolan JJ: A model-based method for assessing insulin sensitivity from the oral glucose tolerance test. Diabetes Care 2001;24:539-548

12. Matthews DR, Hosker JP, Rudenski AS, Naylor BA, Treacher DF, Turner RC: Homeostasis model assessment: insulin resistance and beta-cell function from fasting plasma glucose and insulin concentrations in man. Diabetologia 1985;28:412-419

13. Schoffelen PF, Westerterp KR, Saris WH, Ten Hoor F: A dual-respiration chamber system with automated calibration. J Appl Physiol 1997;83:2064-2072

14. Saris WH, Schrauwen P: Substrate oxidation differences between high- and lowintensity exercise are compensated over 24 hours in obese men. Int J Obes Relat Metab Disord 2004;28:759-765

15. McDonnell CM, Donath SM, Vidmar SI, Werther GA, Cameron FJ: A novel approach to continuous glucose analysis utilizing glycemic variation. Diabetes Technol Ther 2005; 7:253-263

16. Wentholt IM, Kulik W, Michels RP, Hoekstra JB, DeVries JH: Glucose fluctuations and activation of oxidative stress in patients with type 1 diabetes. Diabetologia 2008;51:183-190

17. Flint A, Raben A, Blundell JE, Astrup A: Reproducibility, power and validity of visual analogue scales in assessment of appetite sensations in single test meal studies. Int J Obes Relat Metab Disord 2000;24:38-48 
18. Brouwer E: On simple formulae for calculating the heat expenditure and the quantities of carbohydrate and fat oxidized in metabolism of men and animals, from gaseous exchange (Oxygen intake and carbonic acid output) and urine-N. Acta Physiol Pharmacol Neerl 1957;6:795-802

19. Ravussin E, Lillioja S, Anderson TE, Christin L, Bogardus C: Determinants of 24-hour energy expenditure in man. Methods and results using a respiratory chamber. The Journal of clinical investigation 1986;78:1568-1578

20. Westerterp KR, Wilson SA, Rolland V: Diet induced thermogenesis measured over $24 \mathrm{~h}$ in a respiration chamber: effect of diet composition. Int J Obes Relat Metab Disord 1999;23:287-292

21. Siri WE: The gross composition of the body. Adv Biol Med Phys 1956;4:239-280

22. McLean RA SW, Stroup WW: A Unified Approach to Mixed Linear Models. The American Statistican 1991;45:54-64

23. Bellisle F, McDevitt R, Prentice AM: Meal frequency and energy balance. The British journal of nutrition 1997;77 Suppl 1:S57-70

24. Frayn K: Metabolic regulation: a human perspective. Oxford, Wiley-Blackwell, 2010 25. Mandarino LJ, Wright KS, Verity LS, Nichols J, Bell JM, Kolterman OG, Beck-Nielsen $\mathrm{H}$ : Effects of insulin infusion on human skeletal muscle pyruvate dehydrogenase, phosphofructokinase, and glycogen synthase. Evidence for their role in oxidative and nonoxidative glucose metabolism. The Journal of clinical investigation 1987;80:655-663 26. Cruz-Jentoft AJ, Baeyens JP, Bauer JM, Boirie Y, Cederholm T, Landi F, Martin FC, Michel JP, Rolland Y, Schneider SM, Topinkova E, Vandewoude M, Zamboni M: Sarcopenia: European consensus on definition and diagnosis: Report of the European Working Group on Sarcopenia in Older People. Age Ageing 2010;39:412-423

27. Pennings B, Boirie $Y$, Senden JM, Gijsen AP, Kuipers H, van Loon LJ: Whey protein stimulates postprandial muscle protein accretion more effectively than do casein and casein hydrolysate in older men. Am J Clin Nutr 2011;93:997-1005

28. Nair KS, Halliday D, Griggs RC: Leucine incorporation into mixed skeletal muscle protein in humans. Am J Physiol 1988;254:E208-213

29. Ravussin E, Swinburn BA: Pathophysiology of obesity. Lancet 1992;340:404-408

30. Rowe JW, Young JB, Minaker KL, Stevens AL, Pallotta J, Landsberg L: Effect of insulin and glucose infusions on sympathetic nervous system activity in normal man. Diabetes 1981;30:219-225

31. Berne C, Fagius J, Pollare T, Hjemdahl P: The sympathetic response to euglycaemic hyperinsulinaemia. Evidence from microelectrode nerve recordings in healthy subjects. Diabetologia 1992;35:873-879

32. Verboeket-van de Venne WP, Westerterp KR: Influence of the feeding frequency on nutrient utilization in man: consequences for energy metabolism. European journal of clinical nutrition 1991;45:161-169

33. Taylor MA, Garrow JS: Compared with nibbling, neither gorging nor a morning fast affect short-term energy balance in obese patients in a chamber calorimeter. Int J Obes Relat Metab Disord 2001;25:519-528

34. McCrory MA, Campbell WW: Effects of eating frequency, snacking, and breakfast skipping on energy regulation: symposium overview. J Nutr 2011;141:144-147 


\section{CHAPTER 6}

A low meal frequency improved the $24 \mathrm{~h}$ metabolic and gene expression profiles in subjects with impaired glucose tolerance

MJM Munsters, MV Boekschoten, GH Vijgen, LA Afman, WHM Saris

(submitted) 


\section{Chapter 6}

\section{ABSTRACT}

Introduction: Meal frequency regulates postprandial glucose and insulin responses, which may affect substrate partitioning and thus weight control. This study investigated the effects of meal frequency on the metabolic and transcriptomic profiles in subjects with impaired glucose tolerance (IGT).

Methods: Eleven IGT ( $2 \mathrm{~h}$ glucose; $9.0 \pm 0.3 \mathrm{mmol} / \mathrm{L}$ ) men stayed $2 \times 36$ hours in a respiration chamber to measure substrate partitioning. All subjects randomly received two isoenergetic diets with a low meal frequency (3x; LFr) or a high meal frequency $(14 \mathrm{x} ; \mathrm{HFr})$ consisting of $15 \mathrm{En} \%$ protein, $30 \mathrm{En} \%$ fat, and $55 \mathrm{En} \%$ carbohydrates.

Results: Total glucose output (AUC), carbohydrate oxidation and whole body RQ significantly decreased, and FFA levels increased in the LFr diet. The HFr diet resulted in an up-regulation in expression of genes involved in immune function and inflammation after $24 \mathrm{~h}$ in PBMCs and muscle tissue. Expression of genes involved in PPAR signalling, OXPHOS, and glutathione metabolism were up-regulated in the $\mathrm{HFr}$ diet in muscle tissue only.

Conclusion: The LFr diet improved the metabolic and transcriptomic profiles, and appetite control compared to the HFr diet. This suggests that a LFr diet might be an effective dietary strategy to improve metabolic flexibility, inflammatory characteristics and body weight control in IGT subjects. 


\section{INTRODUCTION}

The increasing trend of dietary snacking and increased meal frequency parallels the rising incidence of obesity. Current literature shows conflicting results concerning the efficacy of increased meal frequency in causing metabolic modifications, especially in relation to body weight control (1-3). A higher meal frequency has been suggested to increase metabolism, improve glucose and insulin control, and to reduce hunger, food cravings and reduce body weight (4). On the other hand, eating three meals a day is proposed to cause a higher insulin peak as a result of higher carbohydrate intake, thereby increasing glucose uptake and oxidation. Accordingly, dietary fat will be mainly stored in the adipose tissue during the postprandial phase. In the fasting state (in between meals), this substrate flux is reversed as insulin levels are lower and lipolysis is stimulated $(5 ; 6)$. Nevertheless, a relationship between meal frequency and body weight could not be confirmed by wellcontrolled intervention studies $(7 ; 8)$. Our previous study did not show an effect of meal frequency on substrate partitioning in young healthy males (9). However, we suggested that these subjects had a good capacity to switch between substrates as the primary fuel source after a meal indicating a high metabolic flexibility (9). Therefore, it is interesting to study the effect of meal frequency in subjects with reduced metabolic flexibility, such as impaired glucose metabolism. Impaired glucose tolerance (IGT) subjects have elevated blood glucose levels caused by a combination of impaired insulin secretion and reduced insulin sensitivity resulting in a higher risk (40-50\%) to develop type 2 diabetes (10).

Accordingly, present study aimed to investigate the effects of meal frequency on the metabolic and appetite profiles and substrate partitioning under well-controlled energy balanced conditions in IGT men. We proposed that in an energy balanced situation eating 3 meals a day provides better opportunities to turn the metabolic flux into a prolonged fasting state with a higher fat oxidation compared to eating 14 meals a day where subjects remain in a continuous postprandial status (9). Moreover, we also investigated meal frequency effects on whole genome transcriptional changes in peripheral blood mononuclear cells (PBMCs) and muscle tissue. Changes in gene expression may reveal leads towards possible molecular mechanisms. 


\section{MATERIALS AND METHODS}

\section{Study population}

Eleven non-smoking men aged $65 \pm 0.9$ y with a mean BMI of $29.1 \pm 1.5 \mathrm{~kg} / \mathrm{m}^{2}$ and body fat percentage of $31.8 \pm 2.1 \%$ participated in this study. Additional inclusion criteria; IGT according to the World Health Organization (glucose levels < 7.0 $\mathrm{mmol} / \mathrm{L}$ at fasting and 2 hours postload $>7.8$ and $<11.1 \mathrm{mmol} / \mathrm{L}$, weight stable over the past 3 months, no major organ dysfunction, and no use of medication that could influence the results. Glucose tolerance was determined with an Oral Glucose Tolerance Test (OGTT) and insulin sensitivity (IS) via the oral glucose insulin sensitivity (OGIS)-index (11). Mean fasting glucose level was $6.0 \pm 0.2 \mathrm{mmol} / \mathrm{L}$, fasting insulin level $23.7 \pm 3.2 \mathrm{mU} / \mathrm{L}$, a mean $2 \mathrm{~h}$ glucose level after the OGTT of 9.0 $\pm 0.3 \mathrm{mmol} / \mathrm{L}$ and $\mathrm{OGIS}_{120}$ of $305.5 \pm 17.9 \mathrm{~mL} / \mathrm{min} / \mathrm{m}^{2}$. Systolic and diastolic blood pressures were respectively $139 \pm 4.4$ and $80 \pm 2.7 \mathrm{~mm} / \mathrm{Hg}$. Body density was determined by underwater weighing, with simultaneous measurement of lung volume with helium dilution technique using a spirometer (Volugraph 2000; Mijnhardt, Bunnik, the Netherlands). Body fat percentage was calculated using the equation of Siri (12). For homogeneity reasons as well as to avoid menstrual cycle effects on energy expenditure, only Caucasian males were included. This study was conducted according to the guidelines laid down in the Declaration of Helsinki (13). The Medical Ethical Committee of the University Hospital Maastricht approved this study. Before inclusion, all subjects signed an informed consent form.

\section{Study design}

This study had a randomized, 2-way crossover design with a wash-out period of at least two weeks. Each intervention lasted 36 hours in the respiration chamber, this system is described in detail by Schoffelen et al. (14). All subjects randomly received the same iso-energetic diet with a Low meal Frequency $(3 x ; L F r)$ or a High meal Frequency (14x; HFr) consisting of 15 energy\% (En\%) dairy protein, $30 \mathrm{En} \%$ fat, and 55 En\% carbohydrates. The protein consisted of $70 \%$ dairy and $30 \%$ vegetable protein. The diet was composed of crisp bread (LU cracottes natural), milk (semiskimmed), yoghurt drink (Vifit natural), melon, tomato and olive oil. The LFr diet consisted of breakfast at $08.00 \mathrm{~h}$, lunch at $12.00 \mathrm{~h}$, and dinner at $17.00 \mathrm{~h}$. In the $\mathrm{HFr}$ diet meals were consumed every hour from $08.00 \mathrm{~h}$ until $21.00 \mathrm{~h}$. Subjects were allowed to consume water and tea after $18.00 \mathrm{~h}$ ad libitum, because after that time point no visual analogue scale (VAS) questionnaires had to be completed. Subjects standardized their food intake and activity for 3 days before each test to have the same baseline condition. Food-intake and activity diaries had to be filled out before the first test and subjects were instructed to follow the same regime preceding the 
second test. Each respiration chamber visit started after insertion of the continuous glucose monitoring system (CGMS) (Medtronic Minimed, Northridge, USA) to measure subcutaneous interstitial fluid glucose at $20.00 \mathrm{~h}$ and finished $36 \mathrm{~h}$ later at $08.00 \mathrm{~h}$. The CGMS was calibrated four time per day with capillary fingerprick glucose readings. Glycemic variability was calculated as stated by McDonnell et al (15). Physical activity was prescribed by means of a standardized physical activity protocol, three repetitions of stepping (15 minutes each). Subjects were carefully controlled to be fed in energy balance, which was based on individually measured and calculated requirements. Details of the procedure as well as the calculation of energy expenditure, and components of energy expenditure and substrate partitioning, are described by Schrauwen et al (16). VAS were completed just before the first meal, 30, and 60 min postprandially after consumption of the three meals in the LFr diet, and the next morning at $08.00 \mathrm{~h}$ to assess appetite profiles (17). At the similar time points, questionnaires were completed in the HFr diet.

\section{Metabolic blood markers and gene expression in PMBCs and muscle tissue}

Blood was sampled just before ingestion of the first meal (baseline), 10, 20 and 30 min postprandially after, and subsequently every hour until $21.30 \mathrm{~h}$ for the determination of plasma levels of insulin, glucose, free fatty acids (FFA), and triglycerides (TG). At TO (baseline $08.00 \mathrm{~h}$ ), and $60 \mathrm{~min}$ postprandially after consumption of the three experimental meals, satiety-related hormones glucagonlike peptide-1 (GLP-1) active and ghrelin-active were sampled. The next morning at $08.00 \mathrm{~h}$ (T24), before subjects left the respiration chamber, fasting blood samples were taken to assess all markers. Metabolic blood collection and processing have been described in detail previously (9). PBMCs were isolated from whole blood on T0 (fasting state), T13 (21.30 h) and T24 (next morning at $08.00 \mathrm{~h}$ in fasting state) by using BD Vacutainer Cell Preparation Tubes according to the manufacturers' manual. A muscle biopsy from the vastus lateralis muscle (18) was taken after each respiration chamber stay in the fasting state (T24). Muscle tissue was directly frozen in melting isopentane and stored at $-80^{\circ} \mathrm{C}$ until assayed. The time points for the collection of blood and tissue samples were similar in both diets.

\section{RNA isolation and microarray processing}

The Qiagen RNAeasy kit (Qiagen, Venlo, the Netherlands) was used for RNA isolation. Total RNA (100 ng / per sample) was labelled by the Ambion WT Expression kit (Life Technologies, $\mathrm{P} / \mathrm{N}$ 4411974) in conjunction with the Affymetrix GeneChip WT Terminal Labeling kit (Affymetrix, Santa Clara, CA; P/N 900671) and 


\section{Chapter 6}

hybridized on Affymetrix GeneChip Human Gene 1.1 ST arrays targeting 19793 unique genes.

\section{Microarray data analysis}

Quality control and data analysis have been described in detail before (19). Individual genes were defined as changed when comparison of the average normalized signal intensities showed a $\mathrm{p}$-value $<0.05$ in a two-tailed paired t-test with Bayesian-correction (Limma) (20). Array data was analysed using an in-house, on-line system (21). Further functional data analysis was performed on the filtered data set (> 4 arrays with signal intensity $>20$ ) with Gene Set Enrichment Analysis (http://www.broad.mit.edu/gsea/). Upstream regulators analyses were performed with the use of Ingenuity (Ingenuity Systems, Redwood City, CA). Array data have been submitted to the Gene Expression Omnibus (GSE52028).

\section{Statistical analyses}

SPSS software (version 17 for windows; SPSS) was used for data entry and analysis. All data is reported as means \pm standard error mean (SEM). Homogeneity of the data was checked with the Kolmogorov-Smirnov test, when data were not normally distributed In transformation was applied. Main outcomes measures were the $24 \mathrm{~h}$ glucose and insulin profiles. CGMS and EE data were calculated per 24 hour, during the day ( $8 \mathrm{am}-23 \mathrm{pm})$ and during the night (23 pm - $8 \mathrm{am})$. CGMS data, EE, substrate partitioning, and the (net incremental) area under the curve ((net i)AUCs), were compared between the two intervention diets with a paired t-test. Mixedmodel ANOVA was used to compare the intervention diets at the different time points for the metabolic markers and VAS scales. Statistical significance was set at $p$ $<0.05$ and Bonferroni's correction was applied for multiple testing.

\section{RESULTS}

\section{Energy expenditure and substrate partitioning}

Energy intake was similar by design in both intervention diets $(11.1 \pm 0.5 \mathrm{MJ} / \mathrm{d})$ (Table 1). Total energy expenditure (TEE) tended to be higher and energy balance tended to be negative (NS) in the HFr diet. There was a tendency for a higher sleeping metabolic rate $(S M R)(p=0.075)$ in the HFr diet. No effect on $24 \mathrm{~h}$ resting metabolic rate (RMR), diet induced thermogenesis (DIT), activity-induced energy expenditure (AEE) and physical activity index PAl was observed between the intervention diets. Whole body $R Q(p=0.046)$ and carbohydrate oxidation $(p=$ 0.015 ) significantly increased on the HFr diet and fat oxidation tended to be lower in 
the HFr diet compared to the LFr diet. No significant differences in day and night substrate partitioning and RQ were found (8 - 23 day, 23 - 8 night; data not shown).

Table 1. $24 \mathrm{~h}$ total energy intake and expenditure, components of energy expenditure and substrate partitioning, according to Low or High Frequency (LFr and HFr diet resp.) diet.

\begin{tabular}{llll}
\hline & LFr diet & HFr diet & p-value \\
\hline EI (MJ/d) & $11.1 \pm 0.5$ & $11.1 \pm 0.5$ & - \\
TEE (MJ/d) & $11.1 \pm 0.5$ & $11.5 \pm 0.6$ & 0.051 \\
EB (MJ/d) & $0.1 \pm 0.2$ & $-0.4 \pm 0.2$ & 0.051 \\
RMR (MJ/d) & $8.4 \pm 0.4$ & $8.8 \pm 0.6$ & 0.158 \\
SMR (MJ/d) & $7.2 \pm 0.3$ & $7.5 \pm 0.4$ & 0.075 \\
DIT (MJ/d) & $1.2 \pm 0.2$ & $1.3 \pm 0.2$ & 0.906 \\
AEE (MJ/d) & $2.7 \pm 0.2$ & $2.7 \pm 0.2$ & 0.852 \\
PAI & $1.55 \pm 0.03$ & $1.52 \pm 0.03$ & 0.433 \\
RQ & $0.89 \pm 0.01$ & $0.91 \pm 0.01^{*}$ & 0.046 \\
Protein oxidation (g/d) & $83.5 \pm 7.5$ & $87.0 \pm 7.7$ & 0.487 \\
Carbohydrate oxidation (g/d) & $382.1 \pm 22.9$ & $421.8 \pm 24.6 *$ & 0.015 \\
Fat oxidation (g/d) & $76.1 \pm 7.9$ & $66.9 \pm 7.4$ & 0.145
\end{tabular}

EI: energy intake. TEE: total energy expenditure. EB: energy balance. RMR: resting metabolic rate. SMR: sleeping metabolic rate. DIT: diet induced thermogenesis. AEE: activity-induced energy expenditure. PAI: physical activity index. RQ: respiratory quotient. Values are expressed as mean $\pm \mathrm{SEM}$. ${ }^{*} \mathrm{P}<0.05$ compared to the LFr diet. P-values were derived by paired t-test analysis and denote the overall significance of differences among the two diets.

\section{Metabolic blood markers}

The LFr diet showed significantly higher peaks and lower troughs for glucose and insulin levels compared to the HFr diet during the day (Fig. 1). In general, AUC of 24 $\mathrm{h}$ glucose levels was significantly lower in the LFr diet, although the AUC of insulin did not differ between the two diets. In the LFr diet FFA levels were significantly higher (AUC), especially after lunch and dinner. TG profiles did not differ between the diets.

\section{Continuous glucose monitoring system}

Mean and minimum glucose levels per 24 hour, day and night were significantly different between the two diets (Table 2). Moreover, the AUC per 24 hour, day and night differed significantly between the diets, however the net iAUC per 24 hour, day and night were not significantly different because of baseline correction. 


\section{Chapter 6}

Glycemic variability as calculated by CONGA1, 2 and 4 did not change between both diets, although the CV significantly decreased in the HFr diet.
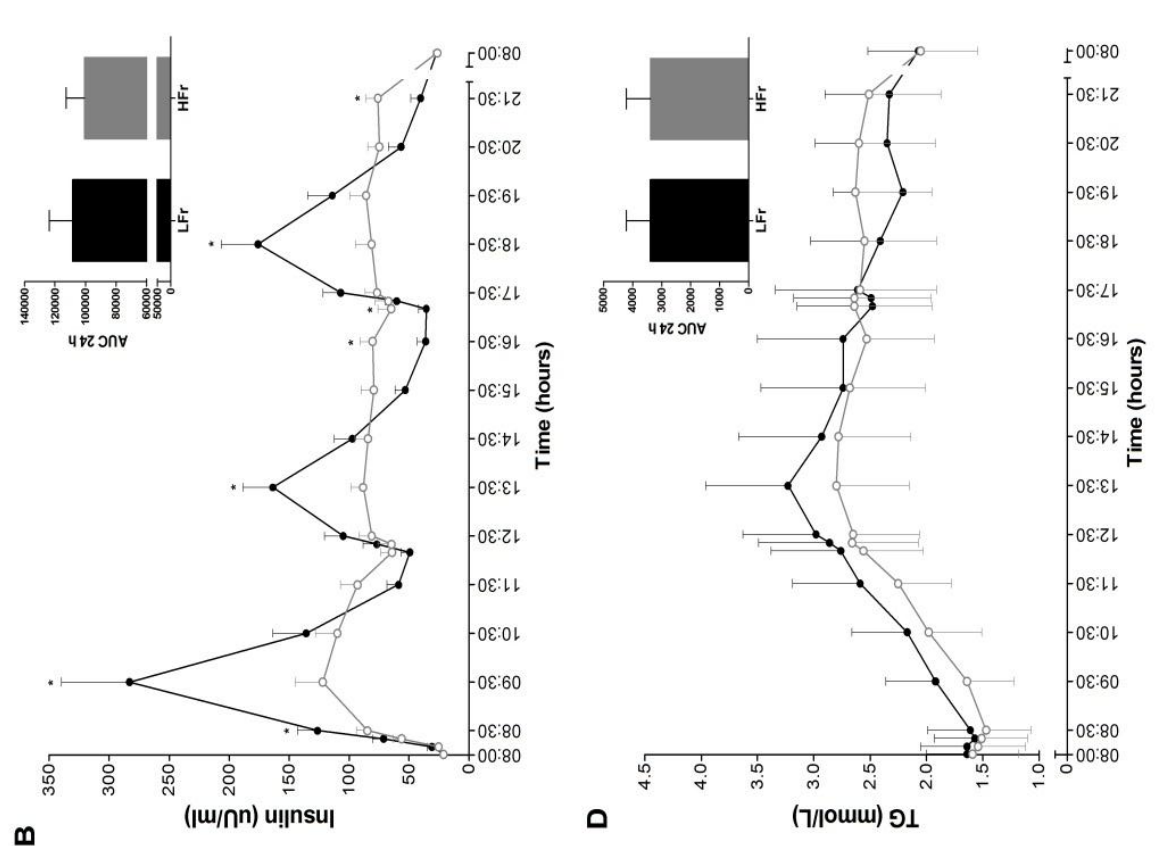

岌

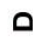

(7//oum) פ।
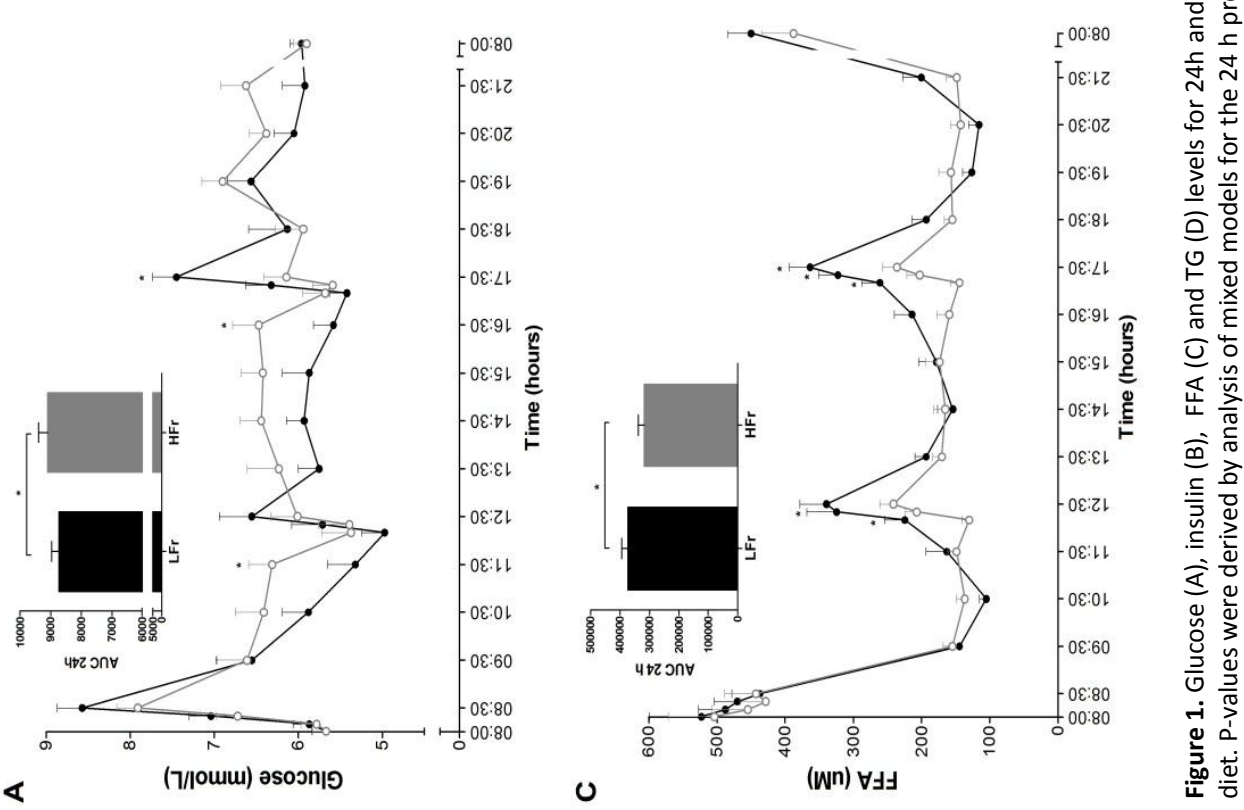
Table 2. Analyses of the CGMS data compared between the two intervention diets $(n=12)$.

\begin{tabular}{llll}
\hline & LFr diet & HFr diet & p-value \\
\hline Mean 24 h (mmol/L) & $5.6 \pm 0.2$ & $6.7 \pm 0.2^{*}$ & 0.000 \\
Min 24 h (mmol/L) & $4.0 \pm 0.3$ & $5.0 \pm 0.1^{*}$ & 0.003 \\
Max 24 h (mmol/L) & $9.0 \pm 0.4$ & $8.9 \pm 0.4$ & 0.842 \\
AUC 24 h & $8185.8 \pm 239.4$ & $9583.9 \pm 300.3^{*}$ & 0.000 \\
AUC 8-23 h & $5463.4 \pm 173.7$ & $6280.2 \pm 218.4^{*}$ & 0.003 \\
AUC 23-8 h & $2745.3 \pm 112.2$ & $3333.8 \pm 114.5^{*}$ & 0.000 \\
net iAUC 24 h & $82.6 \pm 239.4 .3$ & $420.22 \pm 273.0$ & 0.401 \\
net iAUC 8-23 h & $398.8 \pm 151.8$ & $552.9 \pm 152.4$ & 0.528 \\
net iAUC 23-8 h & $74.7 \pm 66.1$ & $-181.1 \pm 120.4$ & 0.097 \\
CONGA1 & $1.04 \pm 0.11$ & $0.76 \pm 0.08$ & 0.090 \\
CONGA2 & $1.12 \pm 0.13$ & $0.83 \pm 0.11$ & 0.124 \\
CONGA4 & $1.18 \pm 0.12$ & $0.89 \pm 0.11$ & 0.117 \\
CV & $0.18 \pm 0.02$ & $0.12 \pm 0.01^{*}$ & 0.017 \\
\hline
\end{tabular}

Min: minimal glucose level. Max: maximal glucose level. AUC: area under the curve. net iAUC: net incremental area under the curve. CONGA1, 2, 4: continuous overall net glycemic action describing intraday glycemic variability between respectively 1,2 and $4 \mathrm{~h}$ time periods over $24 \mathrm{~h}$. CV: coefficient of variability. Values are expressed as mean \pm SEM. ${ }^{* P}<0.05$ compared to the LFr diet. P-values were derived by paired t-test analysis and denote the overall significance of differences among the two diets.

\section{Appetite profile}

The LFr diet significantly increased GLP-1 active levels one hour after breakfast, and tended to be higher throughout the day (Fig. 2). Ghrelin-active levels tended to be higher in the LFr diet, especially one hour after dinner. The AUCs of hunger, prospective food consumption and thirst significantly reduced, and satiety significantly increased in the LFr diet compared to the HFr diet (Fig. 2, graphs of prospective food consumption, thirst and fullness were not shown because of the same trend). 

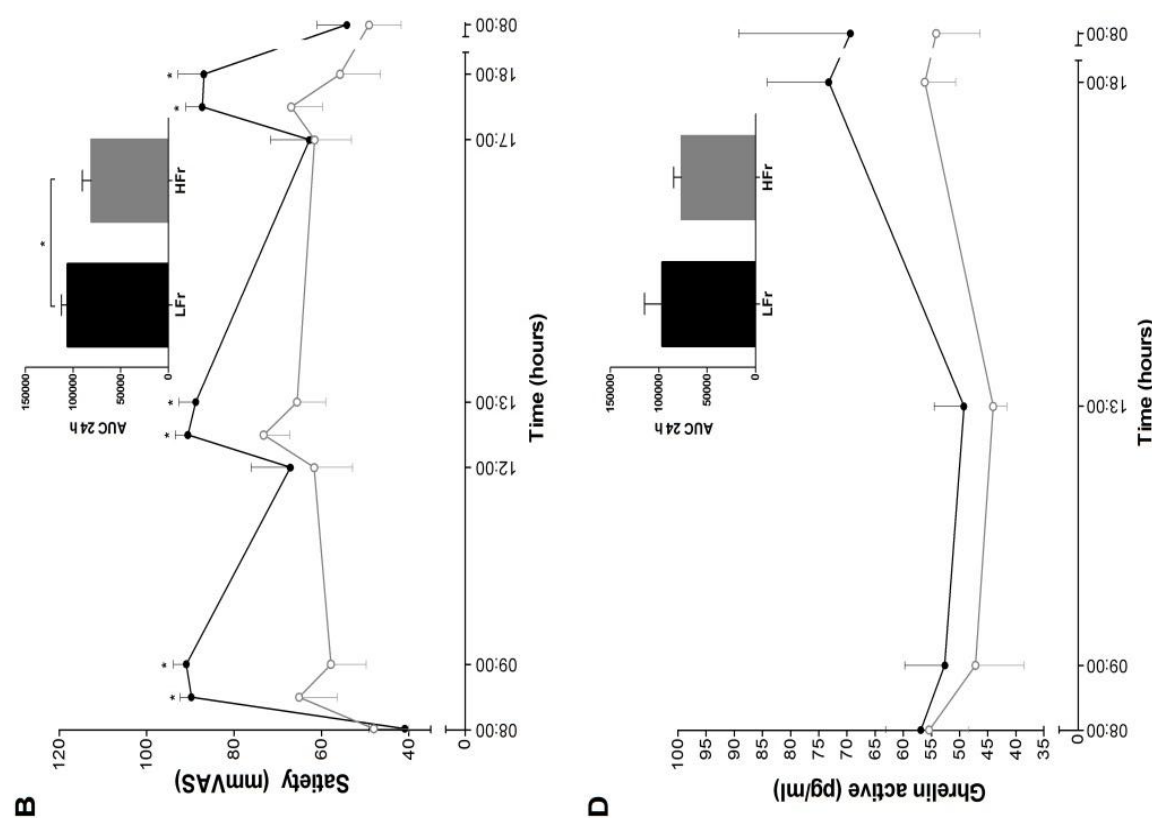

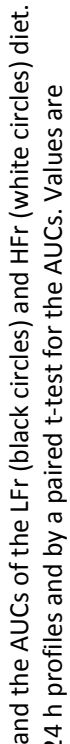

$m$

口

寺

훈

$\frac{n}{d} \frac{n}{d}$
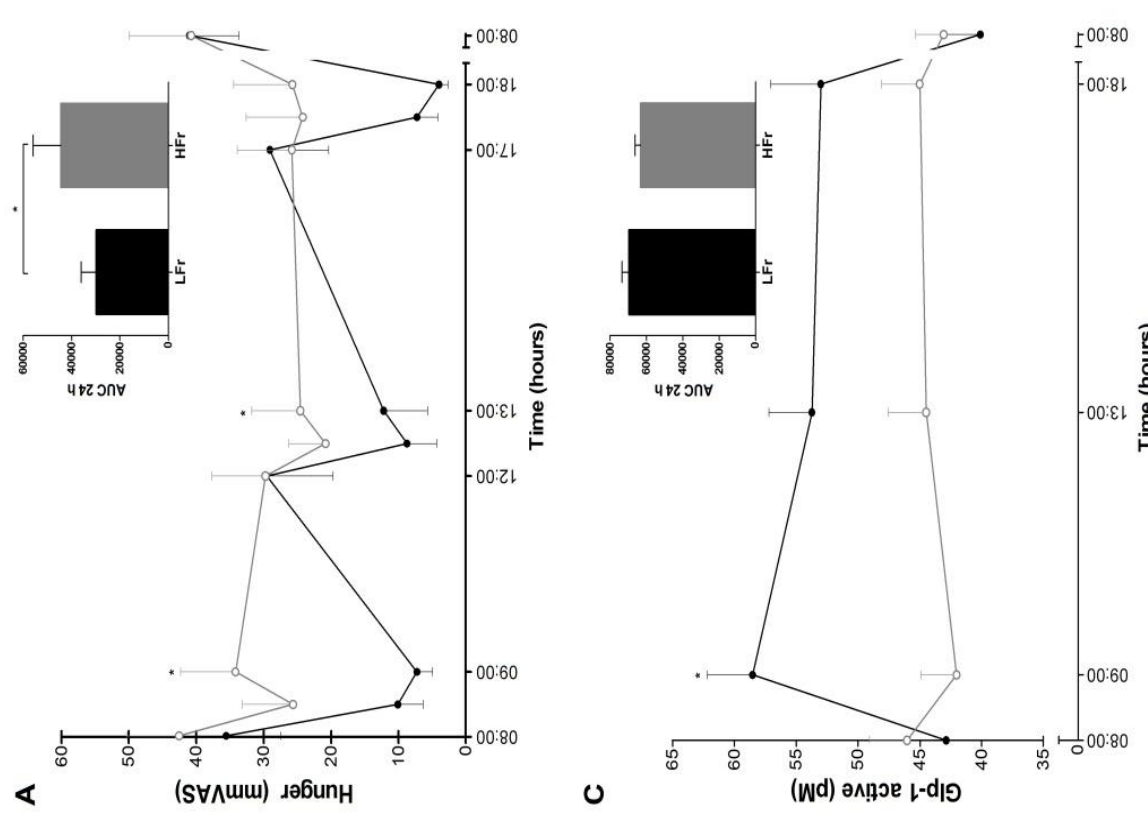

ฮิ

등

离

足

은 $\frac{4}{5}$

放

둥

느웜

क

0 \%

i

उ

产

文

焉

政的

这㶵

㟧

至它

능

o O

v

章* 


\section{Molecular mechanisms of meal frequency}

To clarify potential molecular mechanisms affected by meal frequency, microarray analysis on PMBCs and muscle tissue were performed. At T13 two PBMC samples were missing in both diets, at T24 one PBMC sample was missing in the HFr diet. For muscle tissue, three samples for both diets were missing due to tissue availability (limit or none) and/or not passing quality control. Compared to $0 \mathrm{~h}, 1275$ out of 13298 genes were significantly changed at $24 \mathrm{~h}$ and 768 genes at $13 \mathrm{~h}$ in PBMCs between the two diets (HFr_T24-0 vs. LFr_T24-0; Fig. 1, supplemental data; Limma t-test, $p<0.05)$. Expression of 422 out of 13298 genes were significantly different changed in muscle tissue of eight subjects between the two diets. To identify in which pathways or signalling routes these genes were involved GSEA was performed.

\section{Gene expression profiles in PBMCs}

Only significant different gene sets identified by GSEA with a FDR q-value $<0.01$ between (HFr_T24-0 vs. LFr_T24-0) and in (HFr_T24 vs. HFr_T0 or LFr_T24 vs. LFr_T0) the diets were visualized in Cytoscape (22). A lower cut-off value was chosen compared to T13 and muscle analyses, because at this time point still many effects (35 gene sets) were observed. The significant different gene sets upregulated in the HFr diet were mainly involved in interferon signalling, immune function and inflammation (Fig. 2, supplemental data). Individual gene expression changes of the significantly changed gene from these gene sets are shown in a heatmap (Fig. 3).

Only gene sets that were significant different between (HFr_T13-0 vs. LFr_T13-0) and in (HFr_T13 vs. HFr_T0 or LFr_T13 vs. LFr_T0) with a FDR q-value $<0.02$ were visualized in Cytoscape. React_respiratory electron transport, ATP synthesis by chemiosmotic coupling, and heat production by uncoupling proteins were down regulated in the HFr diet (Fig. 3, supplemental data). Individual gene expression changes of the significantly changed gene from these gene sets are shown in a heatmap (Fig. 4).

\section{Gene expression profiles in muscle tissue}

Significant different gene sets with a FDR q-value $<0.02$ between (HFr_T24 vs. LFr_T24) were visualized in Cytoscape and these gene sets were upregulated in the $\mathrm{HFr}$ diet and mainly involved in oxidative phosphorylation (OXPHOS), glutathione metabolism, PPAR signalling, TG en fatty acid (FA) biosynthesis, and immune function and inflammation (Fig. 4; online supplemental data). Individual gene expression changes of the significantly changed gene from these gene sets are 


\section{Chapter 6}

shown in a heatmap (Fig. 5). In addition, the PPARGC1A gene was significantly ( $p<$ 0.05) upregulated in the HFr diet. In Ingenuity, upstream regulators analyses were performed and indicated higher activation of inflammation pathways in the HFr diet in muscle tissue and PBMCs (Table 3).

Table 3. Transcription factors activated/inhibited in PBMCs and muscle tissue at $24 \mathrm{~h}$ analysed in Ingenuity.

\begin{tabular}{|l|l|l|l|l|l|}
\hline $\begin{array}{l}\text { Upstream } \\
\text { regulator }\end{array}$ & $\begin{array}{l}\text { Activation } \\
\text { z-score }\end{array}$ & $\begin{array}{l}\text { Upstream } \\
\text { regulator }\end{array}$ & $\begin{array}{l}\text { Activation } \\
\text { z-score }\end{array}$ & $\begin{array}{l}\text { Upstream } \\
\text { regulator }\end{array}$ & $\begin{array}{l}\text { Activation } \\
\text { z-score }\end{array}$ \\
\hline \multicolumn{2}{|c|}{$\begin{array}{l}\text { Muscle tissue T24 } \\
\text { HFr vs. LFr }\end{array}$} & \multicolumn{2}{c|}{ PBMC T24 HFr } & \multicolumn{2}{c|}{ PBMC T24 LFr } \\
\hline Interferon alpha & 2.2 & NFKB (complex) & 2.183 & NFKB (complex) & -3.789 \\
IFNG & 2.235 & IFNG & 3.369 & IFNG & -3.587 \\
TNF & 2.434 & TNF & 2.932 & TNF & -4.191 \\
MAPK1 & -2 & MAPK1 & -3 & IL1B & -2.927 \\
& & & & EDN1 & -2.364 \\
\hline
\end{tabular}

Figure 3A. Individual expression changes of significant genes in the most significant $(q<0.01)$ differently regulated immune response and inflammation gene sets in PBMCs after T24. Individual changes in expression (signal log ratios) for each diet group are displayed on a colour scale, ranging from $\leq-0.2$ (green) $\geq 0.2$ (red).

\begin{tabular}{|c|c|c|c|}
\hline $\begin{array}{l}\text { Gene } \\
\text { name }\end{array}$ & Entrez ID & HFr diet & LFr diet \\
\hline \multicolumn{2}{|c|}{ Interferon signalling } & & \\
\hline ADAR & 103 & & \\
\hline CAMK2 & 817 & & \\
\hline CASP1 & 834 & & \\
\hline CHUK & 1147 & & \\
\hline CIITA & 4261 & & \\
\hline GBP2 & 2634 & & \\
\hline GBP4 & 115361 & & \\
\hline IFI30 & 10437 & & \\
\hline IFIT1 & 3434 & & \\
\hline IFIT2 & 3433 & & \\
\hline IFITM3 & 10410 & & \\
\hline IFNAR1 & 3454 & & \\
\hline IFNAR2 & 3455 & & \\
\hline IRF1 & 3659 & & \\
\hline IRF8 & 3394 & & \\
\hline IRF9 & 10379 & & \\
\hline KRAS & 3845 & & \\
\hline MX1 & 4599 & & \\
\hline MX2 & 4600 & & \\
\hline MYD88 & 4615 & & \\
\hline OAS3 & 4940 & & \\
\hline PML & 5371 & & \\
\hline PSMB8 & 5696 & & \\
\hline РТК2B & 2185 & & \\
\hline PTPN2 & 5771 & & \\
\hline RIPK2 & 8767 & & \\
\hline sos1 & 6654 & & \\
\hline STAT2 & 6773 & & \\
\hline
\end{tabular}


Figure 3B. Individual expression changes of significant genes in the most significant $(q<0.01)$ differently regulated immune response and inflammation gene sets in PBMCs after T24. Individual changes in expression (signal log ratios) for each diet group are displayed on a colour scale, ranging from $\leq-0.2$ (green) $\geq 0.2$ (red).

\begin{tabular}{|c|c|c|c|}
\hline $\begin{array}{l}\text { Gene } \\
\text { name }\end{array}$ & Entrez ID & HFr diet & LFr diet \\
\hline \multicolumn{2}{|c|}{$\begin{array}{l}\text { Immune function / } \\
\text { inflammation }\end{array}$} & & \\
\hline ATF3 & 467 & & \\
\hline ATF4 & 468 & & \\
\hline $\mathrm{C} 1 \mathrm{QB}$ & 713 & & \\
\hline CASP6 & 839 & & \\
\hline CASP7 & 840 & & \\
\hline CCNE1 & 898 & & \\
\hline CD274 & 29126 & & \\
\hline CD74 & 972 & & \\
\hline CDKN1A & 1026 & & \\
\hline CFL1 & 1072 & & \\
\hline CREB1 & 1385 & & \\
\hline CUL1 & 8454 & & \\
\hline DTX3L & 151636 & & \\
\hline DZIP3 & 9666 & & \\
\hline ERAP1 & 51752 & & \\
\hline FAS & 355 & & \\
\hline FYB & 2533 & & \\
\hline GNAI2 & 2771 & & \\
\hline HES1 & 3280 & & \\
\hline HLA-DMA & 3108 & & \\
\hline HLA-DPA1 & 3113 & & \\
\hline HLA-DPB1 & 3115 & & \\
\hline HLA-DQB1 & 3119 & & \\
\hline HLA-DQB2 & 3120 & & \\
\hline ITGA4 & 3676 & & \\
\hline JUN & 3725 & & \\
\hline PDCD1LG2 & 80380 & & \\
\hline PDIA3 & 2923 & & \\
\hline PSMA3 & 5684 & & \\
\hline PSMB3 & 5691 & & \\
\hline PSMB9 & 5698 & & \\
\hline PSMD2 & 5708 & & \\
\hline PSMD9 & 5715 & & \\
\hline PSME1 & 5720 & & \\
\hline PVRL2 & 5819 & & \\
\hline RAET1G & 353091 & & \\
\hline RGS1 & 5996 & & \\
\hline RHOB & 388 & & \\
\hline RNF19B & 127544 & & \\
\hline STAT1 & 6772 & & \\
\hline TAP1 & 6890 & & \\
\hline TAP2 & 6891 & & \\
\hline TCEB1 & 6921 & & \\
\hline TNFRSF10B & 8795 & & \\
\hline TP53 & 7157 & & \\
\hline TRADD & 8717 & & \\
\hline TRIM21 & 6737 & & \\
\hline UBA3 & 9039 & & \\
\hline UBA6 & 55236 & & \\
\hline UBE2J2 & 118424 & & \\
\hline UBE2W & 55284 & & \\
\hline UBR1 & 197131 & & \\
\hline VAV2 & 7410 & & \\
\hline VPS4A & 27183 & & \\
\hline WAS & 7454 & & \\
\hline
\end{tabular}




\section{Chapter 6}

Figure 4. Individual expression changes of significant genes in the significant $(q<0.02)$ differently regulated oxidative phosphorylation gene set in PBMCs after T13. Individual changes in expression (signal log ratios) for each diet group are displayed on a colour scale, ranging from $\leq-0.2$ (green) $\geq 0.2$ (red).

\begin{tabular}{|l|r|r|r|}
\hline $\begin{array}{l}\text { Gene } \\
\text { name }\end{array}$ & Entrez ID & HFr diet & LFr diet \\
\hline \multicolumn{3}{|c|}{ Oxidative } & \\
phosphorylation & & \\
\hline ATP5O & 539 & & \\
COX6C & 1345 & & \\
ETFDH & 2110 & & \\
NDUFA11 & 126328 & & \\
NDUFB10 & 4716 & & \\
NDUFB3 & 4709 & & \\
NDUFB4 & 4710 & & \\
NDUFB9 & 4715 & & \\
NDUFV3 & 4731 & & \\
\hline
\end{tabular}

Figure 5. Individual expression changes of significant genes in the significant $(q<0.02)$ differently regulated gene sets in muscle tissue after T24. Individual changes in expression (signal log ratios) for each diet group are displayed on a colour scale, ranging from $\leq-0.2$ (green) $\geq 0.2$ (red).

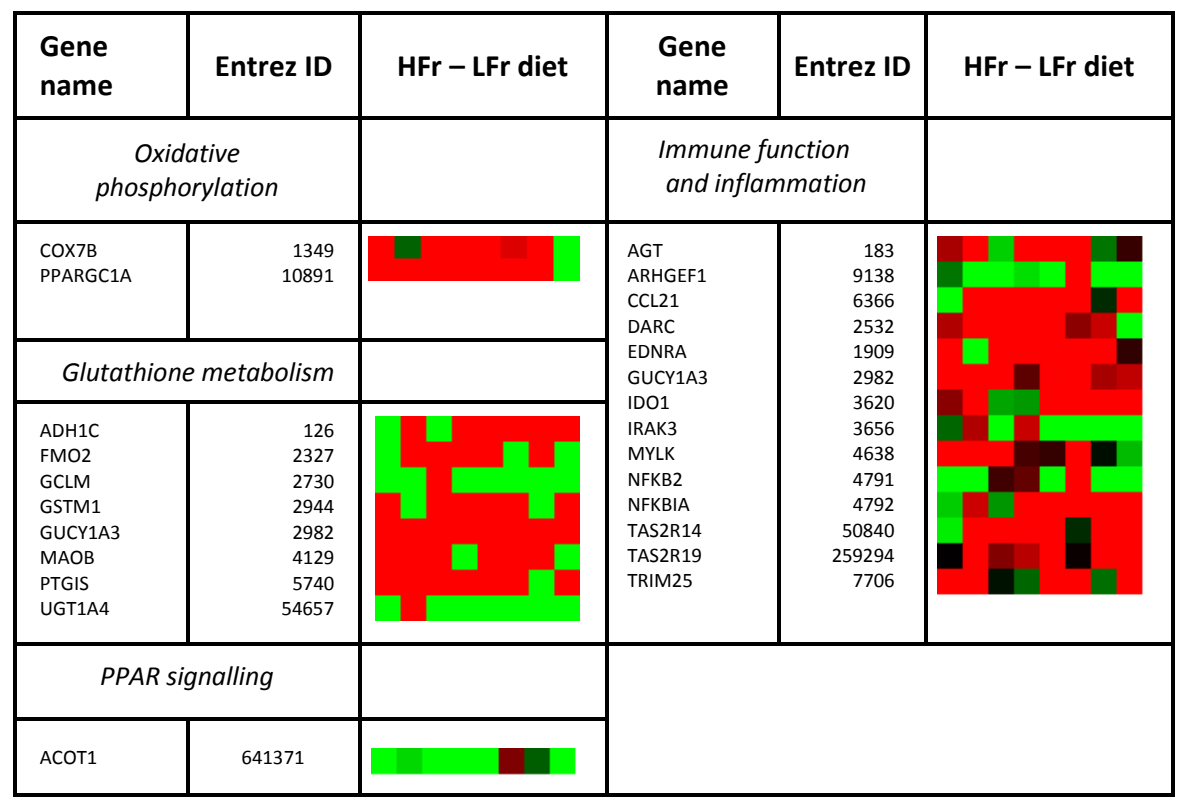




\section{DISCUSSION}

We investigated the effect of meal frequency on both the metabolic and transcriptomic profiles under isoenergetic well-controlled conditions in men with impaired glucose tolerance (IGT). This study clearly showed that these IGT men improved their metabolic and transcriptomic profiles, and appetite control as a result of the LFr diet compared to the HFr diet.

The greater fluctuations in glucose, insulin, and FFA responses in the LFr diet compared to the HFr diet are compliant with the findings of Solomon et al. (2008) (3) indicating an improvement of the metabolic profile in IGT men. These subjects on the LFr diet improved their access to metabolic fuels in between meals which resulted in a lower $24 \mathrm{~h} \mathrm{RQ}$ and carbohydrate oxidation. The elevated plasma FFA levels could induce insulin resistance as well as low grade inflammation (23), nonetheless insulin resistance could exist in obesity without a rise of FFA concentrations (24). Therefore, all present data points towards a restoration of the metabolic profile which could improve the insulin resistant state of these IGT men. These findings are in contrast with our previous study in healthy men (9) and with reviews of current literature $(4 ; 25)$ that found no effect on substrate oxidation. However, inhibition of fat oxidation might only occur in the $\mathrm{HFr}$ diet when the insulin response has reached a certain level and for a longer period of time as we suggested before (9). Other studies showed maximally suppression of fat oxidation at insulin concentrations $>50 \mu \mathrm{U} / \mathrm{ml}(26 ; 27)$. In present study, the average insulin level was $73.1 \mu \mathrm{U} / \mathrm{ml}$ in the $\mathrm{HFr}$ diet. Our data demonstrated that fat oxidation was strongly inhibited in these insulin resistant men due to the prolonged postprandial phase resulting in a higher RQ. Furthermore, a study comparing continuous versus (vs.) pulsatile administration of insulin has further supported the hypothesis that continuous hyperinsulinemia results in a deterioration of the metabolic profile by causing insulin resistance (28).

The observed higher carbohydrate oxidation and RQ in the HFr diet are suggested to be accompanied by a faster depleting of the endogenous glycogen stores in the postabsorptive state, thereby stimulating food intake (29). On the long term, subjects with a habitual high $24 \mathrm{~h} \mathrm{RQ}$ are more prone to gain weight over time as shown by prospective studies in Pima Indians (30). Even though total EE tended to be higher in the HFr diet (NS) this could be compensated by an increased energy intake and consequently weight gain on the long term as explained above.

Furthermore, short-term changes in glucose homeostasis were assessed with the CGMS and only the CV increased in the LFr diet. CONGA values did not vary between the diets and glycemic lability could not be indicated herewith. The higher fluctuations of glucose levels in the LFr diet seems to be of less concern in IGT subjects because of the accompanying beneficial effect of an improved metabolic 
profile. This study was conducted with isoenergetic diets, therefore confounding effects of over- or underfeeding were eliminated.

Expression of genes involved in inflammatory and immune responses, in particular interferon-related genes were upregulated in the HFr diet for $24 \mathrm{~h}$ in both PBMCs and muscle tissue. In contrast, Dixit et al (2011) showed that meal frequency did not affect levels of circulating pro-inflammatory markers in healthy subjects, suggesting that a change in meal frequency does not alter the systemic inflammatory state (31). Furthermore, these authors demonstrated that stimulated PBMCs on a lower meal frequency diet responded with a reduced capability to produce cytokines (31). Nonetheless, this study was conducted in lean healthy subjects (no insulin resistance present) and investigated meal frequency at a lower range; one vs. three meals per day compared to three vs. fourteen meals per day in our study. In present study, eating frequently, and thereby remaining in a continuous postprandial status, resulted in a higher stress response. The postprandial state is known to be associated with a pro-inflammatory state (32), therefore eating small meals frequently and prolonging the postprandial state enhanced postprandial inflammatory response. In accordance, upstream regulators of inflammation such as interferon- $\alpha$ (INF) and INF- $\nu$ increased in muscle tissue after $24 \mathrm{~h}$ indicating a higher inflammatory status. Taken together, the observed changes in improvement of the metabolic profile (and the potential accompanying reduction in insulin resistance) in these IGT men may have initiated the reduced inflammatory status. Thus, a lower meal frequency may be an interesting dietary strategy with anti-inflammatory characteristics for manipulating insulin resistance and therefore metabolic flexibility.

OXPHOS gene expression decreased in the HFr diet at $13 \mathrm{~h}$ in PBMCs and this was absent after $24 \mathrm{~h}$ which may reflect a temporarily circadian induced effect. In muscle tissue, the higher OXPHOS activity is accompanied by a higher expression of genes involved in glutathione metabolism in the HFr diet at $24 \mathrm{~h}$. In addition, expression of PGC-1a was increased in muscle tissue, which is a transcription coactivator that plays a central role in the regulation of cellular energy metabolism and in regulation of OXPHOS. These findings in muscle are consistent with the tendency of a higher $24 \mathrm{~h}$ total EE in the HFr diet. Current literature is not consistent about the consequences of a decreased or increased OXPHOS gene expression in various tissues. Decreased OXPHOS gene expression were observed in PBMCs and skeletal muscle of type 2 diabetic subjects $(33 ; 34)$. These findings in muscle suggested that a lower OXPHOS gene expression could lead to intramuscular lipid accumulation resulting in insulin resistance. On the other hand, Pospislik et al (35) suggested that a decreased OXPHOS may be a consequence rather than a cause of insulin resistance as a decrease in OXPHOS was related with metabolic 
improvements. Our results indicate that the effects on OXPHOS gene expression in muscle in the $\mathrm{HFr}$ diet are concurrent with a reduced metabolic profile possible leading to a higher lipid accumulation and insulin resistance. This was also reflected by the increased triglyceride (TG) and fatty acids (FA) synthesis genesets in muscle tissue after the HFr diet. Our findings illustrated that the phenotypical metabolic effects of the HFr diet vs. the LFr diet on substrate partitioning are confirmed on cellular level by means of transcriptomics.

Present study demonstrated increased feelings of satiety, GLP-1 levels and decreased feeling of hunger throughout the day in the LFr diet. Therefore, we propose that the LFr diet improved appetite control, even though subsequent food intake (ad libitum meals) was not investigated. For this reason, our results should be interpreted carefully. The larger portion size in the LFr diet may explain the observed higher GLP-1 levels since the release of GLP-1 is elicited in response to food intake. In contrast, frequent feeding has been suggested to delay the gastric emptying of a subsequent meal, thereby increasing the exposure of food in the gut and accordingly enhances satiety (36). Nevertheless, present evidence of controlled high meal frequency studies ( $>3$ meals / day) indicate minimal to no improvements in food intake regulation and appetite control (4).

Our study design remained primarily the same as our meal frequency study in lean healthy subjects, therefore the general disadvantages of our study design also remain the same (9). Furthermore, the fourteen meals in the high frequency diet are higher than what is reasonable in daily life. Therefore, it would be important to determine if similar results are seen with 6 small meals, which is a more commonly dietary regimen. Certainly, well-controlled intervention studies have to be performed to investigate the long-term effects of meal frequency on the metabolic and transcriptomic profiles and substrate partitioning.

Altogether, we clearly showed that the LFr diet improved the metabolic, and gene expression profiles, and appetite control compared to the HFr diet. This suggests that a LFr diet might be an effective dietary strategy to improve metabolic flexibility, inflammatory characteristics and body weight control in subjects with impaired glucose metabolism. Current knowledge about meal frequency in this vulnerable population may be helpful to prevent (worsening of) obesity and type 2 diabetes.

\section{ACKNOWLEDGMENTS}

The authors would like to thank the following people for their excellent analytical or technical support, assistance in conducting this study or analyzing the data: J. Stegen, H. Aydeniz, W. Sluijsmans, P. Schoffelen, T. de Weijer, Maastricht University Medical Centert, and P. de Groot, Wageningen University. 


\section{REFERENCES}

1. Chapelot D: The role of snacking in energy balance: a biobehavioral approach. J Nutr 2011;141:158-162

2. McCrory MA, Howarth NC, Roberts SB, Huang TT: Eating frequency and energy regulation in free-living adults consuming self-selected diets. J Nutr 2011;141:148153

3. Solomon TP, Chambers ES, Jeukendrup AE, Toogood AA, Blannin AK: The effect of feeding frequency on insulin and ghrelin responses in human subjects. Br J Nutr 2008;100:810-819

4. Leidy HJ, Campbell WW: The effect of eating frequency on appetite control and food intake: brief synopsis of controlled feeding studies. J Nutr 2011;141:154-157

5. Miller WC, Lindeman AK, Wallace J, Niederpruem M: Diet composition, energy intake, and exercise in relation to body fat in men and women. Am J Clin Nutr 1990;52:426-430

6. Astrup A, Raben A: Carbohydrate and obesity. Int J Obes Relat Metab Disord 1995;19 Suppl 5:S27-37

7. McCrory MA, Campbell WW: Effects of eating frequency, snacking, and breakfast skipping on energy regulation: symposium overview. J Nutr 2011;141:144-147

8. Palmer MA, Capra S, Baines SK: Association between eating frequency, weight, and health. Nutr Rev 2009;67:379-390

9. Munsters MJ, Saris WH: Effects of meal frequency on metabolic profiles and substrate partitioning in lean healthy males. PLoS One 2012;7:e38632

10. Alberti KG: The clinical implications of impaired glucose tolerance. Diabet Med 1996;13:927-937

11. Mari A, Pacini G, Murphy E, Ludvik B, Nolan JJ: A model-based method for assessing insulin sensitivity from the oral glucose tolerance test. Diabetes Care 2001;24:539-548

12. Siri WE: The gross composition of the body. Adv Biol Med Phys 1956;4:239-280

13. Goodyear MD, Krleza-Jeric K, Lemmens T: The Declaration of Helsinki. BMJ 2007;335:624-625

14. Schoffelen PF, Westerterp KR, Saris WH, Ten Hoor F: A dual-respiration chamber system with automated calibration. J Appl Physiol 1997;83:2064-2072

15. McDonnell CM, Donath SM, Vidmar SI, Werther GA, Cameron FJ: A novel approach to continuous glucose analysis utilizing glycemic variation. Diabetes Technol Ther 2005;7:253-263

16. Schrauwen $P$, van Marken Lichtenbelt WD, Westerterp KR: Energy balance in a respiration chamber: individual adjustment of energy intake to energy expenditure. Int J Obes Relat Metab Disord 1997;21:769-774

17. Flint A, Raben A, Blundell JE, Astrup A: Reproducibility, power and validity of visual analogue scales in assessment of appetite sensations in single test meal studies. Int J Obes Relat Metab Disord 2000;24:38-48

18. Bergstrom J, Hermansen L, Hultman E, Saltin B: Diet, muscle glycogen and physical performance. Acta Physiol Scand 1967;71:140-150 
19. Esser D, van Dijk SJ, Oosterink E, Muller M, Afman LA: A high-fat SFA, MUFA, or n3 PUFA challenge affects the vascular response and initiates an activated state of cellular adherence in lean and obese middle-aged men. J Nutr 2013;143:843-851

20. Smyth GK: Linear models and empirical bayes methods for assessing differential expression in microarray experiments. Stat Appl Genet Mol Biol 2004;3:Article3

21. Lin K, Kools $H$, de Groot PJ, Gavai AK, Basnet RK, Cheng F, Wu J, Wang $X$, Lommen A, Hooiveld GJ, Bonnema G, Visser RG, Muller MR, Leunissen JA: MADMAX - Management and analysis database for multiple omics experiments. Journal of integrative bioinformatics 2011;8:160

22. Shannon P, Markiel A, Ozier O, Baliga NS, Wang JT, Ramage D, Amin N, Schwikowski B, Ideker T: Cytoscape: a software environment for integrated models of biomolecular interaction networks. Genome Res 2003;13:2498-2504

23. Boden G: Obesity, insulin resistance and free fatty acids. Curr Opin Endocrinol Diabetes Obes 2011;18:139-143

24. Karpe F, Dickmann JR, Frayn KN: Fatty acids, obesity, and insulin resistance: time for a reevaluation. Diabetes 2011;60:2441-2449

25. Bellisle F, McDevitt R, Prentice AM: Meal frequency and energy balance. Br J Nutr 1997;77 Suppl 1:S57-70

26. Frayn K: Metabolic regulation: a human perspective. Oxford, Wiley-Blackwell, 2010

27. Mandarino LJ, Wright KS, Verity LS, Nichols J, Bell JM, Kolterman OG, BeckNielsen $\mathrm{H}$ : Effects of insulin infusion on human skeletal muscle pyruvate dehydrogenase, phosphofructokinase, and glycogen synthase. Evidence for their role in oxidative and nonoxidative glucose metabolism. J Clin Invest 1987;80:655663

28. Shanik $M H, X u Y$, Skrha J, Dankner R, Zick $Y$, Roth J: Insulin resistance and hyperinsulinemia: is hyperinsulinemia the cart or the horse? Diabetes Care 2008;31 Suppl 2:S262-268

29. Flatt JP: Carbohydrate balance and body-weight regulation. Proc Nutr Soc 1996;55:449-465

30. Zurlo F, Lillioja S, Esposito-Del Puente A, Nyomba BL, Raz I, Saad MF, Swinburn BA, Knowler WC, Bogardus C, Ravussin E: Low ratio of fat to carbohydrate oxidation as predictor of weight gain: study of 24-h RQ. Am J Physiol 1990;259:E650-657

31. Dixit VD, Yang H, Sayeed KS, Stote KS, Rumpler WV, Baer DJ, Longo DL, Mattson MP, Taub DD: Controlled meal frequency without caloric restriction alters peripheral blood mononuclear cell cytokine production. J Inflamm (Lond) 2011;8:6

32. Calder PC, Ahluwalia N, Brouns F, Buetler T, Clement $K$, Cunningham K, Esposito $\mathrm{K}$, Jonsson LS, Kolb H, Lansink M, Marcos A, Margioris A, Matusheski N, Nordmann H, O'Brien J, Pugliese G, Rizkalla S, Schalkwijk C, Tuomilehto J, Warnberg J, Watzl B, Winklhofer-Roob BM: Dietary factors and low-grade inflammation in relation to overweight and obesity. The British journal of nutrition 2011;106 Suppl 3:S5-78 33. Takamura $T$, Honda $M$, Sakai $Y$, Ando $H$, Shimizu A, Ota T, Sakurai M, Misu $H$, Kurita S, Matsuzawa-Nagata N, Uchikata M, Nakamura S, Matoba R, Tanino M, Matsubara K, Kaneko S: Gene expression profiles in peripheral blood mononuclear 


\section{Chapter 6}

cells reflect the pathophysiology of type 2 diabetes. Biochem Biophys Res Commun 2007;361:379-384

34. Patti ME, Butte AJ, Crunkhorn S, Cusi K, Berria R, Kashyap S, Miyazaki Y, Kohane I, Costello M, Saccone R, Landaker EJ, Goldfine AB, Mun E, DeFronzo R, Finlayson J, Kahn CR, Mandarino LJ: Coordinated reduction of genes of oxidative metabolism in humans with insulin resistance and diabetes: Potential role of PGC1 and NRF1. Proc Natl Acad Sci U S A 2003;100:8466-8471

35. Pospisilik JA, Knauf C, Joza N, Benit P, Orthofer M, Cani PD, Ebersberger I, Nakashima T, Sarao R, Neely G, Esterbauer H, Kozlov A, Kahn CR, Kroemer G, Rustin $P$, Burcelin R, Penninger JM: Targeted deletion of AIF decreases mitochondrial oxidative phosphorylation and protects from obesity and diabetes. Cell 2007;131:476-491

36. Jackson SJ, Leahy FE, Jebb SA, Prentice AM, Coward WA, Bluck LJ: Frequent feeding delays the gastric emptying of a subsequent meal. Appetite 2007;48:199205 


\section{SUPPLEMENTAL DATA}

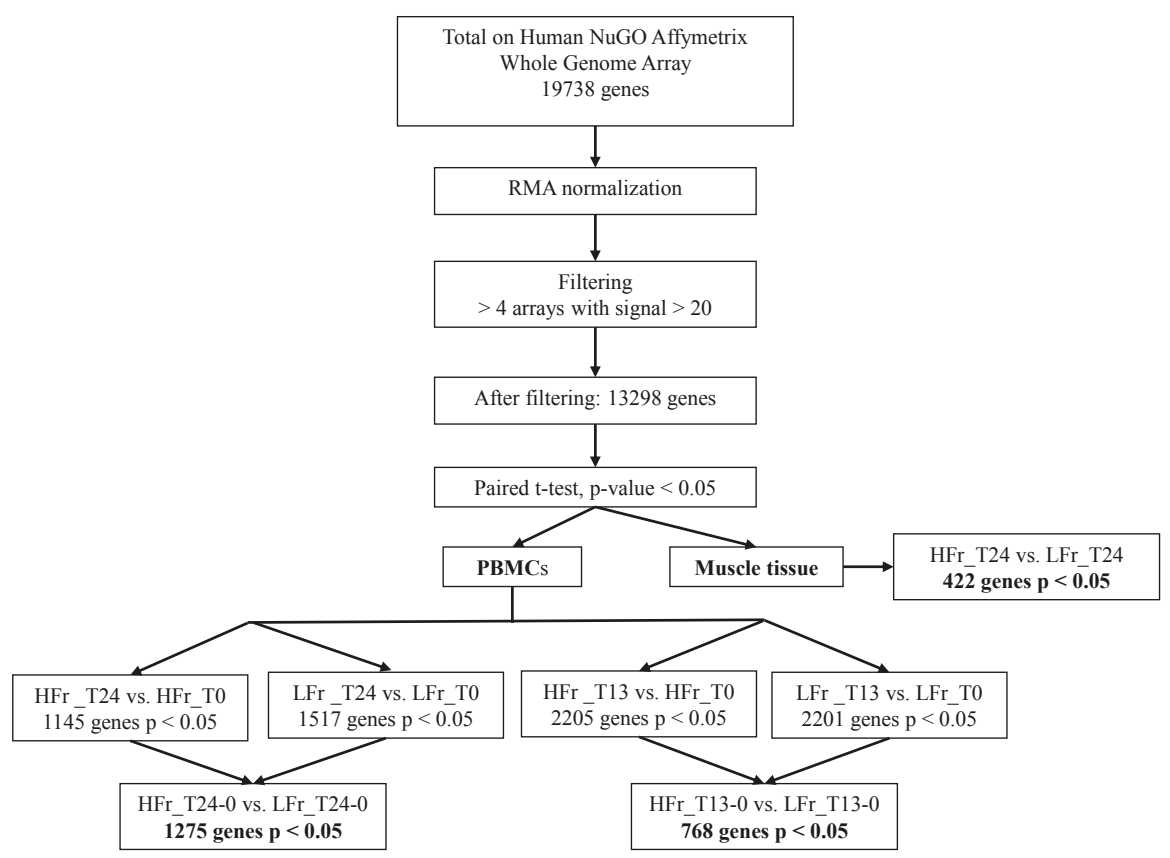

Supplemental figure 1. Selection of genes in microarray analysis of PBMCs and muscle tissue. RMA; Robust Multichip Average. LFr; low meal frequency. HFr; high meal frequency.

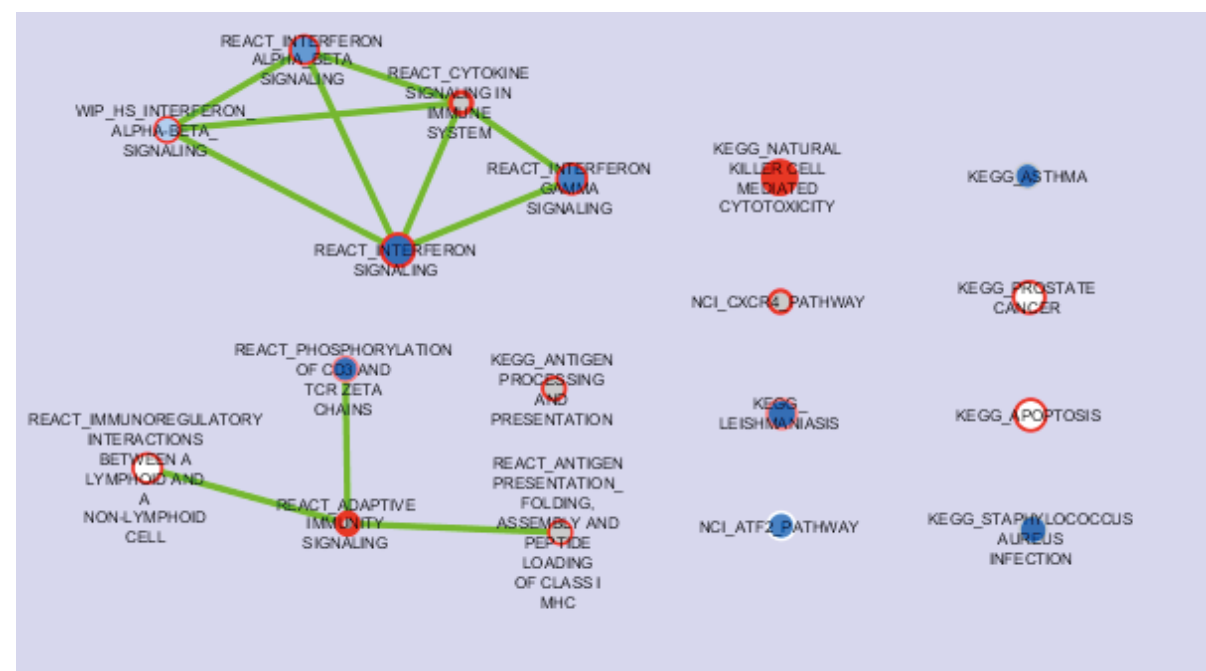

Supplemental figure 2. Significant gene sets different between (HFr_T24-0 vs. LFr_T24-0) and in (HFr_T24 vs. HFr_TO and/or LFr_T24 vs. LFr_T0) the diets with a FDR q-value < 0.01 in PBMCs; similarity cut-off 0.75; p-value cut-off 0.01 in Cytoscape. The node border colour represents the HFr diet, the node colour the LFr diet. Node colours; red indicates up regulation, white indicates no change, blue indicates down regulation; grey indicates no data available. 


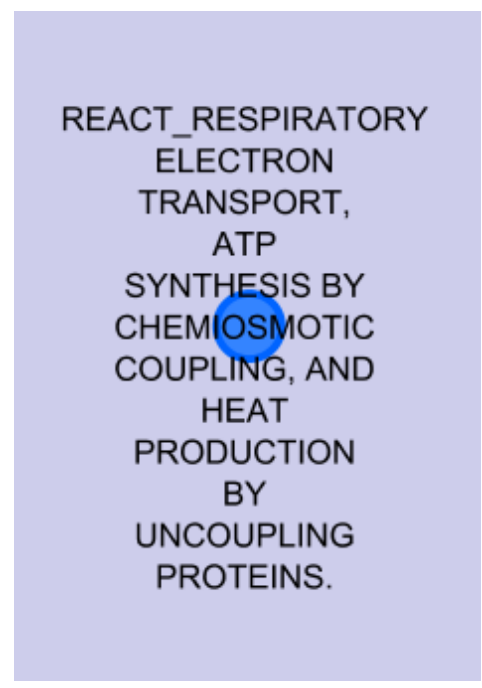

Supplemental figure 3. Significant gene set different between (HFr_T13-0 vs. LFr_T13-0) and in (HFr_T13 vs. HFr_T0 and/or LFr_T13 vs. LFr_T0) the diets with a FDR q-value < 0.02 in PBMCs; similarity cut-off 0.75; p-value cut-off 0.01 in Cytoscape. The node border colour represents the HFr diet, the node colour the LFr diet. Node colours; red indicates up regulation, white indicates no change, blue indicates down regulation.

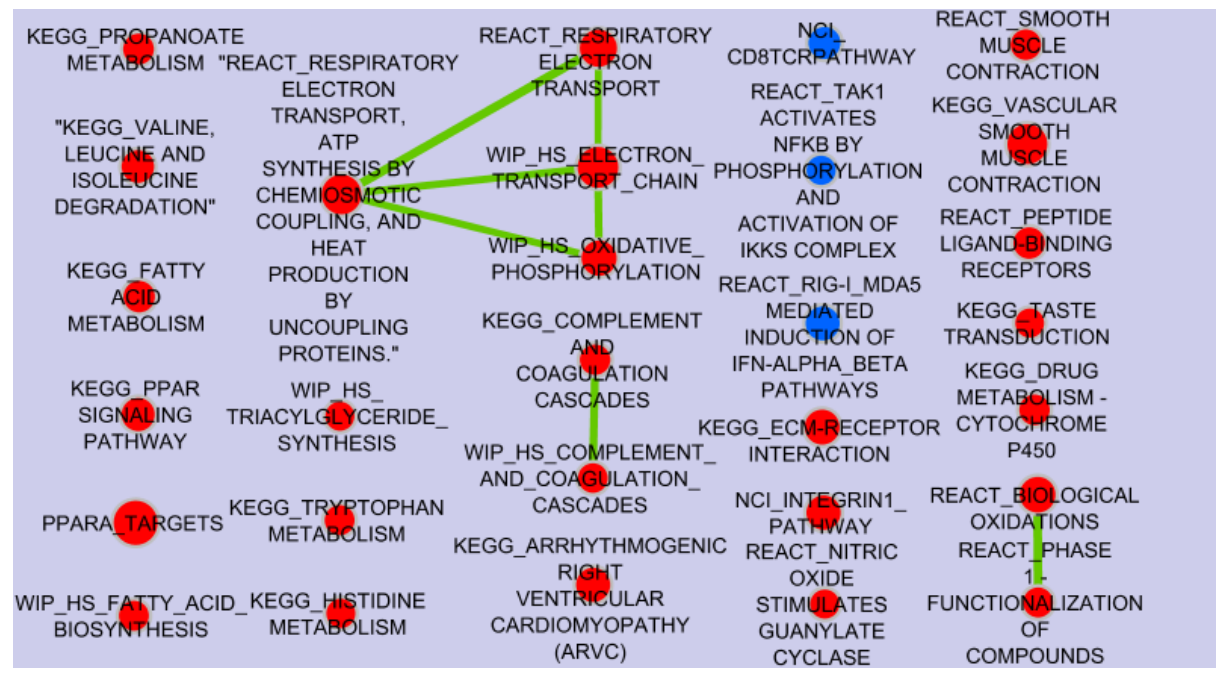

Supplemental figure 4. Significant gene sets different between $\left(\mathrm{HFr} \_T 24\right.$ vs. LFr_T24) the diets with a FDR q-value < 0.02 in muscle tissue; similarity cut-off $0.75 ; p$-value cut-off 0.02 in Cytoscape. The node border colour represents the HFr diet, the node colour the LFr diet. Node colours; red indicates up regulation, white indicates no change, blue indicates down regulation. 
CHAPTER 7

General Discussion 


\section{INTRODUCTION}

Obesity and type 2 diabetes (T2D) are associated with hyperglycemia and hyperinsulinemia as a result of insulin resistance and can be accompanied with a reduced fat oxidation and metabolic inflexibility (1-3). Dietary strategies may improve metabolic flexibility and body weight regulation in obesity and T2D. In this thesis, we focussed on potential benefits of nutritional intervention strategies, such as diet sweetened beverages (SBs) versus nondiet SBs, different protein (content and source) and glycemic index diets, and different meal frequency diets in their capacity to modulate the metabolic profile and thereby increasing metabolic flexibility and body weight control. This chapter combines the results described in this thesis and elaborates on the primary findings. Finally, conclusions are presented followed by recommendations for future research.

\section{SUGAR-SWEETENED BEVERAGES}

Sugar-sweetened beverages (SSB) consumption increased together with the increased incidence of obesity (4). It is suggested that energy containing drinks (sugary origin) have a weak feedback on satiety and food intake suppression, and therefore are a risk for overfeeding and weight gain (5). In addition, SSB consumption may also increase the risk of T2D and cardiovascular diseases as a result of a high dietary glycemic load leading to inflammation and insulin resistance (6). However, literature is not consistent regarding the intake of sugar per se to body weight regulation (7). Several studies concluded that there is a positive association between SSB intake and energy intake and body weight (8; 9), although others concluded that this association was weak (10-12). Overall, a need of randomized controlled long-term studies is indicated. Therefore, in Chapter $\mathbf{3}$ the role of energy derived from SSBs was investigated in a condition where specific SB diet alternatives were used to create a difference in simple carbohydrate intake over a 6-month period in a subsample of the multi-randomized 6-month ad libitum low-fat high-carbohydrate diet trial CARMEN (Carbohydrate Ratio Management in European National) (13). This study showed that energy intake was significantly lower when diet SBs were consumed instead of nondiet SBs in combination with fat reduction. This may be the result of a weak feedback by sugary drinks on satiety and food intake suppression (5). However, in daily life, diet SBs are used partly or completely in addition to sugary products (14). It has been suggested that the use of artificially sweeteners induces feelings of hunger (residual hunger) and will lead to increased food consumption resulting in energy intake levels similar as when sugary products are consumed (15). Nevertheless, current scientific evidence regarding artificially (non-caloric) sweeteners and weight gain has been inconsistent $(16 ; 17)$. 
The consumption of diet products can only be effective in conjunction with a reduced intake of sugary products (18). In accordance, results from three prospective cohort studies suggest that increasing water intake in place of SSBs or fruit juices is associated with lower long-term weight gain (17). Hu (2013) recently pointed out that the evidence that decreasing SSBs will reduce the risk of obesity and related diseases such as T2D is convincing (19). Te Morenga (2013) also concluded in a recent systematic review and meta-analyses of randomised controlled trials and cohort studies that intake of free sugar or SSBs is a determinant of body weight (20). Furthermore, it has been suggested that increased SSB intake may be an important predictor of cardiometabolic risk in young people, independent of weight status (21). These findings support current recommendations to limit consumption of SSBs and fruit juices and increase consumption of water for the prevention of obesity and T2D (17). A lower energy intake can be achieved with the use of diet SBs compared with SSBs, especially in individuals who are frequent consumers of SSBs and are overweight or at risk for weight gain and obesity. Nonetheless, to be effective, the consumption of diet products should be accompanied by a reduction in the consumption of sugary products as increasing consumption of energy from other sources may compensate this reduction in energy intake.

\section{GLYCEMIC INDEX AND HIGH (DAIRY) PROTEIN DIETS}

Diets with a low glycemic index or glycemic load have been suggested to be beneficial in weight management. The diet-induced lower glucose and insulin levels may promote satiety and may result in a reduced inhibition of lipolysis, higher circulating free fatty acids (FFA) concentrations and consequently increased fat oxidation (22). A higher postprandial fat oxidation decreases fat accumulation in non-adipose tissues, thereby improving insulin sensitivity (23). On the long run, a higher fat oxidation may result in a negative energy balance (24). Additionally, high protein diets are also suggested to improve body weight control and improve insulin sensitivity $(25 ; 26)$. High protein diets are linked to lower postprandial glucose concentrations, however proteins (especially dairy products) can have insulinotropic effects resulting in higher postprandial insulin concentrations $(27 ; 28)$. Moreover, the discrepancy between the notion that (dairy) proteins improve body weight control, and the hypothesis that insulinemia is related to insulin resistance and consequently weight gain requires more research (29).

Therefore, in Chapter $\mathbf{4}$ the effect of different protein and GI diets on the metabolic profile and substrate partitioning was investigated. We did not observe an insulinotropic effect or changes in appetite responses induced by the different content or sources of protein in lean healthy men with normal insulin sensitivity. Pal 
and Ellis (2010) (30) observed a strong association where the most satiating proteins (whey) stimulated the highest postprandial insulin response in lean healthy men. Conversely, other authors did not find a relationship between the insulin and appetite responses induced by different protein sources. (31) Therefore, this issue remains controversial (32).

Our data confirmed that a high dairy protein diet gives a lower glycemic response in lean healthy men, nevertheless no significant effects were observed in $24 \mathrm{~h}$ carbohydrate and fat oxidation between the dietary strategies. Possibly, this nonsignificant finding could be caused by the low number of subjects to achieve enough power. Only a higher protein oxidation was observed in the high dairy protein diet, which can be explained by the fact that the body has no flexible storage capacity for excess intake of amino acids, and are therefore actively oxidized or eliminated (33). The higher energy costs of protein turnover play a an important role in energy balance regulation (34). Furthermore, a recent meta-analysis suggested that an energy-restricted high-protein, low-fat diet provides modest benefits for reductions in body weight, fat mass, and triglycerides and attenuates reductions in fat free mass en resting energy expenditure (35). In accordance with our findings, Bendtsen et al. (2013) concluded in a recent review that no clear evidence exists that one protein source results in higher diet-induced thermogenesis and promotes more beneficial changes in body weight and composition compared to other protein sources (36). However, data indicate that amino acid composition, rate of absorption, and protein/food texture may be important factors for proteinstimulated metabolic effects (36). Interestingly, in our study, a tendency towards a higher fat oxidation (20\%) was observed in the low GI diet compared with the high GI diet. This observed effect could be potentially important because a low GI diet might contribute to weight loss maintenance or obesity prevention, as suggested by Brand-Miller et al. (2002) (23). It should be taken into consideration that we investigated these interventions in lean healthy subjects, which are highly regulated to remain in energy balance, therefore a short-term disbalance in substrate partitioning is hard to observe. Likewise, it was observed that substrate oxidation differences during the day were compensated for during the night resulting in the same outcomes over 24 hours (37).

In summary, the lower $24 \mathrm{~h}$ glycemic profile induced by high dairy protein diet did not alter $24 \mathrm{~h}$ substrate partitioning in insulin sensitive subjects.

\section{MEAL FREQUENCY}

Another way to study the effect of lower or higher glucose and insulin levels on substrate partitioning was to modulate meal frequency throughout the day in a very-well controlled feeding environment such as in a respiration chamber. The 
rising incidence of obesity coincides the increasing trend of dietary snacking and meal frequency (38). Nowadays we are consuming more and more calories as inbetween meals with our fingers then during the traditional meals at the dining table. Nonetheless, current literature shows conflicting results concerning the effect of increased meal frequency in relation to body weight control (39). In Chapter 5 and 6 it was hypothesized that a higher meal frequency may lead to increased glucose and insulin levels resulting in a continuous postprandial status, thereby inhibiting fat oxidation, which may result in weight gain and a reduced metabolic flexibility. In Chapter $\mathbf{5}$ meal frequency effects in young healthy men were investigated, however no effect on substrate partitioning was observed despite the greater fluctuations of glucose and insulin levels in the low meal frequency (LFr) diet. Looking at the results we realized that these subjects were insulin sensitive and metabolic flexible, and perhaps an insulin threshold has to be reached before fat oxidation will be inhibited in the high meal frequency (HFr) diet (18). Disrupting the metabolic balance during the day with frequent feeding and postprandial episodes did not lead to long-term effects since over $24 \mathrm{~h}$ no effects could be detected. Our results are comparable with the findings of the group of Melanson (40), which also found no effect of meal frequency on fat oxidation in young healthy subjects. Moreover, these authors pointed out that a higher meal frequency even may have an adverse effect on hunger and satiety (40). Our results indeed demonstrated a lower appetite control in the HFr diet compared to the LFr diet. It should be taken into consideration that they investigated meal frequency at a lower range ( 3 versus 6 meals/day).

In general, we wanted to investigate the underlying mechanisms of dietary interventions in lean healthy young men, eliminating confounding effects of metabolic disturbances associated with obesity such as insulin resistance and a reduced metabolic flexibility. Our results clearly showed that these dietary strategies were able to modulate glucose profiles significantly and insulin profiles to a lesser extent. However subsequently, no effect was observed on substrate partitioning over a $24 \mathrm{~h}$ period. This indicates that lean healthy subjects have very good regulatory mechanisms to remain in energy balance (metabolic flexible). Nevertheless, there are indications that insulin resistant obese subjects and subjects with impaired glucose tolerance (IGT) have impairments in fat oxidation, and are potentially less responsive to dietary strategies to modulate the metabolic profile and therefore fat oxidation (3). Therefore, the meal frequency study was repeated in a population at risk for substrate partitioning; subjects with IGT (Chapter 6). The study design remained the same, and included extra time points for blood sampling and gene expression profiling in peripheral blood mononuclear cells (PMBCs) and muscle tissue. The LFr diet induced greater fluctuations of the metabolic markers, 
resulting in a reduced total glucose output (AUC), and higher FFA levels. No effect on total insulin output (AUC) was observed between both diets, yet the greater fluctuations in glucose and insulin resulted in lower carbohydrate oxidation and whole body respiratory quotient (RQ) in the LFr diet. In the present study, insulin levels ranged from $50-100 \mu \mathrm{U} / \mathrm{ml}$ with an average of $73.1 \mu \mathrm{U} / \mathrm{ml}$ in the $\mathrm{HFr}$ diet. Other studies showed maximally suppression of fat oxidation at insulin concentrations $>50 \mu \mathrm{U} / \mathrm{ml}(41),(42)$. Hence, our results showed that fat oxidation was strongly inhibited as a result of the continuation of the postprandial phase causing a higher RQ in these IGT subjects.

Flatt proposed that subjects with a lower postprandial fat oxidation continue to oxidize carbohydrates in the postabsorptive state resulting in a depleting of endogenous glycogen stores; which stimulates food intake (43). This leads to an increased food intake to replace these reduced carbohydrate stores, thereby increasing fat storage. Our relative short-term study indicated that a higher meal frequency is a risk factor to develop obesity in those subjects who have already problems with their insulin sensitivity and metabolic flexibility. To confirm the Flatt theory much longer controlled observation periods are needed, which is difficult to accomplish in humans.

\section{Gene expression profiles}

Additionally, gene expression profiles were determined in PBMCs and muscle tissue. Interestingly, the expression of immune function and inflammation genes were upregulated in PBMCs and muscle tissue after $24 \mathrm{~h}$ in the HFr diet. On the contrary, Dixit et al. (2011) indicated that levels of pro-inflammatory markers in healthy subjects were not affected by meal frequency, proposing that the systemic inflammatory state is not modified by a change in meal frequency (44). However, lean healthy subjects (high insulin sensitive) were investigated in that study and meal frequency was studied at a lower range; one vs. three meals per day compared to three vs. fourteen meals per day in our study. Overall, the observed modifications in deterioration of the metabolic profile (and the possible related increase in insulin resistance) in our IGT subjects could have increased the inflammatory status. Our results are in accordance with other studies and epidemiological data, which indicated that obesity and insulin resistance are linked with a higher inflammatory status (45). Moreover, a high C-reactive protein level, which is a marker of low-grade inflammation, will reduce after weight loss as shown in the Diogenes trial (46).

The HFr diet resulted in an up-regulation in expression of genes involved in OXPHOS and glutathione metabolism at $24 \mathrm{~h}$ in muscle tissue only. In PBMCs, genes involved in OXPHOS decreased in the HFr diet at $13 \mathrm{~h}$, but this result was absent after $24 \mathrm{~h}$ 
and may implicate a temporarily circadian induced effect. These observations are in line with the metabolic results as $24 \mathrm{~h}$ total EE tended to be higher in the HFr diet. Nevertheless, current literature showed conflicting results as decreased OXPHOS gene expression were measured in PBMCs and skeletal muscle of subjects with T2D $(47 ; 48)$. However, Pospislik et al. (2007) suggested that a decrease in OXPHOS was associated with metabolic improvements (49). The OXPHOS gene expression muscle results in the HFr diet are consistent with a decreased metabolic flexibility, which might cause insulin resistance and a higher fat storage. Furthermore, these findings are supported by the increased triglyceride (TG) and fatty acids (FA) synthesis gene sets in muscle in the HFr diet. Our data clearly showed that the phenotypical metabolic effects between both dietary strategies on substrate partitioning are confirmed on cellular level using transcriptomics.

Overall, this study demonstrated the metabolic and transcriptomics profiles and appetite control improved in the LFr diet compared to the HFr diet. We suggest that a LFr diet may be a beneficial dietary strategy with anti-inflammatory characteristics to improve metabolic flexibility and body weight control in IGT subjects. Current knowledge about meal frequency in this vulnerable population may be helpful to increase metabolic flexibility and therefore prevent (worsening of) obesity and T2D. However, meal frequency effects remain controversial and therefore more research is needed before concrete recommendations for daily living can be made.

\section{FUTURE RESEARCH AND RECOMMENDATIONS}

Our studies wanted to provide an inside into the underlying mechanism of different dietary strategies in relation to glycemic control and weight related substrate partitioning. Our first studies were executed in lean healthy men showing no effects due to the very powerful controlling regulatory mechanisms. Only after extending the meal frequency study to subjects with impaired glucose tolerance we were able to show that dietary strategies have an impact on substrate partitioning leading to long-term weight control. Therefore, these mechanisms of action should be explored in more detail in other populations with metabolic disturbances, such as T2D and in subjects with different levels of insulin resistance.

Furthermore, this thesis showed the additional value of the assessment of gene expression profiles, besides the phenotypical metabolic measurements, that can be a useful tool to get a broader mechanistic view into the effects of the nutritional interventions. The kind of sample selected for the assessment of gene expression profiles should be focussed on multiple samples (muscle- and fat-tissue and PMBCs) so that the metabolic effects can be investigated on a whole body level.

The studies is this thesis represent somewhat daily life circumstances which is deficient in most other studies. This is relevant as it was demonstrated by Saris et al. 


\section{Chapter 7}

(2004) that substrate oxidation changes throughout the day between equicaloric, high- and low-intensity exercise were compensated for throughout the night resulting in no changes over 24 hours (37). Accordingly, it is very valuable to examine at least the 24 hours profiles.

Only short-term studies were performed in this thesis to study underlying mechanism of these dietary strategies. Therefore the potential beneficial effects of these dietary strategies should be investigated on the long term before general recommendations can be made for the prevention or treatment of obesity and T2D. In addition, we investigated the effect of these dietary strategies under isoenergetic well-controlled conditions. Therefore, effects in daily life could differ as overfeeding is commonly observed then.

As indicated in Chapter 2 long-term health effects of low GI and high protein diets seems to be more beneficial for low GI diets. Nonetheless, these findings need to be verified by other long-term randomised controlled trials and prospective cohort studies and the contradiction between these study designs requires more investigation. Our data suggest that it is beneficial to reduce the number of meals a day in order to increase the fluctuations in glucose and insulin levels, thereby providing greater access to fatty acids as fuel, promoting satiety and fat oxidation. In conclusion, dietary strategies intended to reduce postprandial insulin response, increase fat oxidation and metabolic flexibility may prevent and treat obesity and related metabolic disturbances such as T2D. 


\section{REFERENCES}

1. Erdmann J, Kallabis B, Oppel U, Sypchenko O, Wagenpfeil S, Schusdziarra V: Development of hyperinsulinemia and insulin resistance during the early stage of weight gain. Am J Physiol Endocrinol Metab 2008;294:E568-575

2. Martyn JA, Kaneki M, Yasuhara S: Obesity-induced insulin resistance and hyperglycemia: etiologic factors and molecular mechanisms. Anesthesiology 2008;109:137-148

3. Corpeleijn E, Saris WH, Blaak EE: Metabolic flexibility in the development of insulin resistance and type 2 diabetes: effects of lifestyle. Obes Rev 2009;10:178193

4. Bray GA, Nielsen SJ, Popkin BM: Consumption of high-fructose corn syrup in beverages may play a role in the epidemic of obesity. Am J Clin Nutr 2004;79:537543

5. Mattes RD: Dietary compensation by humans for supplemental energy provided as ethanol or carbohydrate in fluids. Physiol Behav 1996;59:179-187

6. Hu FB, Malik VS: Sugar-sweetened beverages and risk of obesity and type 2 diabetes: epidemiologic evidence. Physiol Behav 2010;100:47-54

7. Jebb SA: Dietary determinants of obesity. Obes Rev 2007;8 Suppl 1:93-97

8. Vartanian LR, Schwartz MB, Brownell KD: Effects of soft drink consumption on nutrition and health: a systematic review and meta-analysis. Am J Public Health 2007;97:667-675

9. Malik VS, Schulze MB, Hu FB: Intake of sugar-sweetened beverages and weight gain: a systematic review. Am J Clin Nutr 2006;84:274-288

10. van Baak MA, Astrup A: Consumption of sugars and body weight. Obes Rev 2009;10 Suppl 1:9-23

11. Laville M, Nazare JA: Diabetes, insulin resistance and sugars. Obes Rev 2009;10 Suppl 1:24-33

12. Forshee RA, Anderson PA, Storey ML: Sugar-sweetened beverages and body mass index in children and adolescents: a meta-analysis. Am J Clin Nutr 2008;87:1662-1671

13. Saris WH, Astrup A, Prentice AM, Zunft HJ, Formiguera X, Verboeket-van de Venne WP, Raben A, Poppitt SD, Seppelt B, Johnston S, Vasilaras TH, Keogh GF: Randomized controlled trial of changes in dietary carbohydrate/fat ratio and simple vs complex carbohydrates on body weight and blood lipids: the CARMEN study. The Carbohydrate Ratio Management in European National diets. Int J Obes Relat Metab Disord 2000;24:1310-1318

14. Berg WE OM, Boer JMA: Consumptie van een aantal lightproducten in relatie tot overgewicht. Bilthoven, RIVM, 2006

15. Blundell JE, Hill AJ: Paradoxical effects of an intense sweetener (aspartame) on appetite. Lancet 1986;1:1092-1093

16. Pereira MA: Diet beverages and the risk of obesity, diabetes, and cardiovascular disease: a review of the evidence. Nutrition reviews 2013;71:433-440 
17. Pan A, Malik VS, Hao T, Willett WC, Mozaffarian D, Hu FB: Changes in water and beverage intake and long-term weight changes: results from three prospective cohort studies. Int J Obes (Lond) 2013;

18. Munsters MJ, Saris WH: Effects of meal frequency on metabolic profiles and substrate partitioning in lean healthy males. PLoS One 2012; 7:e38632

19. Hu FB: Resolved: there is sufficient scientific evidence that decreasing sugarsweetened beverage consumption will reduce the prevalence of obesity and obesity-related diseases. Obes Rev 2013;14:606-619

20. Te Morenga L, Mallard S, Mann J: Dietary sugars and body weight: systematic review and meta-analyses of randomised controlled trials and cohort studies. BMJ 2013;346:e7492

21. Ambrosini GL, Oddy WH, Huang RC, Mori TA, Beilin LJ, Jebb SA: Prospective associations between sugar-sweetened beverage intakes and cardiometabolic risk factors in adolescents. Am J Clin Nutr 2013;98:327-334

22. Brand-Miller J, McMillan-Price J, Steinbeck K, Caterson I: Dietary glycemic index: health implications. J Am Coll Nutr 2009;28 Suppl:446S-449S

23. Brand-Miller JC, Holt SH, Pawlak DB, McMillan J: Glycemic index and obesity. Am J Clin Nutr 2002;76:281S-285S

24. Blaak EE, Hul G, Verdich C, Stich V, Martinez A, Petersen M, Feskens EF, Patel K, Oppert JM, Barbe P, Toubro S, Anderson I, Polak J, Astrup A, Macdonald IA, Langin D, Holst C, Sorensen TI, Saris WH: Fat oxidation before and after a high fat load in the obese insulin-resistant state. J Clin Endocrinol Metab 2006;91:1462-1469

25. Larsen TM, Dalskov SM, van Baak M, Jebb SA, Papadaki A, Pfeiffer AF, Martinez JA, Handjieva-Darlenska T, Kunesova M, Pihlsgard M, Stender S, Holst C, Saris WH, Astrup A: Diets with high or low protein content and glycemic index for weight-loss maintenance. N Engl J Med 2010;363:2102-2113

26. Potier M, Darcel N, Tome D: Protein, amino acids and the control of food intake. Current opinion in clinical nutrition and metabolic care 2009;12:54-58

27. van Loon $\mathrm{L}$, Saris WH, Verhagen $\mathrm{H}$, Wagenmakers AJ: Plasma insulin responses after ingestion of different amino acid or protein mixtures with carbohydrate. Am J Clin Nutr 2000;72:96-105

28. Holt SH, Miller JC, Petocz P: An insulin index of foods: the insulin demand generated by 1000-kJ portions of common foods. Am J Clin Nutr 1997;66:1264-1276 29. Ludwig DS: Dietary glycemic index and obesity. J Nutr 2000;130:280S-283S 30. Pal S, Ellis V: The acute effects of four protein meals on insulin, glucose, appetite and energy intake in lean men. The British journal of nutrition 2010;104:1241-1248

31. Lang V, Bellisle F, Alamowitch C, Craplet C, Bornet FR, Slama G, Guy-Grand B: Varying the protein source in mixed meal modifies glucose, insulin and glucagon kinetics in healthy men, has weak effects on subjective satiety and fails to affect food intake. European journal of clinical nutrition 1999;53:959-965

32. Gilbert JA, Bendsen NT, Tremblay A, Astrup A: Effect of proteins from different sources on body composition. Nutrition, metabolism, and cardiovascular diseases : NMCD 2011;21 Suppl 2:B16-31 
33. Paddon-Jones D, Westman E, Mattes RD, Wolfe RR, Astrup A, WesterterpPlantenga $M$ : Protein, weight management, and satiety. Am J Clin Nutr 2008;87:1558S-1561S

34. Wolfe RR: The underappreciated role of muscle in health and disease. Am J Clin Nutr 2006;84:475-482

35. Wycherley TP, Moran LJ, Clifton PM, Noakes M, Brinkworth GD: Effects of energy-restricted high-protein, low-fat compared with standard-protein, low-fat diets: a meta-analysis of randomized controlled trials. Am J Clin Nutr 2012;96:12811298

36. Bendtsen LQ, Lorenzen JK, Bendsen NT, Rasmussen C, Astrup A: Effect of dairy proteins on appetite, energy expenditure, body weight, and composition: a review of the evidence from controlled clinical trials. Advances in nutrition 2013;4:418-438

37. Saris WH, Schrauwen P: Substrate oxidation differences between high- and lowintensity exercise are compensated over 24 hours in obese men. Int J Obes Relat Metab Disord 2004;28:759-765

38. Samuelson G: Dietary habits and nutritional status in adolescents over Europe. An overview of current studies in the Nordic countries. Eur J Clin Nutr 2000;54 Suppl 1:S21-28

39. Solomon TP, Chambers ES, Jeukendrup AE, Toogood AA, Blannin AK: The effect of feeding frequency on insulin and ghrelin responses in human subjects. Br J Nutr 2008;100:810-819

40. Ohkawara K, Cornier MA, Kohrt WM, Melanson EL: Effects of increased meal frequency on fat oxidation and perceived hunger. Obesity (Silver Spring) 2013;21:336-343

41. Frayn K: Metabolic regulation: a human perspective. Oxford, Wiley-Blackwell, 2010

42. Mandarino LJ, Wright KS, Verity LS, Nichols J, Bell JM, Kolterman OG, BeckNielsen $\mathrm{H}$ : Effects of insulin infusion on human skeletal muscle pyruvate dehydrogenase, phosphofructokinase, and glycogen synthase. Evidence for their role in oxidative and nonoxidative glucose metabolism. J Clin Invest 1987;80:655663

43. Flatt JP: The difference in the storage capacities for carbohydrate and for fat, and its implications in the regulation of body weight. Ann $N$ Y Acad Sci 1987;499:104-123

44. Dixit VD, Yang H, Sayeed KS, Stote KS, Rumpler WV, Baer DJ, Longo DL, Mattson MP, Taub DD: Controlled meal frequency without caloric restriction alters peripheral blood mononuclear cell cytokine production. J Inflamm (Lond) 2011;8:6

45. Clarke R: Long-term weight loss and prevention of cardiovascular disease. Circulation 2011;124:2801-2802

46. Gogebakan O, Kohl A, Osterhoff MA, van Baak MA, Jebb SA, Papadaki A, Martinez JA, Handjieva-Darlenska T, Hlavaty $P$, Weickert MO, Holst C, Saris WH, Astrup A, Pfeiffer AF, DiOgenes: Effects of weight loss and long-term weight maintenance with diets varying in protein and glycemic index on cardiovascular risk factors: the diet, obesity, and genes (DiOGenes) study: a randomized, controlled trial. Circulation 2011;124:2829-2838 


\section{Chapter 7}

47. Takamura $T$, Honda $M$, Sakai $Y$, Ando $H$, Shimizu A, Ota $T$, Sakurai M, Misu $H$, Kurita S, Matsuzawa-Nagata N, Uchikata M, Nakamura S, Matoba R, Tanino M, Matsubara K, Kaneko S: Gene expression profiles in peripheral blood mononuclear cells reflect the pathophysiology of type 2 diabetes. Biochem Biophys Res Commun 2007;361:379-384

48. Patti ME, Butte AJ, Crunkhorn S, Cusi K, Berria R, Kashyap S, Miyazaki Y, Kohane I, Costello M, Saccone R, Landaker EJ, Goldfine AB, Mun E, DeFronzo R, Finlayson J, Kahn CR, Mandarino L: Coordinated reduction of genes of oxidative metabolism in humans with insulin resistance and diabetes: Potential role of PGC1 and NRF1. Proc Natl Acad Sci U S A 2003;100:8466-8471

49. Pospisilik JA, Knauf C, Joza N, Benit P, Orthofer M, Cani PD, Ebersberger I, Nakashima T, Sarao R, Neely G, Esterbauer H, Kozlov A, Kahn CR, Kroemer G, Rustin $P$, Burcelin R, Penninger JM: Targeted deletion of AIF decreases mitochondrial oxidative phosphorylation and protects from obesity and diabetes. Cell 2007;131:476-491 
Summary 
The prevalence of overweight and obesity is increasing rapidly worldwide among adults and children that seriously raise the risk for the development of severe metabolic disorders such as type 2 diabetes mellitus, hypertension and cardiovascular diseases. For that reason, there is a need for additional dietary strategies to increase effectiveness of programs directed towards improved body weight regulation. The identification of food and food patterns that could increase fat oxidation, decrease insulin resistance and restore metabolic flexibility may be helpful in the treatment and prevention of obesity and type 2 diabetes mellitus (T2D). Therefore, this thesis focusses on potential benefits of nutritional intervention strategies in their capacity to modulate the metabolic profile and thereby increasing fat oxidation and consequently body weight control.

In Chapter 2, the basic concepts of body weight regulation, substrate partitioning and the role of hyperglycemia and hyperinsulinemia on these concepts are described. Furthermore, current evidence regarding potential nutritional intervention strategies such as low glycemic index (GI) diet, high protein diet and meal frequency in relation to body weight regulation were discussed. Low GI diets and high protein diets have shown to reduce postprandial glucose levels and improve body weight control on the short term. Long-term effects of low Gl diets appear to be more beneficial compared to high protein diets. Nonetheless, these findings need to be verified by other long-term randomised controlled trials and prospective cohort studies. Additionally, there is no consensus in current literature about the effect of increased meal frequency on the metabolic profile and in relation to body weight regulation.

The consumption of sugar-sweetened beverages (SSBs) increased in conjunction with the higher incidence of obesity. However, literature is mixed with regard to the intake of SSBs on body weight regulation. Therefore, in Chapter $\mathbf{3}$ the role of energy originating from SSBs on energy intake was investigated in a subsample of the multirandomized ad libitum low-fat high-carbohydrate diet trial CARMEN (Carbohydrate Ratio Management in European National). Forty-seven overweight-to-obese men and women were assigned for 6 months to a control diet (CD) group, a low-fat (-10 energy per cent) high simple carbohydrate ( $\mathrm{SCHO}$ ) group or low-fat high complex carbohydrate $(\mathrm{CCHO})$ group. The $\mathrm{CD}$ and $\mathrm{SCHO}$ group could consume only nondiet SBs, whereas the $\mathrm{CCHO}$ group could consume only diet sweetened beverages (SBs). A lower energy intake was reached when fat reduction was combined with diet SBs compared to fat reduction along with nondiet SBs in an ad libitum situation. A reduced feedback from sugary drinks on satiety and food intake suppression might explain this difference. Nevertheless, the intake of diet products can only be effective in cooperation with a major reduced intake of sugary products as 
increasing consumption of energy from other sources may compensate this decline in energy intake.

Low GI and high protein diets have been suggested to improve weight management by reducing postprandial glucose levels, increasing fat oxidation and improving insulin sensitivity. At the other end, the high postprandial insulin levels resulting from high protein diets are also associated with insulin resistance and weight gain, which requires further investigation. Therefore, we investigated the effect of different protein and $\mathrm{Gl}$ diets on the $24 \mathrm{~h}$ profiles of metabolic markers and substrate partitioning in lean healthy men (Chapter 4). Our data confirmed that a high dairy protein diet reduced glucose levels, however no effect was observed on insulin levels and fat oxidation. The differences in protein (content and source) and $\mathrm{Gl}$ of the diets did not lead to changes in $24 \mathrm{~h}$ substrate partitioning in the insulin sensitive men.

The growing incidence of obesity also parallels the increasing trend of dietary snacking and meal frequency. In Chapter $\mathbf{5}$ and $\mathbf{6}$ we suggested that a higher meal frequency could increase glucose and insulin levels. This results in a continuous postprandial status, thereby inhibiting fat oxidation, which may cause weight gain and a reduced metabolic flexibility. Particular, in Chapter 5 the effect of different meal frequency diets ( 3 meals a day versus 14 meals a day) was investigated on metabolic makers and substrate partitioning in young healthy men. To our surprise, the greater fluctuations of insulin in the low meal frequency (LFr) diet did not result into a higher fat oxidation. However, these men were insulin sensitive and metabolic flexible and maybe substantial inhibition of fat oxidation only will occur if an insulin threshold is reached in the high meal frequency (HFr) diet. Glucose levels were reduced in the LFr diet indicating glycemic improvements. Additionally, in the LFr diet appetite control improved and the resting metabolic rate was higher, which could improve body weight regulation on the long term.

Moreover, there are indications that obese subjects and subjects with impaired glucose tolerance (IGT) have impairments in fat oxidation and therefore respond less to intervention diets. For this reason, this meal frequency study was repeated in subjects with IGT (Chapter 6). The study design was similar as in the lean healthy men (Chapter 5), but included gene expression profiling in peripheral blood mononuclear cells (PMBCs) and muscle tissue. The LFr diet induced a lower glucose output and higher free fatty acids (FFA) levels, but no effect on insulin output was observed. Carbohydrate oxidation and whole body respiratory quotient (RQ) decreased in the LFr diet. Hence, our data indicated that fat oxidation was strongly inhibited in these insulin resistant men due to the prolonged postprandial phase leading to a higher RQ in the HFr diet. Remarkably, expression of genes involved in immune function and inflammation were up-regulated after $24 \mathrm{~h}$ in the $\mathrm{HFr}$ diet in 
PBMCs and muscle tissue. The HFr diet resulted in an up-regulation in expression of genes involved in oxidative phosphorylation (OXPHOS) at $24 \mathrm{~h}$ in muscle tissue. These OXPHOS gene expression muscle results in the HFr diet are compatible with a reduced metabolic flexibility which might cause insulin resistance and a higher fat storage. Furthermore, this was supported by the increased triglyceride (TG) and fatty acid (FA) synthesis gene sets in muscle in the HFr diet. The observed phenotypical metabolic effects between both dietary strategies on substrate partitioning are confirmed on cellular level using transcriptomics. Therefore, a LFr diet may be a beneficial nutritional strategy to improve metabolic flexibility, inflammatory characteristics and body weight control in IGT subjects.

The research presented in this thesis indicated that dietary strategies intended to reduce postprandial insulin response, increase fat oxidation and metabolic flexibility might prevent and treat obesity and related metabolic disturbances. However, the suggested mechanisms of action in this thesis should be explored in more detail in other populations with metabolic disturbances such as T2D and also the long term effects before general recommendations can be made for the prevention or treatment of obesity and T2D. Additionally, this thesis showed the additional value of the assessment of gene expression profiles besides the metabolic measurements that can be a useful tool to get a broader mechanistic view into the effects of the nutritional interventions on a whole body level. 
Samenvatting 
Wereldwijd neemt de prevalentie van overgewicht en obesitas snel toe zowel bij volwassenen als kinderen. Hierdoor verhoogt het risico op de ontwikkeling van ernstige metabole stoornissen zoals type 2 diabetes mellitus, hypertensie en cardiovasculaire ziektes. Daardoor is er behoefte aan extra dieetstrategieën om de effectiviteit van programma's die gericht zijn op het reguleren van het lichaamsgewicht te verbeteren. Levensmiddelen en voedingspatronen die de vetverbranding verhogen, de insulineresistentie verminderen en de metabole flexibiliteit herstellen kunnen nuttig zijn bij de behandeling en preventie van obesitas en type 2 diabetes. Daarom is dit proefschrift gericht op de potentiële voordelen van diverse strategieën met betrekking tot voedingsinterventies, die mogelijk de capaciteit hebben om het metabole profiel van obese en type 2 diabetes patiënten te beïnvloeden. Welke op hun beurt weer een positief effect kunnen hebben op de vetverbranding en het lichaamsgewicht.

In Hoofdstuk 2 worden de basis concepten van lichaamsgewicht regulatie, substraat gebruik en de rol van hyperglycemie en hyperinsulinemie op deze concepten beschreven. Bovendien wordt de huidige kennis met betrekking tot potentiële voedingsinterventie strategieën, zoals een laag glycemische index (GI) dieet, hoog eiwit dieet en maaltijd frequentie in relatie tot de regulatie van het lichaamsgewicht besproken. Laag Gl diëten en hoog eiwit diëten hebben aangetoond dat glucoseniveaus na de maaltijd dalen en dat lichaamsgewicht regulatie op korte termijn verbetert. Lange-termijn effecten van laag GI diëten lijken gunstiger te zijn in vergelijking met hoog eiwit diëten. Echter deze bevindingen moeten worden gevalideerd in nieuwe lange- termijn gerandomiseerde gecontroleerde studies en prospectieve cohort studies. Bovendien is er geen uniformiteit in de huidige literatuur over het effect van verhoogde maaltijd frequentie op het metabole profiel en ten aanzien van lichaamsgewicht regulatie.

In afgelopen decennia is zowel de incidentie van obesitas als de consumptie van suiker-gezoete dranken gestegen. Echter, de literatuur geeft geen eenvormig beeld over de relatie tussen de inname van suiker-gezoete dranken en het ontstaan van overgewicht. Daarom is er in Hoofdstuk 3 gekeken naar de rol van energie afkomstig van suiker-gezoete dranken op energie inname in een subgroep van de multi-gerandomiseerde ad libitum laag-vet hoog-koolhydraat dieet studie CARMEN (Carbohydrate Ratio Management in de Europese National). In deze studie werden zevenenveertig obese tot zwaarlijvige mannen en vrouwen verdeeld in een controle dieet $(C D)$ groep, een laag vet (-10 energie procent), hoog eenvoudige koolhydraten (SCHO) groep of een laag vet, hoog complexe koolhydraten ( $\mathrm{CCHO}$ ) groep, dit voor een periode van 6 maanden. De CD en SCHO groep mochten alleen suiker-gezoete dranken consumeren, terwijl de $\mathrm{CCHO}$ groep alleen light dranken mocht consumeren. Een lagere energie inname werd bereikt door de combinatie van 
verminderd vet gecombineerd met light dranken in vergelijking met verminderd vet samen met suiker-gezoete dranken in een situatie waar naar behoefte geconsumeerd kan worden (ad libitum). Dit verschil kan verklaard worden doordat suiker-gezoete dranken minder verzadigend zijn waardoor de voedselinname minder wordt onderdrukt. Echter kan de inname van light producten alleen effectief zijn in de verlaging van de energie inname wanneer ook de inname van suikerhoudende producten sterk verminderd wordt.

Van laag GI en hoog eiwit diëten wordt gezegd dat ze gunstige effecten hebben op gewichtsbeheersing door het verminderen van postprandiale glucosespiegels, verhoging van de vetverbranding en verbetering van de gevoeligheid voor insuline. Aan de andere kant, de hoge postprandiale insuline niveaus door hoog eiwit diëten worden ook geassocieerd met insulineresistentie en gewichtstoename, dit vereist verder onderzoek. Daarom hebben wij het effect van verschillende eiwit en GI diëten op de 24 uur profielen van metabole markers en het substraat gebruik in magere gezonde mannen onderzocht (Hoofdstuk 4). Onze resultaten bevestigen dat een hoog zuivel eiwit dieet glucosewaarden verlaagd, echter werd er geen effect waargenomen op insuline niveaus en vetverbranding. De verschillen in eiwit (inhoud en bron) en $\mathrm{Gl}$ van de diëten heeft niet tot wijzigingen in het 24 uur substraat gebruik geleidt in gezonde insuline gevoelige mannen.

De toenemende incidentie van obesitas loopt ook parallel met de stijgende trend in het gebruik van tussendoortjes en maaltijd frequentie in het algemeen. In Hoofdstuk 5 en $\mathbf{6}$ stelden we voor dat een hogere maaltijd frequentie, glucose en insuline niveaus kan verhogen. Dit resulteert in een continue postprandiale status, waardoor de vetverbranding zou worden geremd, wat gewichtstoename en een verminderde metabole flexibiliteit zou kunnen veroorzaken. Specifiek werd er In Hoofdstuk 5 gekeken naar het effect van verschillende maaltijd frequenties (3 maaltijden per dag tegenover 14 maaltijden per dag) op metabole markers en het substraat gebruik bij jonge gezonde mannen. Tot onze verrassing leidde de grotere schommelingen van insuline in het lage maaltijd frequentie (LFr) dieet niet tot een hogere vetverbranding. Echter, deze mannen waren insuline gevoelig en metabool flexibel, waardoor mogelijk alleen een krachtige remming van de vetverbranding kan optreden als een insuline drempel is bereikt in het hoge maaltijd frequentie (HFr) dieet. Het LFr dieet verlaagde de glucosespiegels, wat een glycemische verbeteringen aangeeft. Daarnaast verbeterde de controle van de eetlust en werd het metabolisme in rust verhoogd in het LFr dieet. Dit zou de regulatie van het lichaamsgewicht kunnen verbeteren op de lange termijn.

Bovendien zijn er aanwijzingen dat obese personen en personen met een verminderde glucosetolerantie (IGT) verslechterde vetverbranding hebben en dus minder goed reageren op interventie diëten. Om deze reden werd deze maaltijd 
frequentie studie herhaald bij personen met IGT (Hoofdstuk 6). De studie opzet bleef hetzelfde als bij de magere gezonde mannen (Hoofdstuk 5), maar met extra metingen van genexpressie profielen in perifere bloedcellen lymfocyten en monocyten (PMBC's) en spierweefsel. Het LFr dieet zorgde voor een lagere productie van glucose en hogere vrije vetzuren (FFA) niveaus, maar er werden geen effecten op de insuline productie waargenomen. Koolhydraten verbranding en het respiratoire quotiënt (RQ) daalde in het LFr dieet. Onze resultaten geven aan dat de vetverbranding in deze insuline resistente mannen sterk werd onderdrukt door de verlengde postprandiale status, wat leidde tot een hogere RQ in het $\mathrm{HFr}$ dieet. Opmerkelijk, kwamen de genen betrokken bij het immuunsysteem en ontsteking meer tot expressie na 24 uur in PBMCs en spierweefsel in het $\mathrm{HFr}$ dieet. Het $\mathrm{HFr}$ dieet resulteerde in een verhoogde expressie van genen betrokken bij de oxidatieve fosforylering (OXPHOS) na 24 uur in het spierweefsel. Deze OXPHOS genexpressie resultaten van de spier in het $\mathrm{HFr}$ dieet zijn in lijn met een verminderde metabolische flexibiliteit wat insulineresistentie en een hogere vetopslag zou kunnen veroorzaken. Dit wordt verder ondersteund door de verhoogde synthese van triglyceride (TG) en vetzuren (FA) genen in spier in het $\mathrm{HFr}$ dieet. De waargenomen fenotypische metabole effecten tussen beide dieetstrategieën op substraat gebruik worden bevestigd op cellulair niveau met behulp van genexpressie profielen. Een LFr dieet kan daarom een gunstige voedingsstrategie zijn om de metabole flexibiliteit, inflammatoire eigenschappen en lichaamsgewicht controle in IGT personen te verbeteren.

Uit de onderzoeken beschreven in dit proefschrift blijkt dat dieetstrategieën bedoeld om de postprandiale insuline respons te verlagen en de vetverbranding en metabole flexibiliteit te verhogen, obesitas en gerelateerde metabole stoornissen zouden kunnen voorkomen en behandelen. Toch moeten de voorgestelde werkingsmechanismen in dit proefschrift in meer detail onderzocht worden in andere populaties met metabole stoornissen, zoals type 2 diabetes mellitus, en met de lange termijn effecten voordat algemene aanbevelingen kunnen worden gedaan voor de preventie of behandeling van obesitas en type 2 diabetes mellitus. Bovendien toont dit proefschrift de toegevoegde waarde aan van bepalingen van de genexpressie profielen naast de metabole metingen, welke nuttig kunnen zijn om een bredere mechanistische kijk te krijgen over de effecten van nutritionele interventies op het lichaamsniveau. 
Dankwoord 
Eindelijk is het zover dat ik ga promoveren! In deze periode hebben veel mensen op de een of andere manier een bijdrage geleverd aan dit boekje: door het geven van praktische ondersteuning of advies, belangstelling te tonen of voor de nodige ontspanning te zorgen.

\section{Daarom wil ik graag iedereen bedanken die heeft bijgedragen aan dit proefschrift!}

Allereerst wil ik mijn promotor Prof. dr. Wim Saris bedanken voor alle ondersteuning. Wim, heel erg bedankt voor de gegeven vrijheid, de mogelijkheden om nieuwe dingen te leren en voor de prettige samenwerking. Ook al was je niet vaak op de afdeling aanwezig, ik kon altijd bij je terecht met mijn vragen. Bedankt voor je snelle reacties en je waardevolle input, waar je ook was in de wereld. De leuke 'groep Wim' uitjes had ik niet willen missen!

Daarnaast wil ik alle leden van de beoordelingscommissie bedanken, Prof. dr. Ellen Blaak, Prof. dr. Ir. Ronald Mensink, dr. Gijs Goossens, Prof. dr. Nicolaas Schaper, Prof. dr. Hanno Pijl voor het lezen en beoordelen van dit proefschrift.

Deze onderzoeken zijn natuurlijk onmogelijk uit te voeren zonder proefpersonen. Daarom wil ik iedereen bedanken die meerdere malen in de respiratiekamer opgesloten hebben gezeten (inclusief weekenden), en de testdagen een stuk aangenamer hebben gemaakt!

Op deze speciale dag ben ik blij dat jullie, Carolien en Anouk, mijn paranimfen, mij bij willen staan. Lien, ik vind het erg bijzonder dat we als zussen elkaars paranimf zijn. Bedankt voor je goede tips en motivatie; de zaterdagen dat we gezamenlijk aan onze proefschriften werkten (en liters thee leuten), waren meteen een moment om bij te kletsen. Anouk, bedankt voor de gezelligheid op de kamer, thee momenten, wijze tips (heb je honger ofzo? ;)), en de motivatie om samen te gaan sporten. Ik heb veel bewondering voor je manier van werken (de mannen in het gareel hield) en je gedrevenheid, succes met je laatste onderzoek!

Daarnaast wil ik al mijn collega's bedanken voor de Hb-uitjes, de weekendjes weg, vrijdagmiddag-borrels, lunches en alle andere activiteiten buiten het werk. Ook wil ik Paul, Loek en Laurens bedanken voor het verhelpen van problemen met de respiratiekamer zodat de metingen door konden gaan. Dank je wel Jos, Wendy en Hasibe voor het doen van de analyses van de vele metingen. Het werken in de avonden en weekenden was een altijd een stuk fijner en leuker als je niet alleen op 
de afdeling rond liep, dank je wel Jos, Judith en Ellen. Vooral als je al een keer per ongeluk opgesloten hebt gezeten op een zondagochtend. Het secretariaat van HB wil ik hartelijk bedanken voor de prettige samenwerking, hulp bij het afronden van mijn proefschrift, de lekkere snoepjes, en vooral Desiree voor het plannen van de afspraken met Wim (of misschien wel vaker het verzetten?). Kamergenoten, Joan, Maartje, Denis en later Anouk, Christel en Mark wil ik bedanken voor de gezellige, soms ook serieuze gesprekken en praktische hulp/tips. Ook al mocht ik niet zoveel lab vragen stellen als AIO, hè Denis? Vooral de Brabanders versus de Limburgers grappen/discussies bleven leuk. Ook wil ik de buurmannen Boris, Maarten en Erik bedanken voor jullie humor, wijsheden, slappe klets en voor de afleiding (wat is dat geluid toch?). Daarnaast wil ik Cyriel, Guy, Judith en andere collega's bedanken voor jullie kennis en de gezellige momenten, vooral bij het koffieapparaat. Daarnaast wil ik ook de collega's van PPD bedanken voor hun steun tijdens de laatste fase van mijn promotie onderzoek.

Grote inspanning kan alleen geleverd worden door ontspanning. Daarom wil ik graag mijn vriendinnen, Kristie, Esther, Loes, Anne, Bar, Anneke, Janneke, Anke, Ingrid, Cissy en de vriendengroep van Dirk bedanken voor jullie steun en begrip voor mijn promotie. De ontspannende momenten in de vorm van feestjes, etentjes, weekendjes weg en festivals hebben zeker bijgedragen tot het slagen van mijn proefschrift. Pernette, bedankt voor je interesse, gezelligheid en de slaapplek toen ik begon met mijn promotie, deze tijd en vooral het samen tandenpoetsen had ik niet willen missen! Ook toen ik naar Maastricht verhuisde zagen we elkaar nog regelmatig (altijd eetdates) of tijdens stapavondjes in Maastricht, deze waren altijd een succes! Natuurlijk wil ik ook het tennisteam bedanken voor de benodigde ontspanning in de weekenden.

Zowel mijn familie als die van Dirk wil ik heel erg graag bedanken voor de interesse, aanmoediging en hulp. Harm, Willem en Twan, dank jullie wel voor jullie steun en hulp bij computer problemen. Pap en mam, jullie hebben me altijd gesteund om zo goed mogelijk mijn best te doen en te bereiken wat ik wilde bereiken. Bedankt dat jullie er altijd voor me zijn en jullie bereidheid om me overal bij te helpen waar nodig (vooral met de vele verhuizingen). Ook waardeer ik het erg dat jullie altijd probeerde te zorgen dat we elkaar zagen als gezin.

Dirk, bedankt voor je steun, liefde, geduld ;) en dat je 'ff' op een zondag de oplader van mijn laptop naar Maastricht kwam brengen omdat ik een testdag had. Ik zie er naar uit om verder te 'bouwen' aan onze toekomst en te gaan genieten van onze vrije tijd! 



\section{Curriculum Vitae}




\section{Curriculum Vitae}

Marjet Munsters was born on June $8^{\text {th }}, 1985$ in Veghel, the Netherlands. In 2003 she completed secondary school at the Zwijsen College in Veghel. In the same year she started with her bachelor Health Sciences at Maastricht University. She graduated in 2006 and continued with the Master program Physical Activity and Health at the same university. For her master thesis she performed an internship at the department of Exercise Science, Deakin University, Melbourne, Australia. In January 2008, she started her PhD at the department of Human Biology of Maastricht University. The research performed during this project, under supervision of Prof.dr. Wim Saris, is described in this thesis entitled 'Dietary strategies to modulate the metabolic profile and substrate partitioning'. She is currently working as a start-up Clinical Research Associate at PPD, Bennekom, The Netherlands. 
List of publications 
Munsters MJ, Saris WH. The effect of sugar-sweetened beverage intake on energy intake in an ad libitum 6-month low-fat high-carbohydrate diet. Ann Nutr Metab. 2010;57:116-23.

Geraedts MC, Troost FJ, Munsters MJ, Stegen JH, de Ridder RJ, Conchillo JM, Kruimel JW, Masclee AA, Saris WH. Intraduodenal administration of intact pea protein effectively reduces food intake in both lean and obese male subjects. PLoS One. 2011;6:e24878.

Munsters MJ, Saris WH. Effects of meal frequency on metabolic profiles and substrate partitioning in lean healthy males. PLoS One. 2012;7:e38632.

Munsters MJ, Geraedts MC, Saris WH. Effects of different protein and glycemic index diets on metabolic profiles and substrate partitioning in lean healthy males. Appl Physiol Nutr Metab. 2013;38:1-8.

Munsters MJ, Saris WH. Body weight regulation and obesity: dietary strategies to improve the metabolic profile. Annu Rev Food Sci Technol. 2014.5:1.1-1.13.

Thewissen MM, van de Gaar J, den Boer AT, Munsters MJ, Blaak EE, Duijvestijn A. Monocytes, but not $T$ cells, respond to insulin with Akt(S473) phosphorylation independent of the donor glucometabolic state. Diabetes Metab Res Rev. 2013 doi: 10.1002/dmrr.2498.

Munsters MJ, Boekschoten M, Vijgen G, Afman LA, Saris WH. A low meal frequency improved the $24 \mathrm{~h}$ metabolic and gene expression profiles in subjects with impaired glucose tolerance. Submitted 